\title{
Two bridgehead invasions of Xylella fastidiosa subsp. multiplex in France
}

Authors

Enora Dupas ${ }^{1,2}$, Karine Durand ${ }^{1}$, Adrien Rieux ${ }^{3}$, Martial Briand ${ }^{1}$, Olivier Pruvost ${ }^{3}$, Amandine Cunty $^{2}$, Nicolas Denancé ${ }^{1}$, Cécile Donnadieu ${ }^{4}$, Bruno Legendre ${ }^{2}$, Céline Lopez-Roques ${ }^{4}$, Sophie Cesbron ${ }^{1}$, Virginie Ravigné ${ }^{\dagger \dagger}$, Marie-Agnès Jacques ${ }^{1 \uparrow^{* *}}$

${ }^{1}$ Univ Angers, Institut Agro, INRAE, IRHS, SFR QUASAV, F-49000 Angers, France

${ }^{2}$ French Agency for Food, Environmental and Occupational Health \& Safety, Plant Health Laboratory, Angers, France

${ }^{3}$ CIRAD, UMR PVBMT, Saint Pierre, La Réunion, France

${ }^{4}$ INRAE, US 1426, GeT-PlaGe, Genotoul, Castanet-Tolosan, France

${ }^{5}$ CIRAD, UMR PHIM, F-34398 Montpellier, France

$\dagger$ These authors contributed equally to this work

*corresponding author: marie-agnes.jacques@ INRAE.fr

\section{Abstract}

Of American origin, a wide diversity of Xylella fastidiosa strains belonging to different subspecies have been reported in Europe since 2013 and its discovery in Italian olive groves. Strains from the subspecies multiplex (ST6 and ST7) were first identified in France in 2015 in urban and natural areas. To trace back the most probable introduction scenario, the molecular evolution rate of this subspecies was estimated at $3.2165 \times 10^{-7}$ substitutions per site per year, based on heterochronous genome sequences collected worldwide. This rate allowed the dating of the divergence between French and American strains in 1987 for ST6 and in 1971 for ST7. The development of a new VNTR-13 scheme allowed tracing the spread of the bacterium in France, hypothesizing an American origin. Our results suggest that both sequence types were initially introduced and spread in PACA; then they were introduced in Corsica in two waves from the PACA bridgehead populations.

\section{Teaser}

Tipdating and $\mathrm{ABC}$ analyses on genomic and microsatellite data were combined to provide scenarios for X. fastidiosa introduction in France.

\section{Introduction}

Worldwide global food security is threatened by emerging plant diseases, which frequency is increasing as a consequence of the globalization of plant material exchanges, crop intensification and global climate change (1). Many emerging infectious diseases result from 
geographical expansion following accidental introduction and can be considered as biological invasions (2). Our ability to anticipate, prevent and mitigate emerging infectious diseases depends on a better understanding of current pathogen distribution over space and time, invasion routes, conditions favoring their emergence and population reservoirs (3).

Xylella fastidiosa is a phytopathogenic genetically diverse bacterial species including two largely divergent lineages. One lineage bears two subspecies, fastidiosa and multiplex, originating from Central and North America, respectively $(4,5)$. These subspecies include strains pathogenic on a wide host range, with some plants being common hosts of both subspecies (6). Extensive intersubspecific homologous recombination was experimentally demonstrated between strains of these two subspecies (7), and this phenomenon was previously speculated to be at the origin of host range expansion in these taxa, especially for the strains infecting mulberry and blueberry (8). The other lineage is composed of one highly diverse subspecies, pauca, known to originate from South America, where main economic hosts are citrus and coffee plants (9). MultiLocus Sequence Typing (MLST), which consists in partial sequencing of seven housekeeping genes and leads to sequence type (ST) number attribution, is the reference method used to type X. fastidiosa at an infrasubspecific level (10).

$X$. fastidiosa first detection in Europe was reported from natural settings in Italy in 2013 (11). Since then, the bacterium has devastated thousands of hectares of olive groves in Apulia, Italy, leading to a severe socio-economic crisis (12). This species is considered as one of the most dangerous plant-pathogenic bacteria worldwide (13). X. fastidiosa has a very wide host range, with 655 known host plant species worldwide (6). Its host range includes plants of major socioeconomic interest such as grapevine, citrus, coffee and olive trees, but also fruit and forest trees, ornamental plants, shade trees, and wild species, making $X$. fastidiosa a global threat. For these reasons, $X$. fastidiosa is a priority quarantine pathogen in the European Union (EU), meaning that it is of mandatory declaration and eradication, with the exception of areas where the bacterium is established, and where eradication has been considered as unfeasible $(14,15)$. In EU, these areas are Corsica in France, Apulia in Italy, and the Balearic Islands in Spain (14, 16).

Over short distances, the dissemination of the bacterium results mostly from the movements of insect vectors. Indeed, transmission by sap-feeding insect vectors of the families of Aphrophoridae, Cicadellidae, Cercopidae, and Cicadidae is the only natural way of transmission among plants (17). Over long distances, human activities are responsible for the dispersal of this pathogen through the trade of infected plant material. In the recent past, this bacterium has been introduced in Taiwan via infected grapevine for planting (18). Trade of ornamental coffee plants is the presumed means of introduction of the strain decimating Apulia's olive trees from Central America (19). Several lines of evidence indicate that earlier on, X. fastidiosa strains responsible for the Pierce's disease of grapevine, that still represents a strong constraint on vineyards in California, were introduced from Central America via infected coffee plants (4). 
confirmed this hypothesis $(4,20)$, which was reinforced by historical data documenting the importation of coffee plants from Nicaragua to Los Angeles around 1855 (21). Transport of infected Prunus was the likely vector of the introduction of strains from the subspecies multiplex in Southern Brazil (22). The introduced population then diversified in the United-States and served as reservoir for introductions in Taiwan and Europe (23).

In France, a first suspicion of $X$. fastidiosa infection dates back to 1989, when a grapevine plant was found infected in the Languedoc region (24). Then, in 2010 in the Saint-Emilion area, genomic signatures of $X$. fastidiosa were found in the microbiota of a grapevine plant (25). However, it was not until 2013 that the presence of $X$. fastidiosa subsp. pauca (ST53) was officially identified, in Europe, in the Apulia, in Italy (11). The link between this identification and the disastrous decline of olive trees in Apulia and the previous detections on contained coffee plants (France, Netherlands, Italy, Switzerland, Germany) prompted pest risk assessments in other European countries (13). In 2015, monitoring led to the discovery in France of the subspecies multiplex (ST6, ST7) and pauca (ST53) (26). Then, in the Balearic Islands (Spain) the subspecies fastidiosa (ST1), multiplex (ST7 and ST81) and pauca (ST80) were detected (27). The subspecies multiplex ST6 was then identified in continental Spain in 2017, a close genotype (ST87) was detected in Tuscany (Italy) and ST7 was reported from Portugal in $2018(28,29)$. All these records of different sequence types in distant areas are clear indications of various independent introductions of $X$. fastidiosa strains in Europe (26). Most sequence types (except ST76, ST80, ST81 and ST87) had previously been described in the Americas that hence represents their most probable area of origin and source of introduction in Europe. These hypotheses were tested and confirmed by a first analysis of a limited number of strains from most EU outbreaks (29).

In France, X. fastidiosa was detected in three regions, i.e. Corsica, Provence-Alpes-Côte d'Azur (PACA) and Occitanie. Most foci were infected by ST6 or ST7, clustering in $X$. fastidiosa subsp. multiplex (26). In 2018, while a large number of foci were detected all over Corsica (354 foci), in the Corsican bush and in urban areas; and on a large range of endemic or introduced plant species (39 hosts), a limited number (166 foci) of mostly urban foci were reported in PACA on a range of 25 species, from which 15 plant species were not reported infected in Corsica. Hence, situations seem having different histories.

MLST is one of the most popular technique to genotype pathogenic bacteria. It was widely used to resolve the epidemic spread of pathogens both in human, animals and plants (30-32). Nevertheless, in some cases this method lacks resolution $(33,34)$ and MultiLocus Variable number of tandem repeat Analysis (MLVA) may then be preferred. MLVA is based on the analysis of rapidly evolving markers allowing to study recent events and discriminate individuals with more resolution than MLST (35). MLVA allowed deciphering population genetic structure in the monomorphic bacteria Xanthomonas citri pv. citri and Xanthomonas citri pv. viticola $(34,36)$ and to infer their invasion routes using Approximate Bayesian Computation (ABC) (36). 
Assuming an exogenous origin of $X$. fastidiosa subsp. multiplex in France, our aim was to decipher the most probable scenario of introduction of ST6 and ST7 in Corsica and PACA regions, on the basis of the plant material gathered in the frame of the official French monitoring plan. We mainly based our study on MLVA to take advantage of both the large sample collection and the capacity of these markers to monitor recent evolutionary events. Genome data were used to date the divergence of French $X$. fastidiosa subsp. multiplex strains from their American relatives. Bayesian methodologies were used to infer the number of introductions and the most probable scenario of population evolution and spread in these two French regions, Corsica and PACA.

\section{Results}

\section{A low polymorphism within ST6 and ST7 genome sequences but enough temporal signal to date divergence time}

A set of $49 X$. fastidiosa subsp. multiplex strains isolated from plants between 2015 and 2018 in France and six strains isolated in USA between 1995 and 2011 were available for sequencing. With all genome sequences publicly available at the time of analysis, a total of 82 genome sequences of $X$. fastidiosa subsp. multiplex were analyzed (Table S1). Most genome sequences (85.4\%) were Illumina dye sequences. Average genome length was 2,520,537 bp, with a mean N50 and L50 of 354,785 bp and 7.28, respectively. The dataset comprised strains of diverse geographical origin (Brazil $n=1$, France $n=52$, Italy $n=3$, Spain $n=12$, USA $n=14$ ) spanning 36 years of evolution (isolated between 1983 to 2018). The length of their core genome alignment was 1,679,574 bp, in which 16,739 single nucleotide polymorphisms (SNPs) were detected. After removal of regions with evidence of recombination 13,818 SNPs only originating from mutation events were kept.

Considering ST6 and ST7 strains genome clustering from all geographic origins revealed patterns in partial discordance with traditional MLST grouping (Fig. S1). While all French and American ST6 strains clustered in a homogeneous cluster, as expected from MLST, Spanish ST6 strains were scattered within the ST7 cluster grouping all the French ST7 strains, the three American ST7 strains, and one of the Spanish ST81 strain. The two other Spanish ST81 strains were intermediate between French ST7 and the Spanish ST6 strains. American, Italian and Brazilian X. fastidiosa subsp. multiplex strains of other sequence types grouped into three other clusters (Fig. S1). Similar groupings were observed by plotting the core genome SNPs from mutation on a heatmap (Fig. S2). A range of 560 to 586 SNPs differentiated French ST7 strains from Spanish ST81 strains, 613 to 643 SNPs from Spanish ST6 strains, and 674 to 709 SNPs from USA ST7 strains, when a range of 899 to 912 SNPs differentiated French from Spanish ST6 strains. Moreover, draft genomes of French strains were quite homogeneous with 37 SNPs and 48 SNPs issued from mutations for the 23 ST6 and the 29 ST7 strains, respectively. SNPs were distributed all over the genome sequences. Six ST6 genome sequences (CFBP 8418, CFBP 8431, CFBP 8435, CFBP 13586, CFBP 13623 and CFBP 13742) and five ST7 genome sequences (CFBP 8416, CFBP 8434, CFBP 13552, CFBP 13585 and CFBP 13631) all isolated 
in Corsica, France, between 2015 and 2017 did not show any polymorphism. The strains were isolated from different foci, in central-west Corsica for ST6 and in southern Corsica for ST7. The low polymorphism observed in the core genome and the absence of sub-structuration within ST6 or ST7 genome sequences were not compatible with any further population genetics analysis aiming at reconstructing the pathways of the emergence of $X$. fastidiosa at a regional scale in French territories based only on these data.

In contrast, the complete set of 82 genome sequences, isolated all over the world, was proved suitable for investigate the timing of $X$. fastidiosa subsp. multiplex divergence (Table S1.). Analyzing the linear regression of sample age against root-to-tip distance (Fig. S3) and performing a date randomization test (DRT) with BEAST (37) (Fig. S4) revealed a sufficient temporal signal at the whole-tree scale. Therefore, the dataset could be used to coestimate evolutionary rates with ancestral divergence times with a tip-based calibration approach.

At the scale of the genome, the mean substitution rate for $X$. fastidiosa subsp. multiplex was inferred at $3.2165 \times 10^{-7}$ substitutions per site per year (95\% Highest Posterior Density [HPD] $1.5468 \times 10^{-7}-5.2043 \times 10^{-7}$ substitutions per site per year). The standard deviation of the uncorrelated log-normal relaxed clock calculated by BEAST was 1.020, suggesting moderate variation in rates among branches. The divergence between French and American ST6 strains was estimated in 1987 (1974 to 1994 95\% HPD) (Fig. 1). Then the divergence between these strains and the Spanish ST81 strains was estimated in 1425 (766 to 1914 95\% HPD). The one between ST7 French and American strains was estimated in 1971 (1924 to 1994 95\% HPD). This time to the most recent common ancestor (TMRCA) was due to the USA RAAR6Butte strain, as the TMRCA with the two other ST7 USA strains (M12 and Griffin-1) is older (=1510; 991 to 1911 95\% HPD). The split between Spanish ST6 strains and ST7 strains was estimated in 1027 (120 to 1743 95\% HPD). The divergence between the group of ST7 and Spanish ST6 strains and the group of ST81 and ST6 French and American strains was estimated in 755 (-397 to $154095 \%$ HPD).

\section{Better genotyping resolution with MLVA within $X$. fastidiosa subsp multiplex}

To elucidate the scenario that led to the establishment of $X$. fastidiosa subsp. multiplex in Corsica and PACA, variable number of tandem repeats (VNTRs) were used to complement the relatively low information gained from SNP calling. In silico analysis of the X. fastidiosa subsp. multiplex strain M12 genome sequence led to the identification of 113 VNTR loci, with repeat units ranging from $4 \mathrm{bp}$ to $44 \mathrm{bp}$ in size. After further investigations on a subcollection of 46 genome sequences representing the known diversity of $X$. fastidiosa (10 X. fastidiosa subsp. multiplex, 18 X. fastidiosa subsp. fastidiosa, 18 X. fastidiosa subsp. pauca) (38) and then on a panel test of 16 strains from the present study, only three VNTR loci were retained to complete the set of 10 VNTR loci previously proposed by Lin et al. (2005) and Francisco et al. (2017) (Table 1) $(39,40)$. These 13 VNTR loci were present in all $X$. fastidiosa genome sequences examined, were not redundant with each other, were highly polymorphic, had a TR unit size ranging from $4 \mathrm{bp}$ to $12 \mathrm{bp}$ and a total array sizes from 77 to $360 \mathrm{bp}$. Among these 13 VNTR 
loci, all were chromosomic and six were intergenic (Table 1). Moreover, in silico analyses on the WGS database of bacteria from NCBI revealed that specific amplifications were exclusively obtained on all $X$. fastidiosa genome sequences and on no other genome sequence (date of analysis: 2018-08-22). The 110 other TR loci detected were not further considered, as 39 were imperfect motifs or had incomplete repetitions, 10 were redundant with previously published VNTRs, and 61 had a low allelic diversity or did not allowed to discriminate between ST6 and ST7 as examined on the $10 \mathrm{X}$. fastidiosa subsp. multiplex genome sequences.

The VNTR-13 scheme was specifically developed to type the subspecies multiplex. All 13 VNTR loci were successfully amplified and typed on our collection of 68 French and American $X$. fastidiosa subsp. multiplex strains (Table S2) and on the DNAs of 18 Spanish X. fastidiosa subsp. multiplex strains (Table S3). Interestingly, each VNTR locus was also successfully amplified on the 27 DNAs of $X$. fastidiosa strains belonging to nine different sequence types of $X$. fastidiosa subsp. fastidiosa and pauca (Table S2). Of particular interest, and consistent with SNP data, strains belonging to ST6 were scattered into two clusters, one grouping French and American ST6 strains, and the other grouping ST6 strains from Spain (Fig. S5). The MLVA accurately resolved the different haplotypes in our international strain collection as the haplotype accumulation curve reached a plateau with more than $95 \%$ of the haplotypes detected with nine or more markers (Fig. S6).

\section{Efficient genotyping of the VNTR-13 scheme on both $X$. fastidiosa subsp. multiplex isolated strains and DNA extracted from plants}

Besides a conventional use on isolated strains, VNTR genotyping was attempted directly on large sets of DNA samples extracted from frozen infected plant material. Genotyping conditions were thus optimized by: i) multiplexing the primers by four according to their annealing temperature (Table 1); ii) selecting a highly efficient DNA polymerase, meaning the least affected by PCR inhibitors. Platinum ${ }^{\mathrm{TM}}$ Taq DNA Polymerase (ThermoFisher) was selected as it allowed amplification of some VNTR loci (ASSR-9, ASSR-16, GSSR-4) in bacterial suspensions at ten times lower concentrations than GoTaq ${ }^{\circledR}$ G2 Flexi DNA Polymerase (i.e. concentrations as low as $10^{3}$ to $10^{4} \mathrm{CFU} \cdot \mathrm{mL}^{-1}$ ); and iii) setting sample DNA aliquot volume to $2 \mu \mathrm{L}$ per $20 \mu \mathrm{L}$-total volume reaction to maximize target presence and amplification, as no inhibitory effect was noticed (data not shown).

The MLVA proved to have an excellent ability to genotype $X$. fastidiosa from isolated strains as well as from DNA extracted from plant sample. In fact, we had at our disposal 13 pairs of isolated strains and DNAs extracted from the same original plant samples for a total of five different plant species (Acacia dealbata, Euryops chrysanthemoides, Medicago sativa, Polygala myrtifolia, and Prunus avium) (Table S4). An identical VNTR profile was obtained for each member of these 13 pairs, indicating that VNTR amplification from DNA extracted from plant material was efficient and was not affected by DNA extraction efficiency and/or quality. From this point, each of these 13 pairs was considered as one sample. 


\section{VNTR-13 scheme revealed that French $X$. fastidiosa split into four groups of strains}

In France, from 2015 to 2018, among the plant samples tested in the framework of the French surveillance and officially declared to be $X$. fastidiosa infected, 917 samples had a $\mathrm{Cq}<32$ (the amplification limit Cq of the MLVA), which corresponded to approximately $5.10^{5} \mathrm{X}$. fastidiosa cells per gram of plant. Depending on the availability of frozen samples and in order to avoid the analysis of several samples from the same foci, a selection of samples was made to maximize the number of foci and plant species analyzed and resulted in a set of 534 samples for the MLVA. A total of 396 samples were successfully genotyped for all 13 loci (184 ST6 and 212 ST7; $43.18 \%$ of the French $X$. fastidiosa samples and $74.16 \%$ of the tested samples) (Table 2, Table S4). The loci were all highly polymorphic across the French dataset with a number of alleles ranging from 7 to 21 and a number of TRs ranging from 1 to 30 (Table 3). Simpson's diversity index ranged from 0.52 to 0.88 and allelic richness from 3.82 to 15.73 . For the VNTR loci ASSR-19, XFSSR-40 and XFSSR-58, all possible allele sizes of the allelic range were observed within the collection. For the VNTR loci ASSR-9, ASSR-11, ASSR-12, ASSR-16, COSS-1, GSSR-7, OSSR-16, OSSR-19, XFSSR-37 the observed diversity of TR sizes did not cover the entire allelic range as one to three TR sizes were not observed, indicating either missing infected samples in the evolution path or large mutation steps (Table S4). MLVA accurately resolved the different haplotypes from the French outbreaks as more than $95 \%$ of the haplotypes were detected with 12 markers (Fig. S6). The discriminatory power of the MLVA was 0.9969 , showing a very high level of discrimination. The distribution of allele frequencies for each of the 13 VNTR loci indicated that some allelic forms were specific of each sequence type, with 34 allelic forms strictly specific to ST6 and 46 allelic forms strictly specific to ST7 (Table S5). Moreover, for 10 VNTR loci (ASSR-11, ASSR-12, ASSR-16, ASSR-19, GSSR-4, OSSR-16, OSSR-19, XFSSR-37, XFSSR-40, and XFSSR-58) different allelic profiles were observed between the two sequence types (Fig. S7). The distribution of allele frequencies for each of the 13 VNTR loci did not indicate differences between samples isolated in Corsica or PACA or their host plant (data not shown).

For a minority of 13 French $X$. fastidiosa infected plant samples, several peaks were observed on the electrophoregrams on 3 up to 12 amplified loci (data not shown), and this was confirmed in at least two independent analyses. As some alleles were, for now, specific of ST6 or ST7 (e.g., for ASSR-16: $29 \mathrm{TR}=\mathrm{ST} 6,24 \mathrm{TR}=\mathrm{ST} 7$ ), these results revealed the presence of coinfections by several strains in these plants and for some of them potentially by several sequence types.

MLVA allowed observing a large haplotype diversity within French ST6 and ST7 X. fastidiosa as 320 haplotypes were delineated. The 184 ST6 samples were genotyped in 148 haplotypes, while the 212 ST7 samples were genotyped in 172 other haplotypes, and no VNTR profile was shared between these two sequence types (Table S4). ST6 samples were grouped into four clonal complexes (i.e., networks grouping haplotypes differing from their closest neighbor at a single VNTR locus). The founder haplotype (\#309) of the main clonal complex grouped 11 
samples from three plant species (P. myrtifolia, Lavandula x allardii, Calicotome villosa), and was linked, in this clonal complex, to 95 samples that were all sampled in Corsica (Fig. 2). ST7 samples grouped into 15 clonal complexes. The founder haplotype (\#138) of the main clonal complex comprised 15 samples of three plant species (P. myrtifolia, Genista x spachiana, Helichrysum italicum) and was linked to 88 samples, of which 86 were isolated in Corsica and only two in PACA. The other 17 smaller clonal complexes grouped from two to eight samples that were sampled in a same region, with the exception of one clonal complex that grouped haplotype \#163 sampled in PACA and haplotype \#165 sampled in Corsica. The remaining 167 samples differed by at least two loci (=163 haplotypes, 80 ST6 haplotypes and 83 ST7 haplotypes) or by three and more loci (=36 ST6 haplotypes and 32 ST7 haplotypes). This high number of singletons differing by at least two loci from the clonal complexes originated from the evolution of all VNTRs but OSSR-16 for ST6 samples and ASSR-16, GSSR-4 and XFSSR58 for ST7 samples (Table S4).

Due to the nature of the data that mostly came from official monitoring programs, which aim is the eradication of any infected plant and not population genetics studies, it was impossible to analyze the impact of the host and year of sampling on the minimum spanning tree (MST) structuration. Nevertheless, the presence of infected samples from 2015 in distal parts of evolutionary branches and of founder haplotypes sampled in 2017 (Fig. 2) suggests that sampling was carried out in an already diversified population. Regarding host plants, a large majority $(69.95 \%)$ of our dataset was made of myrtle-leaf milkwort plants (P. myrtifolia), while Spanish broom (Spartium junceum) accounted for $7.07 \%$ of the samples and then all remaining 23 plant species each accounted for less than $3.78 \%$ of the samples, which was highly imbalanced and did not allow the analysis of MST structuration relative to host species. Moreover, $4.68 \%$ of the haplotypes were identified in more than one plant species, indicating that haplotypes did not face intrinsic dispersal barriers.

On the basis of genetic clustering analyses (DAPC and STRUCTURE) and geographical information, we validated the clustering of all 396 samples into four clusters that were, as expected, also supported (p-value $<0.05$ ) by $\mathrm{R}_{\mathrm{ST}}$ and $\mathrm{F}_{\mathrm{ST}}$ pairwise comparisons (Table S6). Because DAPC and STRUCTURE analyses led to almost identical groupings (Fig. 3, Fig. S8), the multivariate analysis of population subdivision method of the DAPC was used, as it does not rely on an underlying population genetics model (41), in contrast to the model-based clustering algorithm of STRUCTURE. As expected, ST6 and ST7 strains from plant samples were always separated in different clusters. We tested increasing numbers of clusters from $\mathrm{k}=2$ upwards, and for k>6, F-statistics $\left(\mathrm{R}_{\mathrm{ST}}\right.$ and $\left.\mathrm{F}_{\mathrm{ST}}\right)$ did not validate the groupings. For k=4, cluster 1 was mainly composed of ST6 samples from Corsica (135 Corsica and two PACA); cluster 2 grouped the rest of the 47 ST6 samples (19 Corsica and 28 PACA); cluster 3 was mainly composed of the ST7 samples from Corsica (110 Corsica and eight PACA); and cluster 4 grouped the remaining 94 ST7 samples mainly sampled from PACA (19 Corsica and 75 PACA) (Fig. 3). In the 20 independent DAPC runs, all 396 samples, except 16, were consistently assigned to a single DAPC cluster (Table S4). For these 16 remaining samples, the 11 ST6 
samples, all from PACA, were most often (i.e. in 70\% of the runs) assigned to DAPC cluster 2 (mix geographical origin), and less frequently to DAPC cluster 1 (i.e. in $30 \%$ of the runs). The five ST7 samples from Corsica and PACA were most often (i.e. in $80 \%$ of the runs) assigned to DAPC cluster 4, and less frequently to DAPC cluster 3 (i.e. in $20 \%$ of the runs). All samples grouped in clonal complexes by MST analysis clustered together at $\mathrm{k}=4$ by DAPC analysis. For lower and higher values of k (two to six) each ST6 and ST7 group of samples were gradually divided from one to three clusters. At $\mathrm{k}=6$, two of the three ST6 clusters grouped both samples isolated in Corsica and PACA regions, without any obvious clustering in relation to host or year of isolation. Moreover, comparing these clusters and the MST, the main ST6 clonal complex containing 95 samples was divided into two clusters. Regarding ST7, the three clusters grouped samples isolated from both regions. MST algorithm and DAPC and STRUCTURE provided coherent clustering for $\mathrm{k}=4$ and this clustering made biological sense (clustering mainly coherent with geographical origin of the strain or potential dissemination of haplotypes), so it was used as a first basis for further analyses.

\section{Bridgehead introductions of $X$. fastidiosa subsp. multiplex ST6 and ST7 in Corsica from PACA}

We inferred the routes of dissemination of $X$. fastidiosa subsp. multiplex in France using Approximate Bayesian Computation, beginning with the definition of a set of evolutionary scenarios that may explain the observed data. Firstly, in order to keep tested scenarios as simple as possible, we analyzed ST6 and ST7 French samples separately, because there was no known element indicating that these different strains were introduced simultaneously into France and tip-dating provided different dates of divergence for French ST6 and ST7 strains from their American relatives. Secondly, we had to define groups of strains likely to have shared common history (in sexual species, these would be populations, but in bacteria this step is not trivial). In each cluster previously defined by DAPC, samples originating from distinct regions were split as subgroups when the corresponding populations were differentiated based on $\mathrm{R}_{\mathrm{ST}}$ and F $_{\mathrm{ST}}$ pairwise comparisons, with a p-value $<0.05$ (Table S4 and S6). Moreover, analysis of molecular variance evaluated that the majority of the genetic variance occurred within the subgroups (ST6: 63.99\%, ST7: 78.12\%) (Table S7). As a result, three groups were defined for each sequence type (Table S4, Fig. 4). For ST6, the DAPC cluster 1 grouping samples mostly from Corsica (135 samples) and a few from PACA (two samples) was named ST6_C1P1. The DAPC cluster 2 was separated into two subgroups: one named ST6_C2, grouping the 19 samples originating from Corsica and another one named ST6_P2 grouping the 28 samples originating from PACA. For ST7, the DAPC cluster 3 grouping samples mostly from Corsica (110 samples) and a few from PACA (eight samples) was named ST7_C1P1. The DAPC cluster 4 was separated into two subgroups, one, named ST7_C2, composed of the 19 samples originating from Corsica, and another one, named ST7_P2, composed of the 75 samples originating from PACA.

The number of scenarios with three French populations, one outgroup population and possible non-sampled (ghost) populations is huge, making it impossible to perform a single analysis to 
answer our question. To cope with this complexity, we adopted a two-step approach composed of i) a bottom-up stage in which population from a same sequence type were analyzed two by two in three different analyses, which aimed at deciphering histories between pairs of French populations (Fig. S9A), and ii) a top-down stage confronting three-population scenarios not excluded by the bottom-up stage (Fig. S9B).

On the three French ST6 populations (C1P1, C2, and P2), after bottom-up approach, no scenario (topology $\times$ combination of populations) achieved sufficiently high posterior probability and low prior error rate to be considered as the best scenario to reconstruct the evolutionary history of the ST6 French populations in regards to their USA counterparts. However, some scenarios had so low posterior probabilities $(\mathrm{p}<0.05)$ that they could be ruled out (Table S8). Specifically, scenarios 2 and 6 testing the possibility of only one French population were ruled out for all combinations of populations, confirming that the French ST6 samples did group into three populations (Fig. S9A).

Scenarios not excluded during this first stage were used in the top-down approach to elaborate scenarios of the evolutionary history of the three French ST6 populations (Fig. S9B). Considering all combinations of populations, 30 scenarios were confronted (Fig. S10). Scenario II.7 was selected in the abcrf analysis as the most probable scenario with $9.9 \%$ of the votes and the highest posterior probability $(0.26-0.37)$ (Table S8). In this scenario, ST6 strains would have been first introduced in PACA (P2 population). Then population C1P1 would have diverged from this initial focus, and would thus represent the first established population in Corsica. A second independent population (C2) would have diverged later on from the first established P2 population in PACA, and established in Corsica (Fig. S10). However, it should be tempered by the fact that this selected scenario also presented a high prior error rate $(0.72)$ (Table S8).

The following most probable scenarios received a low number of votes. The second and third best scenario were III.I.16 and II.9 with respectively 5.8\% and 5.7\% of votes (Table S8). These two scenarios had a close topology to scenario II.7, as both considered an introduction in PACA (P2), from which the population C2 from Corsica would have diverged. Moreover, on the 30 scenarios confronted, the seven scenarios testing the hypothesis that the Corsican population $\mathrm{C} 2$ would have diverged from the P2 population from PACA totalized $35.9 \%$ of the votes, giving more strength to this event.

Similarly, on the three French ST7 populations (C1P1, C2, and P2), the bottom-up approach did not allow to identified the best scenario, but allowed ruling out scenarios 2 and 6 , thereby confirming that the French ST7 samples did group into three populations (Fig. S9A, Table S8). In addition, scenarios 1 and 9 that tested independent and successive introductions of each French populations from the American ancestor were also excluded. It is however interesting to note that similar scenarios (5 and 10) including an unsampled population between the American ancestor and the French ones were not ruled out. In contrast, scenarios 11 and 12 that were slight variations of previous scenarios 1 and 9 including unsampled populations between 
the American ancestor and each French populations were ruled out. Altogether, six scenarios $\left(n^{\circ} 3,4,5,7,8\right.$ and 10, Fig. S9A) were kept for further consideration after this bottom-up approach.

Moving to the top-down approach, based on the results of the bottom-up approach scenarios that tested independent introductions (class I in Fig. S9B) and those testing two independent introductions, one of which was responsible for a bridgehead invasion of the third population (class III.I and III.II in Fig. S9B), were consequently not considered. This left us with two closely related topologies to be tested (Fig. S9B and Fig. S11), i.e., scenarios testing the introduction in France of one population subsequently responsible for two independent bridgehead invasions, (class II in Fig S10B), and scenarios considering that the first introduction lead to two successive bridgehead invasions (class IV in Fig S10B). Considering all combinations of populations, 12 scenarios were confronted. Scenario II.1 was selected in the abcrf analysis as the most likely scenario with $17.5 \%$ of the votes and with the highest posterior probability $(0.41-0.50)$ (Table S8). In this scenario, ST7 strains would have been first introduced in PACA (P2 population). Then population C1P1 would have diverged from this initial focus, and would thus represent the first established population in Corsica. A second independent population (C2) would have diverged later on from the first established P2 population in PACA, and established in Corsica (Fig. S11). However, it should be tempered by the fact that this well supported scenario also presented a high prior error rate $(0.70-0.71)$ (Table S8).

Then scenarios having the highest number of votes were scenario IV.27 and scenario IV.25, to which respectively $12.4 \%$ and $10.9 \%$ of the votes were attributed (Table S8). Both had a close topology to the best scenario, as they considered that a first population would have been introduced in PACA (P2), from which populations $\mathrm{C} 1 \mathrm{P} 1$ and $\mathrm{C} 2$ would have diverged but from two successive bridgehead invasions (C1P1 then $\mathrm{C} 2$ or $\mathrm{C} 2$ then $\mathrm{C} 1 \mathrm{P} 1)$ instead of two independent divergence events. Moreover, among the 12 scenarios confronted, the four scenarios testing the hypothesis that the population from PACA (P2) was the first one introduced in France and from which the other two population diverged totalized $53.24 \%$ of the votes, giving more strength to this event.

\section{Discussion}

While natural spreading capacities of $X$. fastidiosa depend on the activity of the sap-sucking insects that vector this bacterium from plant to plants, the detection of strains outside their areas of origin since the end of the $19^{\text {th }}$ century illustrates the effectiveness of its human-assisted transmission, as elegantly demonstrated for X. fastidiosa strains introduced in the Balearic islands (42). The introduction of infected but asymptomatic plants for planting of species not cultivated in Europe, such as coffee plants, or of various ornamental species is now considered one, if not the main pathway for introduction of X. fastidiosa (13). The introduction of the subspecies fastidiosa in California would have been the first example $(4,21)$ and the introduction of X. fastidiosa subsp. pauca strain ST53 into Apulia, Italy, the most recent one 
(29). It is within this framework that we have sought to reconstruct the invasive scenario of X. fastidiosa subsp. multiplex ST6 and ST7 in France.

First, we estimated the divergence time of strains from the main lineages present in France (ST6 and ST7) from their American relatives and from the ST6 and ST81 Spanish strains. Divergence date between French and American ST6 strains was estimated in 1987 (1974 to 1994 95\% HPD), while divergence date between French and American ST7 strains was estimated a little earlier in 1971 (1924 to 1994 95\% HPD). Moreover, very few SNPs were detected between French strains sharing the same sequence type, confirming recent introductions, even if divergence time is not synonymous to introduction time, but here represent the lower bounds of introduction. The period of divergence of ST6 and ST7 French strains from US counterparts corresponds to the 70's-80's, a period during which alien plants were massively introduced in Corsica (43). To our knowledge, no such data about alien species trade, in particular from the only other known place of occurrence of $X$. fastidiosa subsp. multiplex ST6 and ST7, the USA, could be recovered to document potential introductions in PACA. The period of time for $X$. fastidiosa introduction into France inferred from analysis of genomic data is highly consistent with a previous evaluation dating it in 1985 (1978 to 1993 95\% HPD) (44). That study used a mechanistic-statistical approach based on spatio-temporal modelling of the French surveillance plan data and the assumption of a hidden compartment limiting the exhaustiveness of the sampling (44). This study did not take into account the genetic diversity of the pathogen and considered the subspecies multiplex no matter its sequence type, as a whole, which explains the fact that only one date of introduction was proposed. In contrast, our results are not consistent with estimates from the recent study of Moralejo et al (2020), which dated the introduction in Corsica of X. fastidiosa subsp. multiplex in 2000 (42). Actually, in this study only three Corsican strains all isolated in 2015 were analyzed and strains where clustered by region during analysis without taking into account the presence of the two genetic lineages, ST6 and ST7, both present in Corsica. In our study, the dating of the French strains, make them the earlier ones that would have occurred in Europe, before the introduction of ST1 in 1993 and of ST81 in 1995 in the Balearic Islands, of ST6 in 2005 in mainland Spain and of ST53 in Apulia $(20,42)$. We also confirmed the polyphyly of the French and Spanish ST6 strains previously observed (29). These two groups of strains differed by 899 to 912 SNPs and their divergence date traced back to the divergence between ST6/ST81 and ST7 estimated in 755 (-397 to 1540 95\% HPD). At the time of this study no strain or genome of Spanish ST7 strains was available, which impeded their inclusion in our study.

In order to specify the invasive scenario of ST6 and ST7 introductions and further dissemination over the French territory, genomic data were used. All the 49 X. fastidiosa subsp. multiplex strains isolated in France from plant were sequenced and together with publicly available sequences they allowed the extraction of a core genome of 1,679,574 bp containing 16,739 SNPs. These data are in line with those previously obtained by Landa et al. (2020), in which the core genome of $21 X$. fastidiosa subsp. multiplex strains was estimated at 1,569,508 bp, containing 5,630 core SNPs (29). But these data are surprisingly in contrast with those of 
Vanhove et al. (2019) in which the core genome of 23 strains of $X$. fastidiosa subsp. multiplex was estimated at 736,868 bp containing 37,485 SNPs (20). Differences may rely on the use of different methodologies as Vanhove et al., (2019) study analyzed mapped raw reads data on reference and both Landa's et al., (2020) and our study analyzed assembled genomes which is more precise.

The molecular evolutionary rates of $X$. fastidiosa subsp. multiplex was evaluated using tipcalibrating approach at $3.2165 \times 10^{-7}$ substitutions per site per year $\left(1.5468 \times 10^{-7}-5.2043 \times\right.$ $10^{-7} 95 \%$ HPD). This estimation is congruent with those previously estimated for the subspecies pauca $\left(7.62 \times 10^{-7}\right.$ substitutions per site per year, 95 Confidence Interval $(\mathrm{CI}): 1.027 \times 10^{-7}$ to $\left.1.454 \times 10^{-6}\right)$ and for the subspecies fastidiosa $\left(6.38 \times 10^{-7}\right.$ substitutions per site per year, $95 \mathrm{CI}$ : $3.9277 \times 10^{-7}$ to $9.0912 \times 10^{-7}$ and $7.71 \times 10^{-7}$ substitutions per site per year, $95 \mathrm{CI}: 1.20 \times 10^{-7}$ to $1.69 \times 10^{-6}$ substitutions per site per year) $(20,42,45)$. Moreover, the mean substitution rate estimated in our study is consistent with those of several human and animal bacterial pathogens estimated within a similar time period (46).

To trace back the most probable invasive scenario for ST6 and ST7 strains in France, we developed a MLVA typing scheme, composed of 13 VNTRs adapted for analyses at small evolutionary scales. Another strength of our analysis comes from the fact that it was specifically developed and optimized to study the diversity of the subspecies multiplex. We made use of discriminant existing VNTR loci $(39,40)$ and coupled them to three newly identified VNTR loci, the only ones that we found to complement the observed diversity in our collection of $X$. fastidiosa subsp. multiplex strains. This relatively limited number of examined loci (13) should however be analyzed with regards to the small size of $X$. fastidiosa genome. Another strength of our MLVA scheme is that it has been developed and optimized to be directly usable on genomic DNA extracted from fresh or frozen infected plant material, as it has already shown to be possible for Italian samples infected with $X$. fastidiosa subsp. pauca ST53 (47). Our study further confirms the interest of such direct genotyping techniques.

MLVA highlighted substantial diversity within each sequence type as three subgroups of samples were defined that partially fitted with the geographical location of samples. One subgroup was composed of both PACA and Corsican samples, and the other two were exclusively composed of samples from PACA or Corsica regions. These groups however clustered samples from various plant species. On the one hand such genetic structures are highly indicative of a long distance spread of the pathogen by human activities for the two groups mixing geographical origins of strains, i.e. lacking spatial structuration. Human activities are often associated with fortuitous introductions of pathogens into yet free areas that turned out to be responsible for high losses (48). On the other hand, the two other groups of each sequence type that are highly spatially structured are indicative of a more local dissemination that can result from human activities but also, as it overcomes host barrier, from the activity of insect vectors, the only natural means of dispersion of $X$. fastidiosa. In Corsica, Philaenus spumarius was identified as a potential vector of $X$. fastidiosa ST6 and ST7 strains (49). 
From an American origin, a first ST6_P2 population would have been introduced in PACA and have spread within this region, where it was found on ornamental plants in urban contexts. Contemporary samples are clustered in a limited area around cities Antibes and Nice. Then, a population, named C1P1, diverged from this bridgehead initial population. This divergent population also established in PACA but individuals were also introduced in western Corsica, where they established. This introduction is most likely attributable to the trade of infected plants, i.e. P. myrtifolia, as it is known that plantings of this ornamental species were multiplied in a few places in Tuscany, Italy and PACA and were subsequently moved to Corsica (50). Other hosts identified within this group both come from Corsican bush and ornamentals. In western Corsica the founders of this group were mainly found around the city of Ajaccio. Finally, the last population, named C2, found only in Corsica would have diverged from the bridgehead population established in PACA and spread around Zonza in eastern Corsica. For now, $\mathrm{ABC}$ analysis did not fully validate all these scenarios, but the hypothesis according to which the Corsican $\mathrm{C} 2$ population would have diverged from the population P2 of PACA is the most likely to have happened.

A very similar scenario was found as the most probable for ST7, the differences rely mostly in places of occurrence, with co-location of ST6 and ST7 infected samples in some places. In Corsica the ST7_C1P1 population coming from the P2 population from PACA established in Southern Corsica and then Corsican C2 population, also coming from the P2 population, spread around Ajaccio, but also in distant places in the Northern and Western parts of Corsica. This larger distribution over the Corsican territory is congruent with an older introduction, estimated here as 16 years earlier for the ST7 strains (1971), than the ST6 one (1987). Here again, ABC analysis did not fully validate the entire scenario, but the hypothesis according to which the population P2 from PACA was the first established in France, from which the two other diverged is the most likely to have happened. Bridgehead effect is a concept first developed for eukaryote invasive species (51) and recently applied to phytopathogenic bacteria (36). Here, we suspect that trade of infected myrtle leaf milkwort (the species representing $69.95 \%$ of the samples detected infected over the reference period, from which founder haplotypes of all clonal complexes were detected) represents all initial migration events that served later on as a reservoir for local dissemination by plant movement or insect vectors, which would explain the identification of same haplotypes in plants of different species.

P. myrtifolia is a bush native to South Africa, genetically bred in Florida in the 1980's, before being sold to Europe $(50,52)$. Moreover, the first identification of ST6 and ST7 of X. fastidiosa subsp. multiplex were made in the Eastern and South-Eastern USA (10). In Europe the three largest countries that produce $P$. myrtifolia cuttings are Italy, Spain and then Portugal (50). In Corsica, the trade of plants is unilateral and plants from southern Europe are sold to PACA, which serves as an importer for Corsica or are sold directly to Corsica. In fact, when the $X$. fastidiosa detections arose in 2015 in Corsica, the origins of the first infected $P$. myrtifolia plants were Italy (8 plants), PACA (2 plants) and Spain (1 plant) (50). Furthermore, the dates of diversification of the French ST6 and ST7 strains compared to their American counterparts, in 
1987 and 1971 respectively, correspond to a period of massive introduction of exotic plants, particularly in Corsica (43). Unfortunately, no such data were found for the PACA area plant trade. All these elements are in line with the best scenario that we obtained and could validate the myrtle leaf milkwort as the initial vector of $X$. fastidiosa subsp. multiplex in France. The climate all over France is supposed to be favorable for the spread and survival of $X$. fastidiosa subsp. multiplex (53). A spread to other areas in France or the discovery of $X$. fastidiosa in other places, such as recently reported in Occitanie (28), should be anticipated, as the probable presence of $X$. fastidiosa in Corsica and PACA for half a century has been overlooked. Indeed, in Corsica, sampling was quite exhaustive, as most infected samples grouped in clonal complexes that are biologically meaningful groups of single locus variants epidemiologically related. In contrast, most PACA infected samples grouped in several small clonal complexes and singletons that could not be linked as several evolutionary steps were lacking. Further sampling in PACA would allow refining the scenario we presented here.

\section{Materials and Methods}

\section{Bacterial strains and growth conditions}

A collection of 95 Xylella fastidiosa strains (Table S2) was used in this study. Dr Leonardo

De la Fuente (Auburn University, AL, USA) kindly provided $12 X$. fastidiosa strains isolated in the USA. The Plant Health Laboratory (Anses LSV, Angers, France) shared 39 strains of $X$. fastidiosa subsp. multiplex. All strains were preserved by the French Collection of PlantAssociated Bacteria (CIRM-CFBP. International Centre of Microbial Resource (CIRM) French Collection for Plant-associated Bacteria. INRAE. https://doi.org/10.15454/E8XX$\underline{4 Z 18}$ ). Strains were grown on BCYE medium (10) or modified PWG medium (54) at $28^{\circ} \mathrm{C}$ for one to two weeks.

\section{DNA extraction and DNA sample collections used for MLVA}

Bacterial suspensions were prepared from fresh cultures in sterile distilled water, adjusted at $\mathrm{OD}_{600 \mathrm{~nm}}=0.1\left(1 \times 10^{8} \mathrm{CFU} \cdot \mathrm{mL}^{-1}\right)$, boiled for $20 \mathrm{~min}$, cooled on ice and centrifuged at 10,000 g during 10 min. DNAs from the 18 Spanish X. fastidiosa strains (Table S3) were kindly provided by Dr Blanca Landa (Institute for Sustainable Agriculture, Córdoba, Spain) and were extracted using CTAB protocol (10). A collection of 357 DNAs from X. fastidiosa subsp. multiplex infected French plant samples (Table 2, Table S4) was used in this study. These infected samples were collected in Corsica and in PACA between 2015 and 2018 in the framework of the national official surveillance strategy for $X$. fastidiosa and other dedicated sampling campaigns and were declared infected based on positive Harper's qPCR test at $\mathrm{Cq}<38$ (10). Plant samples were finely chopped in distilled water, optionally sonicated (54), and incubated 15 min at room temperature before DNA extraction using CTAB or QuickPick ${ }^{\mathrm{TM}}$ SML Plant DNA Kit (Bio-Nobile, Turku, Finland) as described in PM7/24 (10). The DNA samples were stored at $-20^{\circ} \mathrm{C}$ before analysis. 


\section{DNA extraction and whole-genome sequencing}

Highly concentrated bacterial suspensions of the 48 strains to be sequenced by Illumina HiSeq $\mathrm{X}$ (Table S1) were prepared from fresh cultures in $5 \mathrm{~mL}$ of ultrapure sterile water. The genomic DNA was extracted using the Wizard ${ }^{\circledR}$ Genomic DNA Purification Kit (Promega), following the manufacturer's recommendations. DNA was rehydrated in $100 \mu \mathrm{L}$ of ultrapure sterile water. Quality and quantity of extracted DNA were verified using a NanoDrop ND-100 Spectrophotometer (Thermofisher) and a Qubit Fluorometer 1.0 (Invitrogen). Library preparation and sequencing were performed on Illumina HiSeq 4000 platform (BGI, Hong Kong). For the seven strains sequenced using the PacBio technology, DNA was extracted from fresh cultures in $10 \mathrm{~mL}$ of ultrapure sterile water following Mayjonade et al.'s recommendations (55). Library preparation and sequencing were performed at the GeT-PlaGe core facility, INRAE Toulouse, according to the manufacturer's instructions "Shared protocol-20kb Template Preparation Using BluePippin Size Selection system (15kb size Cutoff)". At each step, DNA was quantified using the Qubit dsDNA HS Assay Kit (Life Technologies). DNA purity was tested using the NanoDrop (Thermofisher) and size distribution and degradation assessed using the Fragment analyzer (AATI) High Sensitivity Large Fragment 50kb Analysis Kit. Purification steps were performed using 0.45X AMPure PB beads (PacBio). 10 $\mu \mathrm{g}$ of each DNA was purified then sheared at $40 \mathrm{~kb}$ using the megaruptor1 system (diagenode). Using SMRTBell template Prep Kit 1.0 (PacBio), a DNA and END damage repair step was performed on $5 \mu \mathrm{g}$ of each sample. Then blunt hairpin adapters were ligated to the libraries. The libraries were treated with an exonuclease cocktail to digest unligated DNA fragments. A size selection step using a 10kb cutoff was performed on the BluePippin Size Selection system (Sage Science) with $0.75 \%$ agarose cassettes, Marker S1 high Pass 15-20kb. Conditioned Sequencing Primer V2 was annealed to the size-selected SMRTbells. The annealed libraries were then bound to the P6-C4 polymerase using a ratio of polymerase to SMRTbell at 10:1. Then after a magnetic bead-loading step (OCPW), 7 SMRTbell libraries were sequenced on 7 SMRTcell on RSII instrument at $0.2 \mathrm{nM}$ with a $360 \mathrm{~min}$ movie.

\section{Design and development of the VNTR-13 scheme}

The complete genome sequence of the M12 strain of $X$. fastidiosa subsp. multiplex isolated from Prunus dulcis in the USA in 2003 (GenBank accession number NC_010513.1) was screened for the presence of candidate TR loci using Tandem Repeat Finder 4.09 (https://tandem.bu.edu/trf/trf.html). Parameters were set as follows: total length in a range of $50-500 \mathrm{bp}$ and TR length $\leq 44 \mathrm{bp}$. Other parameters were set as default. The identified loci were analyzed for (i) presence in $10 \mathrm{X}$. fastidiosa subsp. multiplex (38) using BLASTn, (ii) absence of redundancy with the previously published set of VNTR loci $(39,40)$, and (iii) existence of polymorphism in the $10 \mathrm{X}$. fastidiosa subsp multiplex genome sequences by manual checking. Three novel VNTR loci (XFSSR-37, XFSSR-40 and XFSSR-58) were retained for further analyses to complete the set of 10 previously published VNTR loci (nine VNTR loci previously designed by Lin et al. (2005) and one VNTR locus designed by Francisco et al. 
(2017), Table 1). The 150 bp flanking regions of these VNTR loci were extracted from the 10 genome sequences of $X$. fastidiosa subsp multiplex. Oligonucleotide primers were designed in their homologous segments using Primer3 2.3.4 (56). The specificity of all 13 VNTR primer pairs was tested in silico using PrimerSearch (Val Curwen, Human Genome Mapping Project, Cambridge, UK) on the 154,478 bacterial Whole Genome Shotgun (WGS) sequences available in the NCBI database (as on August 22, 2018). The primer pair sets were tested using Amplify to verify the absence of dimer and cross-amplification (57).

\section{VNTR-13 scheme genotyping}

Primers were tested by PCR using 16 strains of $X$. fastidiosa as a "panel test" (Table S2). Primer pair multiplexing was done according to the annealing temperature. Finally, all forward primers were labeled with one of the fluorescent dyes (6-FAM, HEX, ATTO550 and ATTO565) (Eurofins) at their 5' end. To optimize VNTR amplification protocol for direct use in plant material, the efficiency of two Taq polymerases (Platinum ${ }^{\mathrm{TM}}$ Taq DNA Polymerase, Invitrogen, and GoTaq ${ }^{\circledR}$ G2 Flexi DNA Polymerase, Promega) were compared, as well as the impact of the DNA volume ( $1 \mu \mathrm{L}$ and $2 \mu \mathrm{L})$ added to the reaction mix on ASSR-9, ASSR-16 and GSSR4 VNTR loci amplification. Tests were run on DNA extracted from maceration of healthy Polygala myrtifolia samples $\left(0.2 \mathrm{~g} \cdot \mathrm{ml}^{-1}\right)$ spiked with CFBP 8416 strain suspensions ranging from $1 \times 10^{2}$ to $1 \times 10^{6}$ CFU.mL ${ }^{-1}$. These tests allowed the determination of the limit of VNTR genotyping directly in plant extract as a function of $\mathrm{Cq}$, as spiked solutions were all tested with the Harper's qPCR test (58). Finally, the PCRs were performed in a $20 \mu \mathrm{L}$-final volume containing 1X PCR buffer (no magnesium chloride) (Invitrogen), $1.5 \mathrm{mM}$ of magnesium chloride (Promega), $0.2 \mathrm{mM}$ of each dNTP, $0.2 \mu \mathrm{M}$ of each primer (Promega), $1 \mathrm{U}$ of Platinum ${ }^{\circledR}$ Taq DNA Polymerase (Invitrogen) and $2 \mu \mathrm{L}$ of sample DNA or $1 \mu \mathrm{L}$ of boiled bacterial suspension. The optimal PCR conditions were $5 \mathrm{~min}$ at $95^{\circ} \mathrm{C}$, followed by 35 cycles of $30 \mathrm{~s}$ at $95^{\circ} \mathrm{C}, 30 \mathrm{~s}$ at the annealing temperature (Table 1) and $30 \mathrm{~s}$ at $72^{\circ} \mathrm{C}$, and ended by $10 \mathrm{~min}$ at $72^{\circ} \mathrm{C}$.

To test VNTR typing repeatability the strain CFBP 8416 was included as a control in each series of amplification. For samples previously detected infected by $X$. fastidiosa with the Harper's qPCR test at Cq values below 27, VNTRs were amplified in multiplex formats and $2.4 \mu \mathrm{L}$ of PCR products were mixed with $9.35 \mu \mathrm{L}$ of Hi-Di formamide (Sigma-Aldrich) and $0.15 \mu \mathrm{L}$ of Genescan $500 \mathrm{Liz}$ internal line size standard (Applied Biosystems) for capillary electrophoresis using an ABI PRISM 3130 genetic analyzer (Applied Biosystems): injection of $16 \mathrm{sec}$ at 1.2 kvolts, voltage steps $20 \mathrm{nk}$, interval of $15 \mathrm{sec}$, data delay time of $60 \mathrm{sec}$, run of $12000 \mathrm{sec}$ at 15 kvolts,. For samples with Cq values equal at 27 or lower than 32, VNTRs were amplified in simplex assays and products were visualized on $1 \%$ agarose gel electrophoresis in Tris-borate-EDTA buffer. PCR products were multiplexed by four for capillary electrophoresis. 


\section{Data scoring}

Electrophoregrams were analyzed using Geneious 9.1.8 software (Biomatters) and peaks were first automatically detected using the predict peaks mode. Each ladder and VNTR peaks were then carefully checked by eye and artefacts or small peaks were corrected. The reproducibility of the entire experiment was checked by amplifying and sequencing the strain CFBP 8416 in each run. Sets of 13 VNTRs were sequenced for the strains CFBP 8416, CFBP 8417, and CFBP 8418 to confirm TR sequence length, length of the repeat flanking region, and the number of repeats. The number of repeats in each locus was calculated based on the fragment sizes using Geneious 9.1.8 software (Biomatters).

\section{MLVA analyses and statistics}

MSTs were drawn and clonal complexes analyzed using the algorithm recommended for MLVA data combining global optimal Euclidean and goeBURST distances in PHYLOViZ v2.0 (59). Haplotypes differing one another by only one locus (single-locus variant, SLV) were grouped in clonal complexes. The discriminatory power of the MLVA was calculated using http://insilico.ehu.es/mini_tools/discriminatory_power/index.php. Data were analyzed using two different methods in order to infer population structure and assign samples to clusters. Bayesian clustering approach (STRUCTURE 2.3.4 software) (60) was applied with 10 independent runs, performed for $\mathrm{K}=1$ to 10 , with a burn-in period of 100,000 iterations followed by 500,000 Monte Carlo Markov Chain (MCMC) replicates. This analysis was completed with the Discriminant Analysis of Principal Components (DAPC), which was used as it does not rely on any assumption about the population genetic model (41). DAPC analyses were conducted on 20 independent k-means runs in order to verify the stability of the clustering. Analyses were performed using a single individual per haplotype with the adegenet package from the $\mathrm{R}$ software (61). Simpson's index of diversity using BioNumerics 7.6 (Applied Maths) and allelic richness using Fstat 2.9.4 (62) were calculated to access the discriminatory power of each VNTR. Using the groups defined by DAPC, the number of alleles and their frequency distribution were determined using GenAlEx 5.5.1 (63). Genetic differentiation of the DAPC groups was estimated using $\mathrm{F}_{\mathrm{ST}}$ and $\mathrm{R}_{\mathrm{ST}}$ with Arlequin 3.5.2.2 (64). Using the same software an analysis of molecular variance was performed. The individuals were grouped according to the groups established for DIYABC analysis. Spatial representation of the distribution of the French samples and their genetic clustering on the French territory were made using the $\mathrm{R}$ package maptools (65).

\section{Approximate Bayesian Computation (ABC) analysis}

We investigated whether the French emergence of $X$. fastidiosa subsp. multiplex was the result of multiple independent introduction events or the result of one or a few events that subsequently spread. First, we conducted a scenario choice using ABC. This method consists in generating a large number of datasets, simulated under each of the tested scenarios, and measuring the similarity between the simulated data and the real data with statistics (66). The 
posterior probability of each scenario is then obtained from its occurrence in the simulations that are the closest to the real dataset using a post-sampling adjustment (66). To decipher the scenario of introduction of $X$. fastidiosa subsp. multiplex in France, we first used an ABC approach which is implemented in the DIYABC software v2.1 (67). Then, the machine learning tool $\mathrm{ABC}$ random forest (ABC-rf), implemented in the R package "abcrf" (68) was used to analyzed DIYABC results, as it is the most robust and offers a larger discriminative power among competing scenarios $(68,69)$.

Data were analyzed independently per sequence type number (ST6 and ST7). As X. fastidiosa subsp. multiplex ST6 and ST7 were previously known to occur only in the USA, the American ST6 Dixon strain and the American ST7 M12 and Griffin strains were used as representatives of ancestral populations, from which the French strains were linked. All MLVA data from French infected samples and strains were used to run ABC analyses. Four genetic groups were defined for ST6 and ST7 strains, using results previously obtained from DAPC and STRUCTURE clustering analysis, goeBURST tree topology, historical and geographical information. For both sequence type analyses, three French populations were defined, one grouping both Corsica and PACA samples (named C1P1), one grouping exclusively Corsica samples (named C2) and one grouping exclusively PACA samples (named P2). Based on these assumptions and data, the number of possible scenarios to test was estimated at 30, without taking into account the existence of unsampled population(s). In order to limit the number of scenarios analyzed in each run, a Nested strategy was followed. Populations were first compared by a bottom-up approach, in which scenarios were composed only of American strain(s) and two French populations. Then, the following analyses used the conclusions obtained from previous analyses and allowed to eliminate assumptions. Second, all French populations were simultaneously compared in a top-down approach, in which each scenario topology was analyzed separately. For a detailed description of the scenarios analyzed and software parameters read "Supplemental material".

\section{Genome assembly, alignment and SNP calling}

A total of 82 genome sequences of $X$. fastidiosa subsp. multiplex was analyzed in this study (Table S1), including 27 publicly available genome sequences (NCBI on 16/12/2019) and 55 genome sequences of strains that were sequenced in this study (49 from France and 6 from USA). Genome assembly was performed with SOAPdenovo version 2.04, SOAPGapCloser version 1.12 (70) and Velvet version 1.2.02. (71). The 82 genome sequences were aligned using the strain M12 as a reference with Parsnp tool v1.2 from Harvest suite (72) to obtain $X$. fastidiosa subsp. multiplex core genome. The matrix of SNPs was extracted using Gingr tool v1.3 from Harvest suite (72). Detection of recombinant sequences within the core genome alignment was performed using ClonalFrame (73), running three independent MCMCs of 50,000 iterations, a burn-in length of 10,000 iterations and iteration samples every 100 iterations. The recombinant events detected were discarded from the SNP matrix using R scripts (M. Mariadassou and D. Merda pers. comm.) sourcing the "ape" (74) and "coda" packages (75). 


\section{Population structure}

To infer population structure, the fastStructure program based on a Bayesian clustering approach was run on the whole core SNPs alignment (76). Ten independent runs were performed for $\mathrm{K}=1$ to 10 , with a $\mathrm{MCMC}$ of $1,000,000$ iterations. The other parameters were set

\section{Molecular Tip dating}

The no-recombining core genome of the 82 strains, spanning 36 years of evolution (1983 to 2018) was used to investigate the presence of temporal signal thanks to two different tests. At first, a Maximum Likelihood (ML) tree was constructed with RAxML 8.2.4 (78) using a rapid Bootstrap analysis, a General Time-Reversible model of evolution following a $\Gamma$ distribution with four rate categories (GTRGAMMA) and 1,000 alternative runs. A linear regression test between sample age and root-to-tip distances was computed at each internal node of the ML tree using Phylostems (79). Temporal signal was considered present at nodes displaying a significant positive correlation. Secondly, a date-randomisation test $(80)$ was performed with 40 independent date-randomised datasets built with the R package "TipDatingBeast" $(81)$. The "RandomCluster" function allowed to randomized the isolation dates of samples per cluster of 10 years (1983-1989; 1990-1999; 2000-2009; 2010-2018). Results were generated using the "PlotDRT" function. Temporal signal was considered present when there was no overlap between both the inferred root height and substitution rate 95\% HPD of the initial dataset and that of the date-randomized datasets. Tip-dating inferences were performed using the Bayesian MCMC method implemented in BEAST v2.6.1 (37). Leaf heights were constrained to be proportional to sample ages. Flat priors (i.e., uniform distributions) were applied both for the substitution rate $\left(10^{-12}\right.$ to $10^{-2}$ substitutions/site/year) and for the age of all internal nodes in the tree. We also considered a general time reversible (GTR) substitution model with a $\Gamma$ distribution and invariant sites $(\mathrm{GTR}+\mathrm{G}+\mathrm{I})$, an uncorrelated relaxed log-normal clock to account for variations between lineages, and a tree prior for demography of coalescent Bayesian skyline. Six independent chains were run for 200,000,000 step and sampled every 20,000 steps, after a discarded burn-in of $10 \%$. Convergence, sufficient sampling and mixing were verified by visual inspection of the posterior samples using Tracer v1.7.1 (37). Parameter estimation was based on the samples combined from the six different chains. The six tree output files were merged using LogCombiner software v2.6.1 after a 20\% burn-in period and the best supported tree was drawn using the maximum clade credibility method implemented in Tree-Annotator software v2.6, after a 10\% burn-in period (37). In parallel, Bayesian skyline analysis was performed to observe effective population size along time using Tracer v1.7.1 (37).

\section{References}

1. S. Savary, L. Willocquet, Modeling the Impact of Crop Diseases on Global Food Security. Annual Review of Phytopathology. 58, 313-341 (2020). 
2. P. K. Anderson, A. A. Cunningham, N. G. Patel, F. J. Morales, P. R. Epstein, P. Daszak, Emerging infectious diseases of plants: pathogen pollution, climate change and agrotechnology drivers. Trends in Ecology \& Evolution. 19, 535-544 (2004).

3. C. Bonneaud, L. A. Weinert, B. Kuijper, Understanding the emergence of bacterial pathogens in novel hosts. Phil. Trans. R. Soc. B. 374, 20180328 (2019).

4. L. Nunney, X. Yuan, R. Bromley, J. Hartung, M. Montero-Astúa, L. Moreira, B. Ortiz, R. Stouthamer, Population genomic analysis of a bacterial plant pathogen: novel insight into the origin of Pierce's disease of grapevine in the U.S. PLOS ONE. 5, e15488 (2010).

5. L. Nunney, D. Hopkins, L. Morano, S. Russell, R. Stouthamer, Intersubspecific Recombination in Xylella fastidiosa Strains Native to the United States: Infection of Novel Hosts Associated with an Unsuccessful Invasion. Applied and Environmental Microbiology. 80, 1159-1169 (2014).

6. EFSA, A. Delbianco, D. Gibin, L. Pasinato, M. Morelli, Update of the Xylella spp. host plant database systematic literature search up to 30 June 2021. EFSA Journal. 20, e07039 (2022).

7. P. P. Kandel, R. P. P. Almeida, P. A. Cobine, L. De La Fuente, Natural Competence Rates Are Variable Among Xylella fastidiosa Strains and Homologous Recombination Occurs In Vitro Between Subspecies fastidiosa and multiplex. MPMI. 30, 589-600 (2017).

8. L. Nunney, E. L. Schuenzel, M. Scally, R. E. Bromley, R. Stouthamer, Large-Scale Intersubspecific Recombination in the Plant-Pathogenic Bacterium Xylella fastidiosa Is Associated with the Host Shift to Mulberry. Appl Environ Microbiol. 80, 3025-3033 (2014).

9. L. Nunney, X. Yuan, R. E. Bromley, R. Stouthamer, Detecting Genetic Introgression: High Levels of Intersubspecific Recombination Found in Xylella fastidiosa in Brazil. Appl. Environ. Microbiol. 78, 47024714 (2012).

10. EPPO, PM 7/24 (4) Xylella fastidiosa. EPPO Bulletin. 49, 175-227 (2019).

11. M. Saponari, D. Boscia, F. Nigro, G. P. Martelli, Identification of DNA sequences related to Xylella fastidiosa in oleander, almond and olive trees exhibiting leaf scorch symptoms in Apulia (southern Italy). Journal of Plant Pathology. 95, 659-668 (2013).

12. M. Saponari, A. Giampetruzzi, G. Loconsole, D. Boscia, P. Saldarelli, Xylella fastidiosa in Olive in Apulia: Where We Stand. Phytopathology. 109, 175-186 (2019).

13. EFSA, C. Bragard, K. Dehnen-Schmutz, F. D. Serio, P. Gonthier, M. A. Jacques, J. A. J. Miret, A. F. Justesen, A. MacLeod, C. S. Magnusson, P. Milonas, J. A. Navas-Cortés, R. Potting, P. L. Reignault, H.-H. Thulke, W. van der Werf, A. V. Civera, J. Yuen, L. Zappalà, D. Boscia, D. Chapman, G. Gilioli, R. Krugner, A. Mastin, J. R. S. Lopes, A. Simonetto, S. White, J. C. Abrahantes, A. Delbianco, A. Maiorano, O. MosbachSchulz, G. Stancanelli, M. Guzzo, S. Parnell, Update of the Scientific Opinion on the risks to plant health posed by Xylella fastidiosa in the EU territory. EFSA Journal. 17, e05665 (2019).

14. EPPO, EPPO A2 List of pests recommended for regulation as quarantine pests - version 2018-09 - (2018), (available at https://www.eppo.int/ACTIVITIES/plant_quarantine/A2_list).

15. European Commission, Commission Delegated Regulation (EU) 2019/1702 of 1 August 2019 supplementing Regulation (EU) 2016/2031 of the European Parliament and of the Council by establishing the list of priority pests. Official Journal of the European Union (2019) (available at http://data.europa.eu/eli/reg_del/2019/1702/oj/eng).

16. European Commission, Commission implementing regulation (EU) 2020/1201 of 14 August 2020 as regards measures to prevent the introduction into and the spread within the Union of Xylella fastidiosa (Wells et al.). Official Journal of the European Union (2020). 
17. R. Krugner, M. S. Sisterson, E. A. Backus, L. P. Burbank, R. A. Redak, Sharpshooters: a review of what moves Xylella fastidiosa. Austral Entomology. 58, 248-267 (2019).

18. C. C. Su, C. J. Chang, C. M. Chang, H. T. Shih, K. C. Tzeng, F. J. Jan, C. W. Kao, W. L. Deng, Pierce's Disease of Grapevines in Taiwan: Isolation, Cultivation and Pathogenicity of Xylella fastidiosa. Journal of Phytopathology. 161, 389-396 (2013).

19. A. Giampetruzzi, M. Saponari, G. Loconsole, D. Boscia, V. N. Savino, R. P. P. Almeida, S. Zicca, B. B. Landa, C. Chacón-Diaz, P. Saldarelli, Genome-Wide Analysis Provides Evidence on the Genetic Relatedness of the Emergent Xylella fastidiosa Genotype in Italy to Isolates from Central America. Phytopathology. 107, 816-827 (2017).

20. M. Vanhove, A. C. Retchless, A. Sicard, A. Rieux, H. D. Coletta-Filho, L. D. L. Fuente, D. C. Stenger, R. P. P. Almeida, Genomic Diversity and Recombination among Xylella fastidiosa Subspecies. Appl. Environ. Microbiol. 85, e02972-18 (2019).

21. J. M. Guinn, A History of California and an Extended History of Los Angeles and Environs: Also Containing Biographies of Well Known Citizens of the Past and Present (Historic Record Company, 1915), vol. 1.

22. L. R. Nunes, Y. B. Rosato, N. H. Muto, G. M. Yanai, V. S. da Silva, D. B. Leite, E. R. Gonçalves, A. A. de Souza, H. D. Coletta-Filho, M. A. Machado, S. A. Lopes, R. C. de Oliveira, Microarray Analyses of Xylella fastidiosa Provide Evidence of Coordinated Transcription Control of Laterally Transferred Elements. Genome Res. 13, 570-578 (2003).

23. A. I. Castillo, I. Bojanini, H. Chen, P. P. Kandel, L. De La Fuente, R. P. P. Almeida, Allopatric Plant Pathogen Population Divergence following Disease Emergence. Appl Environ Microbiol. 87, e02095-20 (2021).

24. D. Boubals, La maladie de Pierce arrive dans les vignobles d'Europe. Prog. Agric. Vitic., 85-87 (1989).

25. G. Martins, B. Lauga, C. Miot-Sertier, A. Mercier, A. Lonvaud, M.-L. Soulas, G. Soulas, I. MasneufPomarède, Characterization of Epiphytic Bacterial Communities from Grapes, Leaves, Bark and Soil of Grapevine Plants Grown, and Their Relations. PLOS ONE. 8, 1-9 (2013).

26. N. Denancé, B. Legendre, M. Briand, V. Olivier, C. de Boisseson, F. Poliakoff, M.-A. Jacques, Several subspecies and sequence types are associated with the emergence of Xylella fastidiosa in natural settings in France. Plant Pathol. 66, 1054-1064 (2017).

27. D. Olmo, A. Nieto, D. Borras, M. Montesinos, F. Adrover, A. Pascual, P. A. Gost, B. Quetglas, A. Urbano, J. de Dios Garcia, M. Pilar Velasco-Amo, C. Olivares-Garcia, O. Beidas, A. Juan, E. Marco-Noales, M. Gomila, J. Rita, E. Moralejo, B. B. Landa, Landscape Epidemiology of Xylella fastidiosa in the Balearic Islands. Agronomy-Basel. 11, 473 (2021).

28. EPPO Global Database. https://gd.eppo.int/reporting/article-6447, (available at https://gd.eppo.int/reporting/article-6447).

29. B. Landa, A. Castillo, A. Giampetruzzi, A. Kahn, M. Román-Écija, M. P. Velasco-Amo, J. Navas-Cortés, E. Marco-Noales, S. Barbé, E. Moralejo, H. Coletta-Filho, P. Saldarelli, M. Saponari, R. Almeida, Emergence of a Plant Pathogen in Europe Associated with Multiple Intercontinental Introductions. Appl. Environ. Microbiol. 86, 1-15 (2020).

30. C. van der Veer, M. Himschoot, S. M. Bruisten, Multilocus sequence typing of Trichomonas vaginalis clinical samples from Amsterdam, the Netherlands. BMJ Open. 6, e013997 (2016).

31. S. A. Vollmer, A. Bormane, R. E. Dinnis, F. Seelig, A. D. M. Dobson, D. M. Aanensen, M. C. James, M. Donaghy, S. E. Randolph, E. J. Feil, K. Kurtenbach, G. Margos, Host migration impacts on the phylogeography of Lyme Borreliosis spirochaete species in Europe. Environmental Microbiology. 13, 184192 (2011). 
32. R. M. Gonçalves, M. I. Balbi-Peña, J. M. Soman, A. C. Maringoni, G. Taghouti, M. Fischer-Le Saux, P. Portier, Genetic diversity of Curtobacterium flaccumfaciens revealed by multilocus sequence analysis. Eur J Plant Pathol. 154, 189-202 (2019).

33. M. C. J. Maiden, Multilocus Sequence Typing of Bacteria. Annu. Rev. Microbiol. 60, 561-588 (2006).

34. M. A. S. V. Ferreira, S. Bonneau, M. Briand, S. Cesbron, P. Portier, A. Darrasse, M. A. S. Gama, M. A. G. Barbosa, R. de L. R. Mariano, E. B. Souza, M.-A. Jacques, Xanthomonas citri pv. viticola Affecting Grapevine in Brazil: Emergence of a Successful Monomorphic Pathogen. Front. Plant Sci. 10, 1-18 (2019).

35. L. M. Schouls, H. G. J. van der Heide, L. Vauterin, P. Vauterin, F. R. Mooi, Multiple-Locus Variable-Number Tandem Repeat Analysis of Dutch Bordetella pertussis Strains Reveals Rapid Genetic Changes with Clonal Expansion during the Late 1990s. J Bacteriol. 186, 5496-5505 (2004).

36. A. Leduc, Y. N. Traoré, K. Boyer, M. Magne, P. Grygiel, C. C. Juhasz, C. Boyer, F. Guerin, I. Wonni, L. Ouedraogo, C. Vernière, V. Ravigné, O. Pruvost, Bridgehead invasion of a monomorphic plant pathogenic bacterium: Xanthomonas citri pv. citri, an emerging citrus pathogen in Mali and Burkina Faso. Environmental Microbiology. 17, 4429-4442 (2015).

37. R. Bouckaert, T. G. Vaughan, J. Barido-Sottani, S. Duchêne, M. Fourment, A. Gavryushkina, J. Heled, G. Jones, D. Kühnert, N. D. Maio, M. Matschiner, F. K. Mendes, N. F. Müller, H. A. Ogilvie, L. du Plessis, A. Popinga, A. Rambaut, D. Rasmussen, I. Siveroni, M. A. Suchard, C.-H. Wu, D. Xie, C. Zhang, T. Stadler, A. J. Drummond, BEAST 2.5: An advanced software platform for Bayesian evolutionary analysis. PLOS Computational Biology. 15, e1006650 (2019).

38. N. Denancé, M. Briand, R. Gaborieau, S. Gaillard, M.-A. Jacques, Identification of genetic relationships and subspecies signatures in Xylella fastidiosa. BMC Genomics. 20, 1-21 (2019).

39. H. Lin, E. L. Civerolo, R. Hu, S. Barros, M. Francis, M. A. Walker, Multilocus simple sequence repeat markers for differentiating strains and evaluating genetic diversity of Xylella fastidiosa. Applied and environmental microbiology. 71, 4888-4892 (2005).

40. C. S. Francisco, P. C. Ceresini, R. P. P. Almeida, H. D. Coletta-Filho, Spatial Genetic Structure of CoffeeAssociated Xylella fastidiosa Populations Indicates that Cross Infection Does Not Occur with Sympatric Citrus Orchards. Phytopathology. 107, 395-402 (2017).

41. T. Jombart, S. Devillard, F. Balloux, Discriminant analysis of principal components: a new method for the analysis of genetically structured populations. BMC Genetics. 11, 1-15 (2010).

42. E. Moralejo, M. Gomila, M. Montesinos, D. Borràs, A. Pascual, A. Nieto, F. Adrover, P. A. Gost, G. Seguí, A. Busquets, J. A. Jurado-Rivera, B. Quetglas, J. de D. García, O. Beidas, A. Juan, M. P. Velasco-Amo, B. B. Landa, D. Olmo, Phylogenetic inference enables reconstruction of a long-overlooked outbreak of almond leaf scorch disease (Xylella fastidiosa) in Europe. Commun Biol. 3, 1-13 (2020).

43. D. Jeanmonod, A. Natali, Les xénophytes de Corse: un danger pour la flore indigène. Lagascalia, 19 (12), 783-792. (1997).

44. S. Soubeyrand, P. de Jerphanion, O. Martin, M. Saussac, C. Manceau, P. Hendrikx, C. Lannou, Inferring pathogen dynamics from temporal count data: the emergence of Xylella fastidiosa in France is probably not recent. New Phytol. 219, 824-836 (2018).

45. M. Vanhove, A. Sicard, J. Ezennia, N. Leviten, R. P. P. Almeida, Population structure and adaptation of a bacterial pathogen in California grapevines. Environmental Microbiology. 22, 2625-2638 (2020).

46. S. Duchêne, K. E. Holt, F.-X. Weill, S. Le Hello, J. Hawkey, D. J. Edwards, M. Fourment, E. C. Holmes, Genome-scale rates of evolutionary change in bacteria. Microb Genom. 2, 1-12 (2016). 
901

902

903

904

905

906

907

908

909

910

911

912

913

914

915

916

917

918

919

920

921

922

923

924

925

926

927

928

929

930

931

932

933

934

935

936

937

938

939

940

941

47. A. Mazzaglia, Y. J. Rahi, M. C. Taratufolo, M. Tatì, S. Turco, S. Ciarroni, V. Tagliavento, F. Valentini, A. M. D'Onghia, G. M. Balestra, A new inclusive MLVA assay to investigate genetic variability of Xylella fastidiosa with a specific focus on the Apulian outbreak in Italy. Scientific Reports. 10, 10856 (2020).

48. A. Santini, A. Liebhold, D. Migliorini, S. Woodward, Tracing the role of human civilization in the globalization of plant pathogens. The ISME Journal. 12, 647-652 (2018).

49. A. Cunty, B. Legendre, P. de Jerphanion, V. Juteau, A. Forveille, J.-F. Germain, J.-M. Ramel, P. Reynaud, V. Olivier, F. Poliakoff, Xylella fastidiosa subspecies and sequence types detected in Philaenus spumarius and in infected plants in France share the same locations. Plant Pathology. 69, 1798-1811 (2020).

50. G. Chauvel, A. Cruaud, B. Legendre, J.-F. Germain, J.-Y. Rasplus, Mission d'expertise sur Xylella fastidiosa en Corse (3 au 11 août 2015) (2015).

51. N. Miller, A. Estoup, S. Toepfer, D. Bourguet, L. Lapchin, S. Derridj, K. S. Kim, P. Reynaud, L. Furlan, T. Guillemaud, Multiple Transatlantic Introductions of the Western Corn Rootworm. Science. 310, 992-992 (2005).

52. W. Van Der, Polygala myrtifolia L. Population Genetics of Plant Pathogens (2003), (available at plantZafrica.com).

53. M. Godefroid, A. Cruaud, J.-C. Streito, J.-Y. Rasplus, J.-P. Rossi, Xylella fastidiosa: climate suitability of European continent. Sci Rep. 9, 8844 (2019).

54. E. Dupas, M. Briand, M.-A. Jacques, S. Cesbron, Novel Tetraplex Quantitative PCR Assays for Simultaneous Detection and Identification of Xylella fastidiosa Subspecies in Plant Tissues. Front. Plant Sci. 10, 1-15 (2019).

55. B. Mayjonade, J. Gouzy, C. Donnadieu, N. Pouilly, W. Marande, C. Callot, N. Langlade, S. Muños, Extraction of high-molecular-weight genomic DNA for long-read sequencing of single molecules. BioTechniques. 61, 203-205 (2016).

56. T. Koressaar, M. Remm, Enhancements and modifications of primer design program Primer3. Bioinformatics. 23, 1289-1291 (2007).

57. W. R. Engels, Contributing software to the internet: the amplify program. Trends in Biochemical Sciences. 18, 448-450 (1993).

58. S. J. Harper, L. I. Ward, G. R. G. Clover, Development of LAMP and real-time PCR methods for the rapid detection of Xylella fastidiosa for quarantine and field applications. Phytopathology. 100, 1282-1288 (2010).

59. M. Nascimento, A. Sousa, M. Ramirez, A. P. Francisco, J. A. Carriço, C. Vaz, PHYLOViZ 2.0: providing scalable data integration and visualization for multiple phylogenetic inference methods. Bioinformatics. 33, 128-129 (2017).

60. M. J. Hubisz, D. Falush, M. Stephens, J. K. Pritchard, Inferring weak population structure with the assistance of sample group information. Molecular Ecology Resources. 9, 1322-1332 (2009).

61. T. Jombart, adegenet: a R package for the multivariate analysis of genetic markers. Bioinformatics. 24, 1403-1405 (2008).

62. J. Goudet, FSTAT Version 2.9.4.: A Program to Estimate and Test Population Genetics Parameters. Available from URL: http://www2.unil.ch/popgen/softwares/fst ?at.htm. (2005).

63. R. Peakall, P. E. Smouse, GenAlEx 6.5: genetic analysis in Excel. Population genetic software for teaching and research-an update. Bioinformatics. 28, 2537-2539 (2012). 
942

943

944

945

946

947

948

949

950

951

952

953

954

955

956

957

958

959

960

961

962

963

964

965

966

967

968

969

970

971

972

973

974

975

976

977

978

979

980

981

982

64. L. Excoffier, H. E. L. Lischer, Arlequin suite ver 3.5: a new series of programs to perform population genetics analyses under Linux and Windows. Mol Ecol Resour. 10, 564-567 (2010).

65. R. Bivand, N. Lewin-Koh, E. Pebesma, E. Archer, A. Baddeley, N. Bearman, H.-J. Bibiko, S. Brey, J. Callahan, G. Carrillo, Package 'maptools.' 0.9-9 (2019).

66. M. A. Beaumont, W. Zhang, D. J. Balding, Approximate Bayesian Computation in Population Genetics, 12 (2002).

67. J.-M. Cornuet, P. Pudlo, J. Veyssier, A. Dehne-Garcia, M. Gautier, R. Leblois, J.-M. Marin, A. Estoup, DIYABC v2.0: a software to make approximate Bayesian computation inferences about population history using single nucleotide polymorphism, DNA sequence and microsatellite data. Bioinformatics. 30, 11871189 (2014).

68. P. Pudlo, J.-M. Marin, A. Estoup, J.-M. Cornuet, M. Gautier, C. P. Robert, Reliable ABC model choice via random forests. Bioinformatics. 32, 859-866 (2016).

69. A. Fraimout, V. Debat, S. Fellous, R. A. Hufbauer, J. Foucaud, P. Pudlo, J.-M. Marin, D. K. Price, J. Cattel, X. Chen, M. Deprá, P. François Duyck, C. Guedot, M. Kenis, M. T. Kimura, G. Loeb, A. Loiseau, I. MartinezSañudo, M. Pascual, M. Polihronakis Richmond, P. Shearer, N. Singh, K. Tamura, A. Xuéreb, J. Zhang, A. Estoup, Deciphering the routes of invasion of Drosophila suzukii by means of $A B C$ random forest. Mol Biol Evol, msx050 (2017).

70. R. Luo, B. Liu, Y. Xie, Z. Li, W. Huang, J. Yuan, G. He, Y. Chen, Q. Pan, Y. Liu, J. Tang, G. Wu, H. Zhang, Y. Shi, Y. Liu, C. Yu, B. Wang, Y. Lu, C. Han, D. W. Cheung, S.-M. Yiu, S. Peng, Z. Xiaoqian, G. Liu, X. Liao, Y. Li, H. Yang, J. Wang, T.-W. Lam, J. Wang, SOAPdenovo2: an empirically improved memoryefficient short-read de novo assembler. Gigascience. 1, 18 (2012).

71. D. R. Zerbino, E. Birney, Velvet: algorithms for de novo short read assembly using de Bruijn graphs. Genome Res. 18, 821-829 (2008).

72. T. J. Treangen, B. D. Ondov, S. Koren, A. M. Phillippy, The Harvest suite for rapid core-genome alignment and visualization of thousands of intraspecific microbial genomes. Genome Biology. 15, 524 (2014).

73. X. Didelot, D. Falush, Inference of Bacterial Microevolution Using Multilocus Sequence Data. Genetics. 175, 1251-1266 (2007).

74. E. Paradis, J. Claude, K. Strimmer, APE: Analyses of Phylogenetics and Evolution in R language. Bioinformatics. 20, 289-290 (2004).

75. M. Plummer, N. Best, K. Cowles, K. Vines, CODA: convergence diagnosis and output analysis for MCMC. R News. 6, 7-11 (2006).

76. A. Raj, M. Stephens, J. K. Pritchard, fastSTRUCTURE: Variational Inference of Population Structure in Large SNP Data Sets. Genetics. 197, 573-589 (2014).

77. Warnes, Bolker, Bonebakker, Gentleman, Liaw, Lumley, Maechler, Magnusson, Moeller, Schwartz, Venables, gplots: Various R Programming Tools for Plotting Data. $R$ package version 3.0.1.1 (available at https://CRAN.R-project.org/package=gplots).

78. A. Stamatakis, RAXML version 8: a tool for phylogenetic analysis and post-analysis of large phylogenies. Bioinformatics. 30, 1312-1313 (2014).

79. A. Doizy, A. Prin, G. Cornu, F. Chiroleu, A. Rieux, "Phylostems: a new graphical tool to investigate temporal signal of heterochronous sequences at various evolutionary scales" (2020), p. 2020.10.19.346429, doi:10.1101/2020.10.19.346429. 
80. S. Duchêne, D. Duchêne, E. C. Holmes, S. Y. W. Ho, The Performance of the Date-Randomization Test in Phylogenetic Analyses of Time-Structured Virus Data. Molecular Biology and Evolution. 32, 1895-1906 (2015).

81. A. Rieux, C. E. Khatchikian, tipdatingbeast: an $r$ package to assist the implementation of phylogenetic tip-dating tests using beast. Molecular Ecology Resources. 17, 608-613 (2017).

\section{References Supplementary Materials}

82. J.-M. Cornuet, V. Ravigné, A. Estoup, Inference on population history and model checking using DNA sequence and microsatellite data with the software DIYABC (v1.0). BMC Bioinformatics. 11, 401 (2010).

83. J.-M. Cornuet, F. Santos, M. A. Beaumont, C. P. Robert, J.-M. Marin, D. J. Balding, T. Guillemaud, A. Estoup, Inferring population history with DIY ABC: a user-friendly approach to approximate Bayesian computation. Bioinformatics. 24, 2713-2719 (2008).

\section{References Supplementary Tables}

84. A. Bhattacharyya, S. Stilwagen, N. Ivanova, M. D'Souza, A. Bernal, A. Lykidis, V. Kapatral, I. Anderson, N. Larsen, T. Los, G. Reznik, E. Selkov, T. L. Walunas, H. Feil, W. S. Feil, A. Purcell, J.-L. Lassez, T. L. Hawkins, R. Haselkorn, R. Overbeek, P. F. Predki, N. C. Kyrpides, Whole-genome comparative analysis of three phytopathogenic Xylella fastidiosa strains. Proc. Natl. Acad. Sci. U.S.A. 99, 12403-12408 (2002).

85. J. Chen, G. Xie, S. Han, O. Chertkov, D. Sims, E. L. Civerolo, Whole Genome Sequences of Two Xylella fastidiosa Strains (M12 and M23) Causing Almond Leaf Scorch Disease in California. J Bacteriol. 192, 4534 (2010).

86. C. Van Horn, C.-J. Chang, J. Chen, De Novo Whole-Genome Sequence of Xylella fastidiosa subsp. multiplex Strain BB01 Isolated from a Blueberry in Georgia, USA. Genome Announc. 5, e01598-16 (2017).

87. A. Giampetruzzi, M. P. Velasco-Amo, E. Marco-Noales, M. Montes-Borrego, M. Román-Écija, I. Navarro, A. Monterde, S. Barbé, R. P. P. Almeida, P. Saldarelli, M. Saponari, V. Montilon, V. N. Savino, D. Boscia, B. B. Landa, Draft Genome Resources of Two Strains ("ESVL" and "IVIA5901") of Xylella fastidiosa Associated with Almond Leaf Scorch Disease in Alicante, Spain. Phytopathology. 109, 219-221 (2019).

88. J. Chen, H. Huang, C.-J. Chang, D. C. Stenger, Draft Genome Sequence of Xylella fastidiosa subsp. multiplex Strain Griffin-1 from Quercus rubra in Georgia. Genome Announc. 1, e00756-13 (2013).

89. A. Giampetruzzi, G. D’Attoma, S. Zicca, R. Abou Kubaa, D. Rizzo, D. Boscia, P. Saldarelli, M. Saponari, Draft Genome Sequence Resources of Three Strains (TOS4, TOS5, and TOS14) of Xylella fastidiosa Infecting Different Host Plants in the Newly Discovered Outbreak in Tuscany, Italy. Phytopathology. 109, 1516-1518 (2019).

\section{Acknowledgments}

We thank Quentin Beaurepère for technical support, Muriel Bahut (ANAN technical facility, SFR QUASAV, Angers, FR) for DNA extraction automation and VNTRs sequencing, CIRMCFBP (Beaucouzé, INRAE, France http://www6.inra.fr/cirm_eng/CFBP -Plant-AssociatedBacteria) for strain preservation and supply, Jérôme Gouzy (CATI BARIC) for the genome assembly pipeline, Mahendra Mariadassou and Déborah Merda for script sharing. We also thank Leonardo de la Fuente (Auburn University, AL, USA) and LSV-ANSES for sharing 
strains, Blanca L. Landa (Institute for Sustainable Agriculture, Córdoba, Spain) for sharing DNA; Valérie Oliver and Françoise Poliakoff for information related to the analysis of plant samples and strains in the framework of official surveillance, Marina Blanc for preliminary experiments on VNTR design, Laetitia Hugo from CNBC and François Casabianca from Corsican INRAE center for facilitating samplings, and Charles Manceau for co-writing the initial project providing ED funding support.

\section{Funding}

INRAE SPE division and ANSES (ED salary).

European Union's Horizon 2020 research and innovation program under grant agreement 727987 XF-ACTORS (Xylella fastidiosa Active Containment Through a MultidisciplinaryOriented Research Strategy) (SC, MAJ). The present work reflects only the authors' view and the EU funding agency is not responsible for any use that may be made of the information it contains.

XyleCor funded by the SPE division of INRAE (MAJ).

Sap Alien project funded by the RFI Objectif Végétal (ND salary)

France Génomique National infrastructure, funded as part of "Investissement d'avenir" program managed by Agence Nationale pour la Recherche (contract ANR-10-INBS-09) and by the GET-PACBIO program («Programme operationnel FEDER-FSE MIDI-PYRENEES ET GARONNE 2014-2020 ») (CD, CLR).

European Union (European Regional Development Fund, ERDF contract GURDT I20161731-0006632), Conseil Régional de La Réunion and Centre de Coopération Internationale en Recherche Agronomique pour le Développement (CIRAD) (AR, OP, VR).

Agence Nationale pour la Recherche JCJC MUSEOBACT contrat ANR-17-CE35-000901(AR).

\section{Author contributions}

Conceptualization: MAJ, ED, SC

Material and Methodology: ED, SC, MAJ, VR, AR, KD, MB, OP, ND, CD, CLR, AC, BL Supervision: MAJ, VR, SC, AR

Writing-original draft: ED, MAJ, SC, AR, VR

Writing-review \& editing: ED, MAJ, VR, AR, OP, MB, KD, SC, AC, BL, ND, CD, CLR

\section{Competing interests:}

All other authors declare they have no competing interests. 


\section{Data and materials availability:}

Strains of X. fastidiosa were deposited at the CIRM-CFBP (International Centre of Microbial Resource (CIRM) - French Collection for Plant-associated Bacteria. INRAE. https://doi.org/10.15454/E8XX-4Z18). Genome sequences were deposited at NCBI under the accession numbers listed in Table $\mathrm{S} 1$.

All data are available in the main text or the supplementary materials.

\section{Figures}

Fig. 1. Phylogenetic tip-dated tree showing the estimated divergence date between $X$. fastidiosa subsp. multiplex strains $(\mathbf{n}=\mathbf{8 2})$. Genealogy was inferred by Maximumlikelihood phylogenetic inference using BEAST 2.6.1. and a GTR model, based on SNPs variations among the 82 genome sequences. For details on the data, refer to Table S1. The tree main sequence types are highlighted in green (ST6), red (ST7) and blue (ST81) and flags refer to the country of isolation of the strains. Node bars refer to 95\% HPD.

Fig. 2. Minimum spanning trees of the 396 French $X$. fastidiosa subsp. multiplex infected samples typed using the VNTR-13 scheme. Dot diameter represents the number of strains per haplotype. Link number refer to the number of TR loci polymorphic and distinguishing two haplotypes. Dot colors refer to A) sampling region; B) year of sampling; C) ABC grouping. Colored area around haplotypes the clonal complexes.

Fig. 3. Scatterplot representing the Discriminant Analysis of Principal Components clusters for the 396 French $X$. fastidiosa infected samples for $\mathrm{k}=2$ to 6 inferred by use of the VNTR-13 scheme. The eigenvalues showed that the genetic structure was captured by the first two principal components retained onto axis 1 (horizontal axis) and axis 2 (vertical axis). The dots represent the individuals, and the clusters are shown as inertia ellipses. Clusters green, red and orange grouped ST6 samples and clusters blue, yellow and purple grouped ST7 samples.

Fig. 4. Distribution of the French $X$. fastidiosa infected samples used in this study. A) ST6 plant samples and strains, B) ST7 plant samples and strains.

Fig. S1. Genome clustering by FastSTRUCTURE software for K=5. Color bars represent groups identified by Bayesian clustering. ST numbers are indicated above strain codes. Color names represents their country of origin of strains: black for France, blue for USA, green for Brazil, purple for Italy and red for Spain.

Fig. S2. Heatmap representing the number of SNPs that came from mutations and differed between the 82 genome sequences. For details on genome sequences refer to Table S1.

Fig. S3. Local temporal signal detection. Linear regression between the age of the samples and their root-to-tip genetic distances. 
Fig. S4. Date randomization tests. Comparison of A) the mean rate, B) the ucldMean, C) the tree height estimated using BEATS 2.6.1. from the original dataset (red) and 40 daterandomized datasets using the TIPDATINGBEAST R package.

Fig. S5. Minimum Spanning Trees of the 113 X. fastidiosa strains isolated in Costa Rica, Ecuador, France, the Netherlands, Spain and the USA typed using the VNTR-13 scheme. Colors refer to A) the sequence type of the strains, B) the country of origin of the strains. For details on strains refer to Table S2 and S3.

Fig. S6. Genotype accumulation curve of $X$. fastidiosa over 13 loci. A) for the 113 strains of the study, B) on the 396 French samples.

Fig. S7. Allele frequencies at each VNTR locus per sequence type for the 396 French $X$. fastidiosa infected samples. At each locus, colors represent the set of haplotypes.

Fig. S8. Sample clustering by STRUCTURE software. Colors represent groups identified by Bayesian clustering. Cluster 1 (green), cluster 2 (red), cluster 5 (orange) grouped ST6 samples and cluster 3 (blue), cluster 4 (yellow), cluster 6 (purple) grouped ST7 samples.

Fig. S9. The scenarios compared using ABC used independently for ST6 and ST7 samples. A) The 12 scenarios compared by the bottom-up approach. All scenarios considered that the French populations (Pop1 and Pop2) derived from an initial USA population. Ghost populations, i.e. populations that would have existed but were not sampled, were used in scenario 5-8 and 10-12. The time on the $\mathrm{Y}$ axis refers to the divergence date between populations. B) The five topologies analyzed by the top-down approach. All scenarios considered that the French populations (Pop1, Pop2 and Pop3) derived from an initial USA population. The time on the $\mathrm{Y}$ axis refers to the divergence date between populations.

Fig. S10. List and visual representation of the 30 scenarios analyzed by ABC for ST6 samples. All scenarios considered that the French populations (C1P1, C2, and P2) derived from an initial USA population. The time on the $\mathrm{Y}$ axis refers to the divergence date between populations. Scenario II.7 (boxed in red) is the one defined by Abcrf analysis as the most probable.

Fig. S11. List and visual representation of the 12 scenarios analyzed by ABC for ST7 samples. All scenarios considered that the French populations (C1P1, C2, and P2) derived from an initial USA population. The time on the $\mathrm{Y}$ axis refers to the divergence date between populations. Scenario II.7 (boxed in red) is the one defined by Abcrf analysis as the most probable.

\section{Tables}

Table 1. Nomenclature, location, function and genetic diversity of the 13 TR loci.

Table 2. Characteristics of the 396 French strains and plant samples used in this study.

Table 3. Genetic diversity based on 13 VNTRs in the 396 French samples. 
Table S1. List of the $82 X$. fastidiosa genome sequences used in this study.

Table S2. List of the $95 X$. fastidiosa strains used in this study and their VNTR allelic profile.

* CFBP refers to strains from the CIRM-CFBP (https://www6.inra.fr/cirm_eng/CFBP -PlantAssociated-Bacteria); LSV to strains isolated by the Plant Health Laboratory at ANSES, $\uparrow$ NA: not available, + the 16 strains used as "panel test" to set up the MLVA scheme.

Table S3. List of the 18 Spanish $X$. fastidiosa subsp. multiplex strain DNAs used in this study and their VNTR allelic profile.

Table S4. List of the $396 X$. fastidiosa subsp. multiplex-infected French plant samples used in this study and their VNTR allelic profile. * 13 pairs of isolated strains and the DNA extracted from the same original plant sample, $\uparrow$ the 16 samples for which DAPC clustering differed over the 20 runs, $\$$ the samples collected by the DGAL in the framework of the national official surveillance strategy.

Table S5. Summary of private allele frequencies of ST6 and ST7 samples.

Table S6. Genetic differentiation of the clusters of $X$. fastidiosa subsp. multiplex estimated by RST (bellow the diagonal) and FST (above the diagonal) pairwise comparisons for A) the DAPC k=4 groups; B) the three ST6 clusters used in ABC analyses; C) the three ST7 clusters used in ABC analyses. All pairwise population comparisons were significantly different $(\mathrm{P}<0.05)$ after 1,000 permutations.

Table S7. Hierarchical AMOVA for A) ST6 $X$. fastidiosa subsp. multiplex DIYABC groups and B) ST7 X. fastidiosa subsp. multiplex DIYABC groups.

Table S8. Percentage of votes obtained for each scenario using Abcrf. A) results of the ST6 bottom-up analyses; B) results of the ST6 top-down analyses; C) results of the ST7 bottom-up analyses; D) results of the ST7 top-down analyses.

Table S9. Distribution of prior parameters used for the DIYABC analyses. 


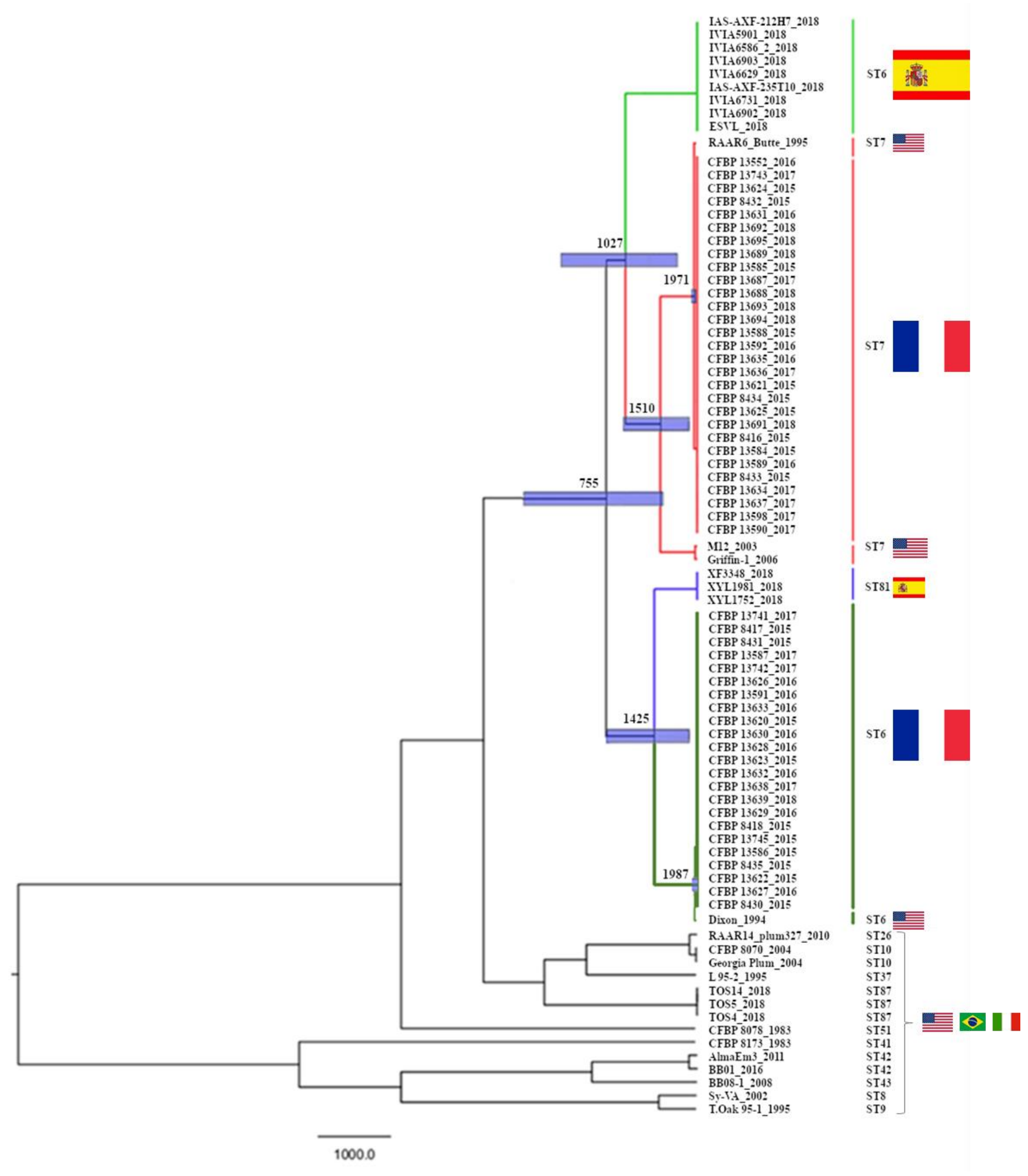

Fig. 1. Phylogenetic tip-dated tree showing the estimated divergence date between $X$. fastidiosa subsp. multiplex strains $(\mathbf{n}=\mathbf{8 2})$. Genealogy was inferred by Maximumlikelihood phylogenetic inference using BEAST 2.6.1. and a GTR model, based on SNPs variations among the 82 genome sequences. For details on the data, refer to Table $\mathrm{S} 1$. The tree main sequence types are highlighted in green (ST6), red (ST7) and blue (ST81) and flags refer to the country of isolation of the strains. Node bars refer to 95\% HPD. 

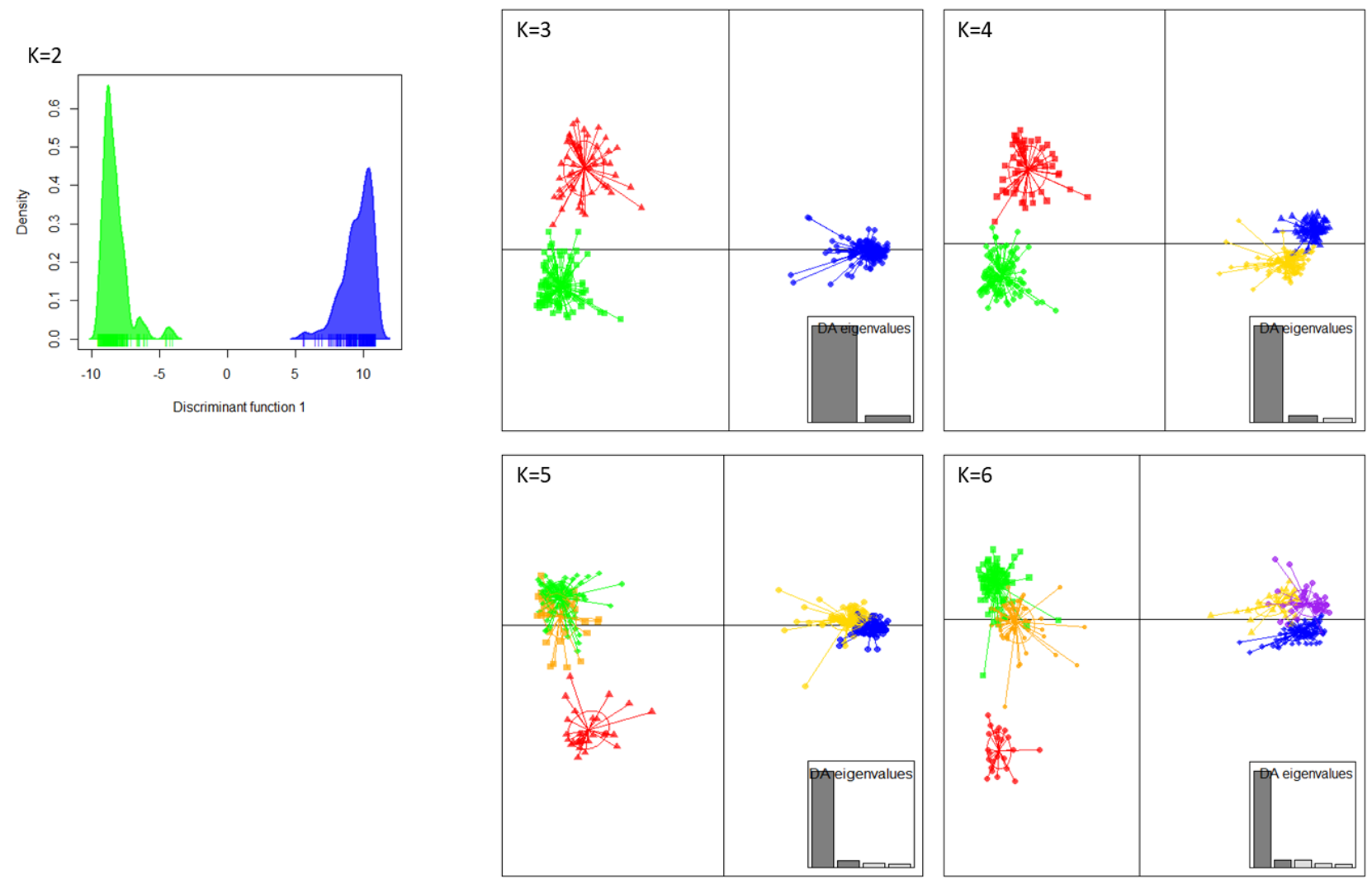

Fig. 3. Scatterplot representing the Discriminant Analysis of Principal Components clusters for the 396 French $X$. fastidiosa infected samples for $k=2$ to 6 inferred by use of the VNTR-13 scheme. The eigenvalues showed that the genetic structure was captured by the first two principal components retained onto axis 1 (horizontal axis) and axis 2 (vertical axis). The dots represent the individuals, and the clusters are shown as inertia ellipses. Clusters green, red and orange grouped ST6 samples and clusters blue, yellow and purple grouped ST7 samples. 


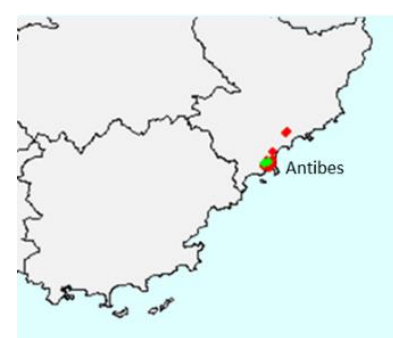

1173

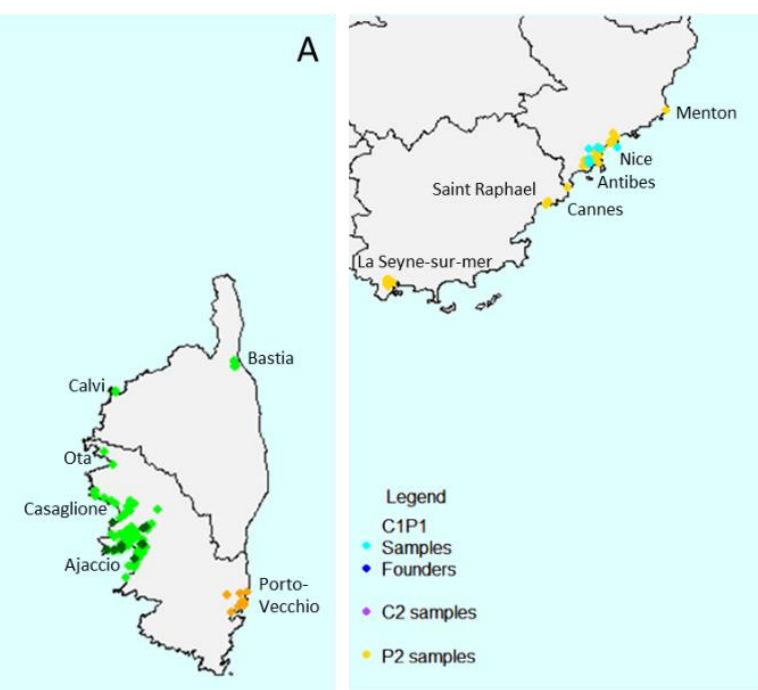

B

Legend
C1P1

C1P1
Samples

- Founders

- C2 samples

- P2 samples

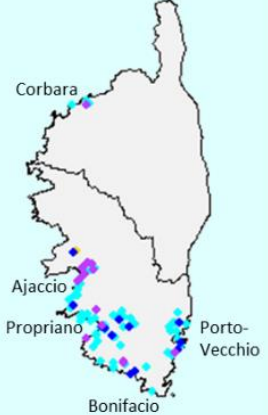

Fig. 4. Distribution of the French $X$. fastidiosa subsp. multiplex infected samples used in this study in PACA and Corsica. A) ST6 plant samples and strains, B) ST7 plant samples and strains. 
Table 1. Nomenclature, location, function and genetic diversity of the 13 TR loci.

\begin{tabular}{|c|c|c|c|c|c|c|c|c|c|c|}
\hline \multirow[b]{2}{*}{ Locus } & \multirow[b]{2}{*}{ Primers } & \multirow[b]{2}{*}{ Repeat motif } & \multirow[b]{2}{*}{$\begin{array}{l}\text { Number } \\
\text { of motif } \\
\text { repetition }\end{array}$} & \multicolumn{2}{|c|}{ On the M12 genome sequences } & \multirow[b]{2}{*}{$\begin{array}{l}\text { Multiplexing } \\
\text { annealing } \\
\text { temperature } \\
\left({ }^{\circ} \mathrm{C}\right)\end{array}$} & \multicolumn{4}{|c|}{$\begin{array}{l}\text { On the } 10 \text { genome sequences of } \\
\text { X. fastiosa subsp. multiplex }\end{array}$} \\
\hline & & & & Location & $\begin{array}{l}\text { Coordinates } \\
\text { (start - end) }\end{array}$ & & $\begin{array}{l}\text { Number } \\
\text { of } \\
\text { alleles }\end{array}$ & $\begin{array}{l}\text { Range of } \\
\text { repetition } \\
\text { number }\end{array}$ & $\begin{array}{l}\text { Simpson's } \\
\text { diversity } \\
\text { index }\end{array}$ & Reference \\
\hline ASSR-11 & $\begin{array}{l}\text { ATTO550 - AGAGGCAACGCAGGAACAG } \\
\text { GTGAGTTATATCGGTGCAGCAG }\end{array}$ & ACGCATC & 14 & Hypothetical protein & $2,074,633-2,074,920$ & 53 & 6 & $3-14$ & 0.18 & Lin et al., 2005 \\
\hline ASSR-16 & $\begin{array}{l}\text { ATTO565 - TTAATCAACAACGCTTATCC } \\
\text { TCGCAGTAGCCAGTATAC }\end{array}$ & GCTCCGGTTCTA & 19 & 1,4-beta-cellobiosidase CDS & $658,561-658,173$ & 53 & 8 & $8-29$ & 0.16 & Lin et al., 2005 \\
\hline COSS-1 & $\begin{array}{l}\text { 6-FAM - GAAACAAGATGGCGGTTGC } \\
\text { CATTTAAACGGGCGGCATA }\end{array}$ & ATTGCTG & 2 & Non coding & $18,250-18,484$ & 53 & 7 & $1-11$ & 0.16 & Francisco et al., 2017 \\
\hline OSSR-19 & $\begin{array}{l}\text { HEX - GCTGTGAACTTCCATCAATCC } \\
\text { GCAAGTAGGGGTAAATGTGAC }\end{array}$ & CAGGATCA & 7 & adenylosuccinate lyase CDS & $967,661-967,412$ & 53 & 6 & $3-11$ & 0.2 & Lin et al., 2005 \\
\hline GSSR-7 & $\begin{array}{l}\text { ATTO550 - ATCATGTCGTGTCGTTTC } \\
\text { CAATAAAGCACCGAATTAGC }\end{array}$ & AGCAAC & 11 & Non coding & $19,289-19,595$ & 55 & 8 & $9-25$ & 0.14 & Lin et al., 2005 \\
\hline OSSR-16 & $\begin{array}{l}\text { ATTO565 - GCAAATAGCATGTACGAC } \\
\text { GTGTTGTGTATGTGTTGG }\end{array}$ & CTGCTA & 9 & Non coding & $593,243-593,502$ & 55 & 6 & $7-17$ & 0.24 & Lin et al., 2005 \\
\hline XFSSR-37 & HEX - CACCTGCAACGAACACCAAT & CTGATGTG & 8 & hydroxyacylglutathione & $1,421,433-1,421,644$ & 55 & 4 & $3-12$ & 0.3 & This study \\
\hline
\end{tabular}




\begin{tabular}{|c|c|c|c|c|c|c|c|c|c|c|}
\hline XFSSR-58 & $\begin{array}{l}\text { 6-FAM - } \\
\text { CCCTAGCAAAACAATACTGCCA } \\
\text { GGTATGTGCTGTGTGGTTGG }\end{array}$ & AAGGGGC & 7 & Non coding & $1,997,325-1,997,556$ & 55 & 6 & $3-12$ & 0.22 & This study \\
\hline ASSR-9 & $\begin{array}{l}\text { 6-FAM - GGTTGTCGGGCTCATTCC } \\
\text { TTGTCACAGCATCACTATTCTC }\end{array}$ & CAAGTAC & 9 & Non coding & $949,863-950,106$ & 57 & 6 & $3-15$ & 0.22 & Lin et al., 2005 \\
\hline ASSR-12 & $\begin{array}{l}\text { ATTO565 - TGCTCATTGTGGCGAAGG } \\
\text { CGCAACGTGCATTCATCG }\end{array}$ & GATTCAG & 9 & Hypothetical protein & $2,116,062-2,115,798$ & 57 & 7 & $4-14$ & 0.16 & Lin et al., 2005 \\
\hline ASSR-19 & $\begin{array}{l}\text { ATTO550 - CGCCGACTGTCTATGTGAC } \\
\text { TTCCTAGCAATGGCAATGTTG }\end{array}$ & ACAACG & 3 & Hypothetical protein & $2,075,410-2,075,699$ & 57 & 7 & $2-12$ & 0.16 & Lin et al., 2005 \\
\hline GSSR-4 & $\begin{array}{l}\text { HEX - GCGTTACTGGCGACAAAC } \\
\text { GCTCGTTCCTGACCTGTG }\end{array}$ & ATCC & 4 & Hypothetical protein & $1,702,352-1,702,608$ & 57 & 3 & $3-5$ & 0.38 & Lin et al., 2005 \\
\hline XFSSR-40 & $\begin{array}{l}\text { 6-FAM - ACACACTCACACTGTCCGAT } \\
\text { GGGTTAGGAGTTGGTGTCGA }\end{array}$ & ACAGCAAT & 5 & Non coding & $1,513,631-1,513,860$ & 60 & 6 & $3-11$ & 0.2 & This study \\
\hline
\end{tabular}


Table 2. Characteristics of the 396 French strains and plant samples used in this study.

\begin{tabular}{lccc}
\hline Summary per host of isolation & Corsica & PACA & Total \\
Acacia sp. & $/$ & 1 & 1 \\
Artemisia arborescens & 1 & $/$ & 1 \\
Calicotome villosa & 15 & $/$ & 15 \\
Cistus spp. & 5 & $/$ & 5 \\
Convolvulus cneorum & $/$ & 3 & 3 \\
Coronilla spp. & 1 & 4 & 5 \\
Cytisus villosus & 2 & $/$ & 2 \\
Euryops chrysanthemoides & $/$ & 8 & 8 \\
Genista spp. & 6 & $/$ & 6 \\
Grevillea juniperina & $/$ & 1 & 1 \\
Hebe sp. & 1 & $/$ & 1 \\
Helichrysum spp. & 12 & 3 & 15 \\
Lavandula spp. & 7 & 1 & 8 \\
Lonicera japonica & $/$ & 1 & 1 \\
Medicago sativa & $/$ & 1 & 1 \\
Metrosideros excelsa & 1 & $/$ & 1 \\
Pelargonium spp. & 5 & $/$ & 5 \\
Phagnalon saxatile & 1 & $/$ & 1 \\
Polygala myrtifolia & 205 & 72 & 277 \\
Prunus spp. & 3 & 3 & 6 \\
Quercus suber & 1 & $/$ & 1 \\
Rosa canina & 1 & $/$ & 1 \\
Spartium junceum & 16 & 12 & 28 \\
Veronica spp. & $/$ & 2 & 2 \\
Westringia fruticosa & $/$ & 1 & 1 \\
\hline Summary per year of isolation & & & \\
2015 & 166 & 14 & 180 \\
2016 & 75 & 4 & 79 \\
2017 & 34 & 39 & 73 \\
2018 & 8 & 56 & 64 \\
\hline Summary per sequence type & & & \\
ST6 & 154 & 30 & 184 \\
ST7 & 129 & 83 & 212 \\
\hline & & &
\end{tabular}


Table 3. Genetic diversity based on 13 VNTRs in the 396 French samples.

$\begin{array}{cccc} & \text { Nb of repetition } & \text { Simpson's } \\ \text { Locus Nb of alleles } & \min -\max & \text { diversity } & \begin{array}{c}\text { Allelic } \\ \text { richness }\end{array} \\ & & \text { index (1-D) }\end{array}$

\begin{tabular}{lccrr}
\hline ASSR-11 & 11 & $5-16$ & 0.69 & 7.79 \\
ASSR-16 & 7 & $22-30$ & 0.52 & 8.41 \\
COSS-1 & 11 & $1-12$ & 0.76 & 5.25 \\
OSSR-19 & 11 & $3-14$ & 0.64 & 4.28 \\
& & & & \\
GSSR-7 & 19 & $10-29$ & 0.88 & 13.46 \\
OSSR-16 & 21 & $6-29$ & 0.75 & 9.45 \\
XFSSR-37 & 8 & $1-10$ & 0.56 & 6.88 \\
XFSSR-58 & 8 & $4-11$ & 0.54 & 6.71 \\
& & & & \\
ASSR-9 & 13 & $5-18$ & 0.82 & 4.98 \\
ASSR-12 & 7 & $7-14$ & 0.62 & 7.86 \\
ASSR-19 & 8 & $7-14$ & 0.74 & 3.82 \\
GSSR-4 & 7 & $8-21$ & 0.52 & 15.73 \\
& & & & \\
XFSSR-40 & 8 & $5-12$ & 0.73 & 6.1 \\
\hline
\end{tabular}




\section{Supplementary materiel and methods}

\section{Scenarios}

The bottom-up approach consisted in searching for the most probable topology for each population combination of the American ancestor and two French populations in presence or not of an unsampled (ghost) population. Altogether this lead to three independent analyses and in each analysis, 10 to 12 topologies were tested (Fig. S9 A). A total of 30 scenarios (combination of population choice and topology) were analyzed for ST6 and 36 for ST7 in this bottom-up approach.

Topologies 1, 5, 9, 10, 11 and 12 assumed that the French populations were introduced separately from two events. Topologies 2 and 6 hypothesizes that samples which belonged to the same population may have been mistakenly separated into two populations. Topologies $3,4,7$ and 8 assumed that a first population was introduced in France and that a bridgehead invasion was responsible for the emergence of the second French populations. Topologies 5, 6, 7, 8, 10, 11 and 12 assumed that one or two populations may have been unsampled (named ghost population).

The top-down approach consisted in searching for the most probable population combinations for each possible topology. A total of 5 topologies were tested for each of the three French ST6 and ST7 populations (six combinations) (Fig. S9 B). The topologies differed by the number of independent introductions and divergence events. However, based on the results of the bottomup approach, a number of scenario were considered statistically impossible and were not tested in the top-down approach.

In consequence, from the six possible population combinations all were tested for ST6, for a total of 30 scenarios (Fig. S10) and only two topologies for ST7 for a total of 12 scenarios (Fig. S11).

Class 1 topology (I) assumed three independent introductions in France from a source population. Class 2 topology (II) assumed that one population was introduced in France and is responsible for two independent bridgehead invasions. Class 3 topologies (III.I and III.II) assumed that two independent introductions occurred and one of them was responsible for a bridgehead invasion of the third population. Class 4 topology (IV) assumed that one population was first introduced and was responsible for two successive bridgehead invasions. 


\section{Choice and validation of priors}

For the DiyABC analyses, parameters were drawn in the prior distribution described in Table S9. Due to the lack of knowledge concerning the bacterium population biology (population effective sizes, date of founder event, existence and duration of a bottleneck, for example), a log uniform distribution with large ranges was chosen. Parameters for microsatellite mutation models were set by default following a stepwise mutation model (82). Other parameters of the mutation models were set by default at " 0 " and all summary statistics were selected.

Prior choices were validated by performing a principal component analysis (PCA) implemented in DiyABC, in the space of summary statistics for all simulated datasets (106 per scenario) with parameter values drawn from the prior parameters. The observed dataset was projected as a supplementary individual to determine by visual check whether it fell within the variability of simulated data (82).

\section{Simulations and posterior probability estimation}

A total of 106 simulations were performed for each competing scenario using DiyABC software (83). Because the DiyABC lack of discriminative power among competing scenarios, abcrf were used to estimate best scenarios or the rejected one, using the R package "abcrf" (68). Following Pudlo et al., 2016 abcrf treatments were processed on reference tables including 104 simulations per scenario (68). In the constructed random-forests the number of trees was fixed at $\mathrm{n}=1000$. For each abcrf analysis the best scenario, its prior error rates and its posterior probability were evaluated over 10 replicate runs of the same reference table. Moreover, for the bottom-up approach, an event was rejected when less than 50/1000 $(<5 \%)$ of votes were attributed to it. Scripts published by Fraimout et al., 2017 were optimized to fit our dataset (69). 
Fig. S1. Genome clustering by FastSTRUCTURE software for K=5. Color bars represent groups identified by Bayesian clustering. ST numbers are indicated above strain codes. Color names represents their country of origin of strains: black for France, blue for USA, green for Brazil, purple for Italy and red for Spain.
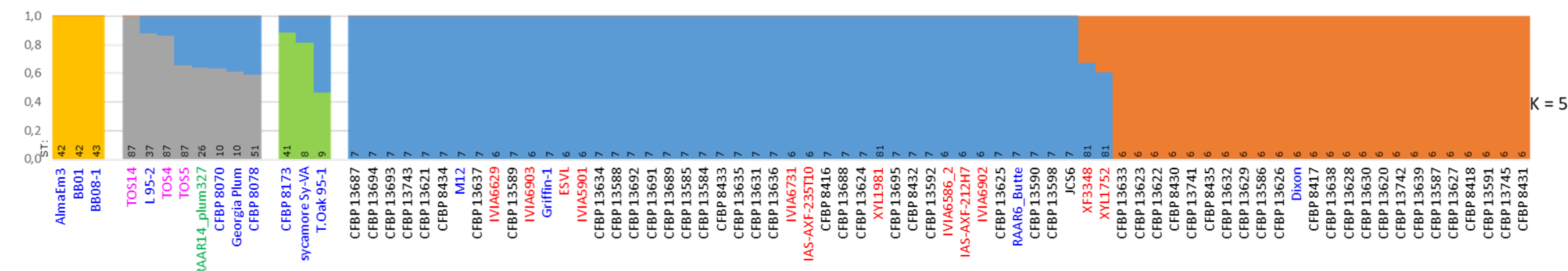
Fig. S2. Heatmap representing the number of SNPs that came from mutations and differed between the 82 genome sequences. For details on genome seauences refer to Table S1.
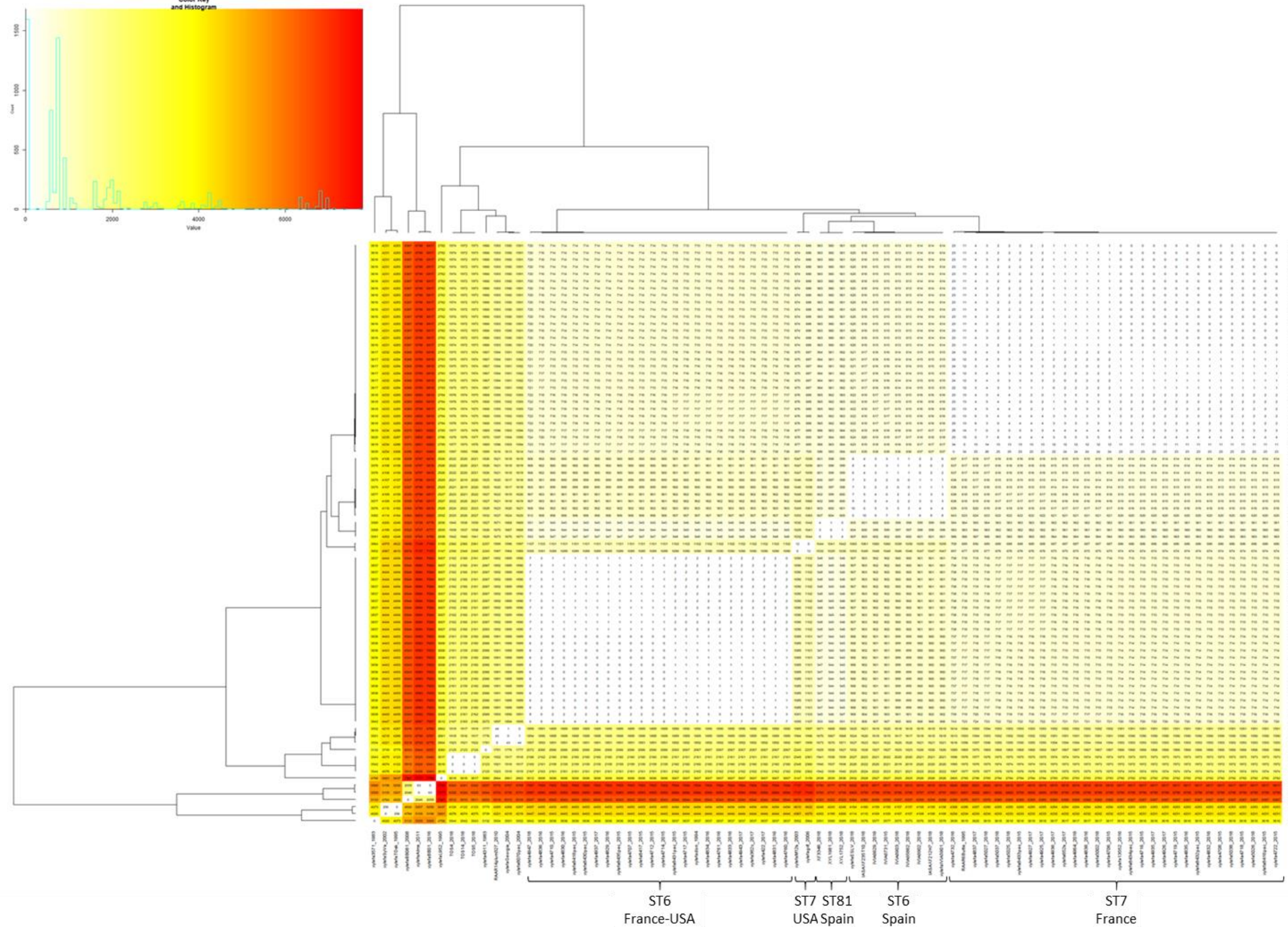
Fig. S3. Local temporal signal detection. Linear regression between the age of the samples and their root-to-tip genetic distances. Local Temporal Signal

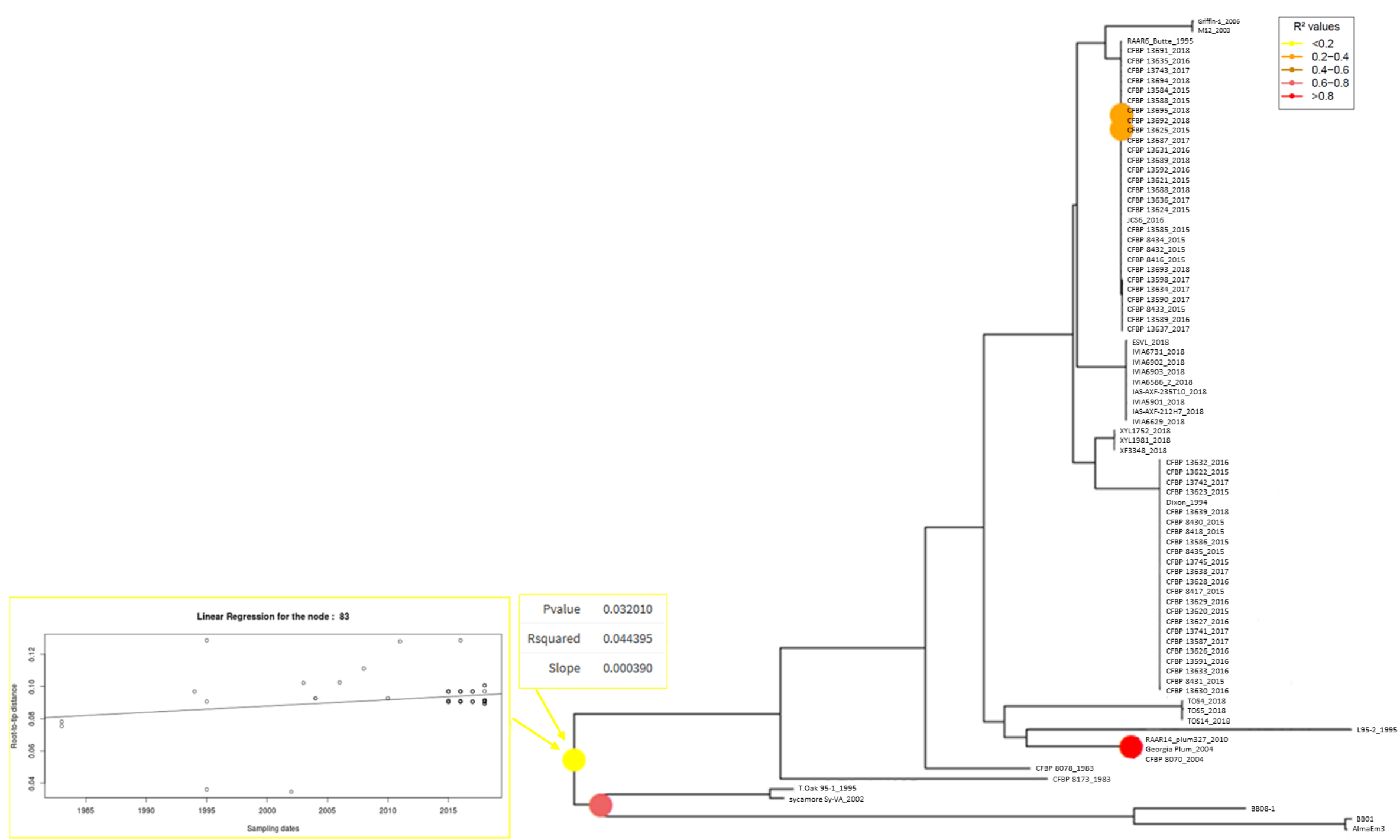


Fig. S4. Date randomization tests. Comparison of A) the mean rate, B) the ucldMean, C) the tree height estimated using BEATS 2.6.1. from the original dataset (red) and 40 date-randomized datasets using the TIPDATINGBEAST R package.

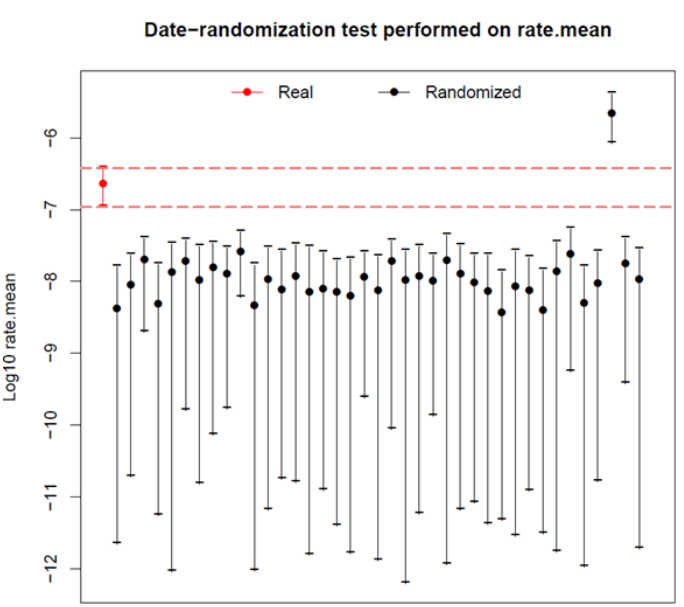

No Overlapping: DRT SUCCESSFULLY PASSED II

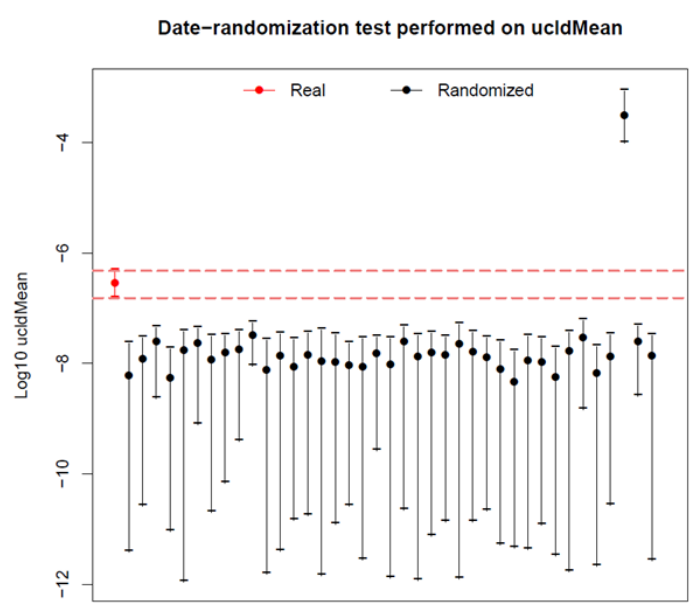

No Overlapping: DRT SUCCESSFULLY PASSED III
Date-randomization test performed on TreeHeight

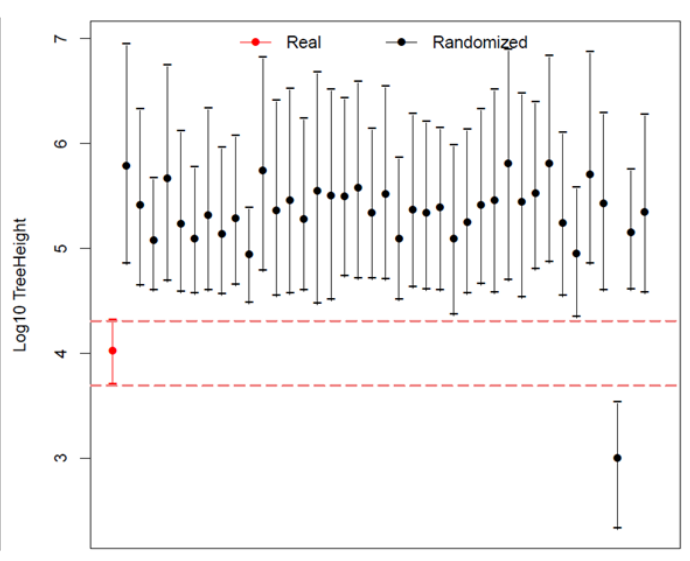

No Overlapping: DRT SUCCESSFULLY PASSED 
Fig. S5. Minimum Spanning Trees of the 113 X. fastidiosa strains isolated in Costa Rica, Ecuador, France, the Netherlands, Spain and the USA typed using the VNTR-13 scheme. Colors refer to A) the sequence type of the strains, B) the country of origin of the strains. For details on strains refer to Table S2 and S3.

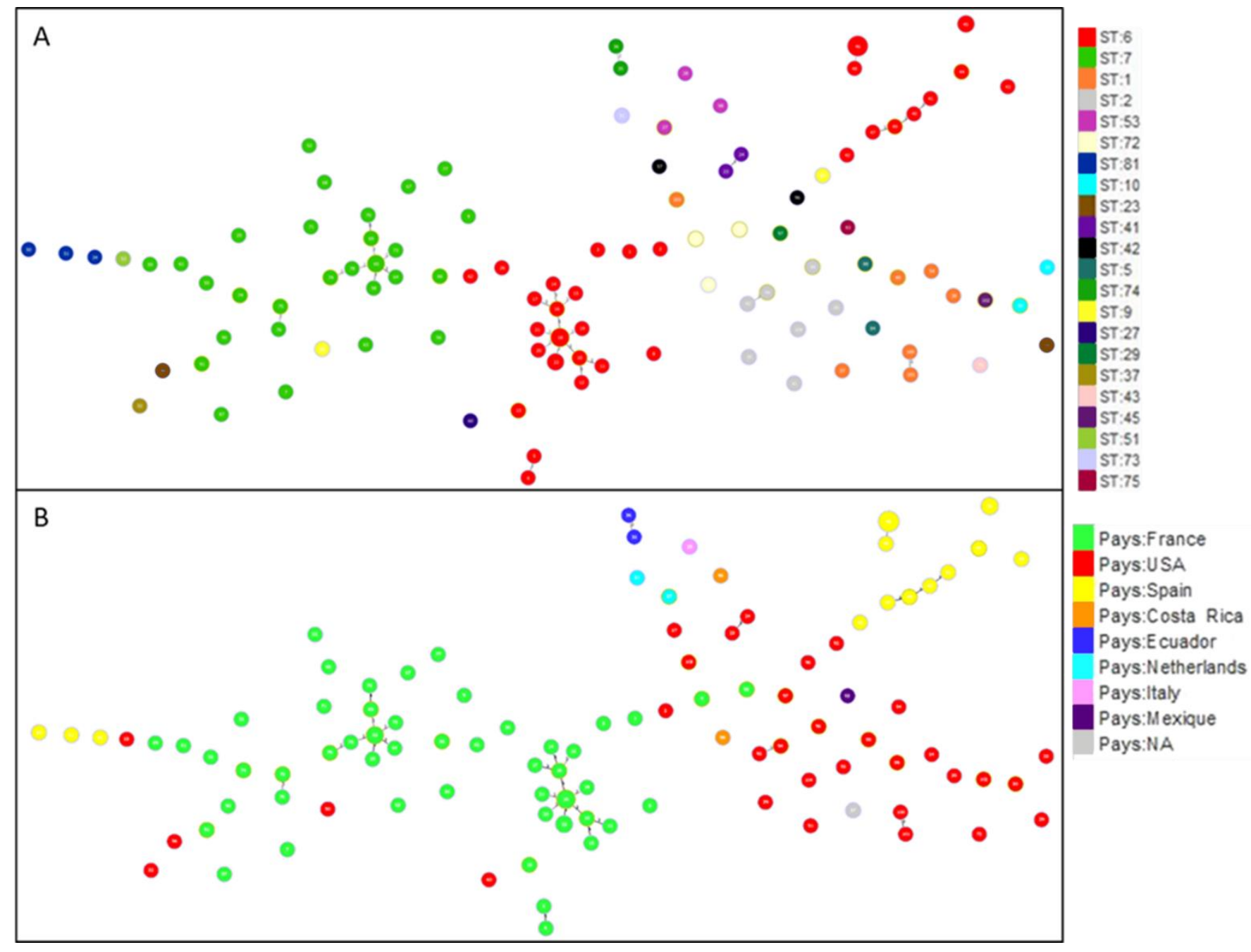


Fig. S6. Genotype accumulation curve of X. fastidiosa over 13 loci. A) for the 113 strains of the study, B) on the 396 French samples.
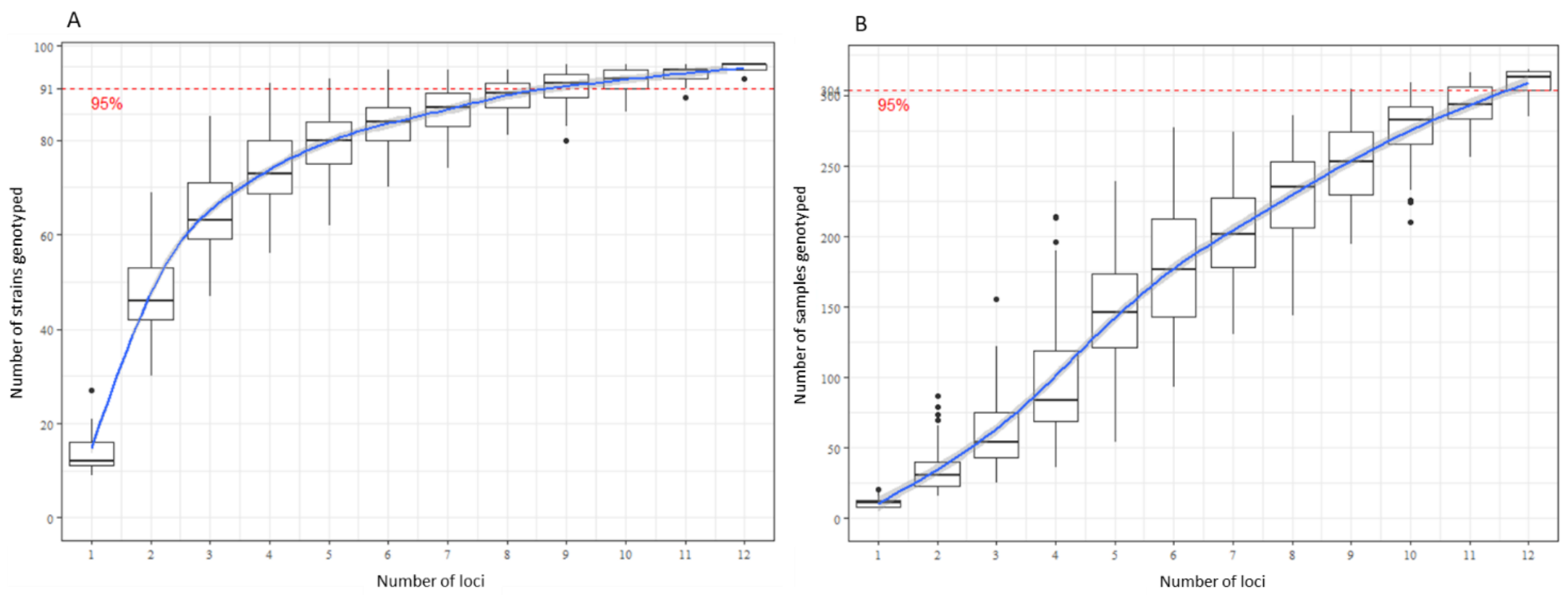
Fig. S7. Allele frequencies at each VNTR locus per sequence type for the 396 French X. fastidiosa infected samples. At each locus, colors represent the set of haplotypes.

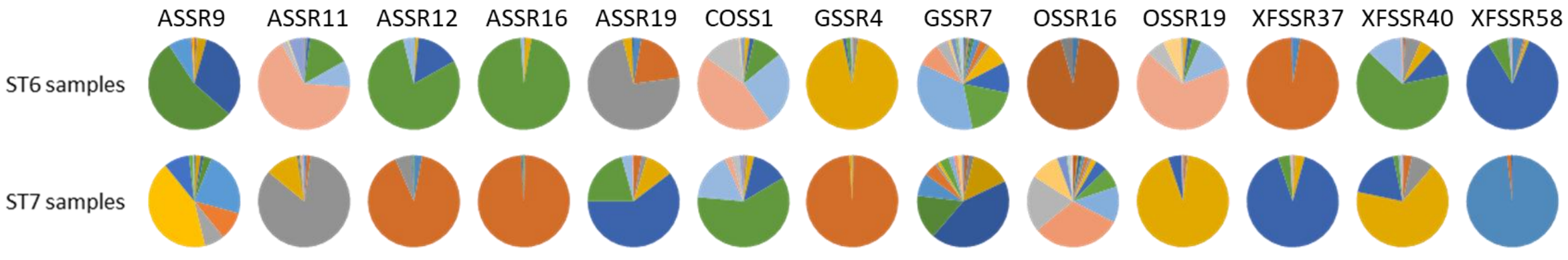

Fig. S8. Sample clustering by STRUCTURE software. Colors represent groups identified by Bayesian clustering. Cluster 1 (green), cluster 2 (red), cluster 5 (orange) grouped ST6 samples and cluster 3 (blue), cluster 4 (yellow), cluster 6 (purple) grouped ST7 samples.

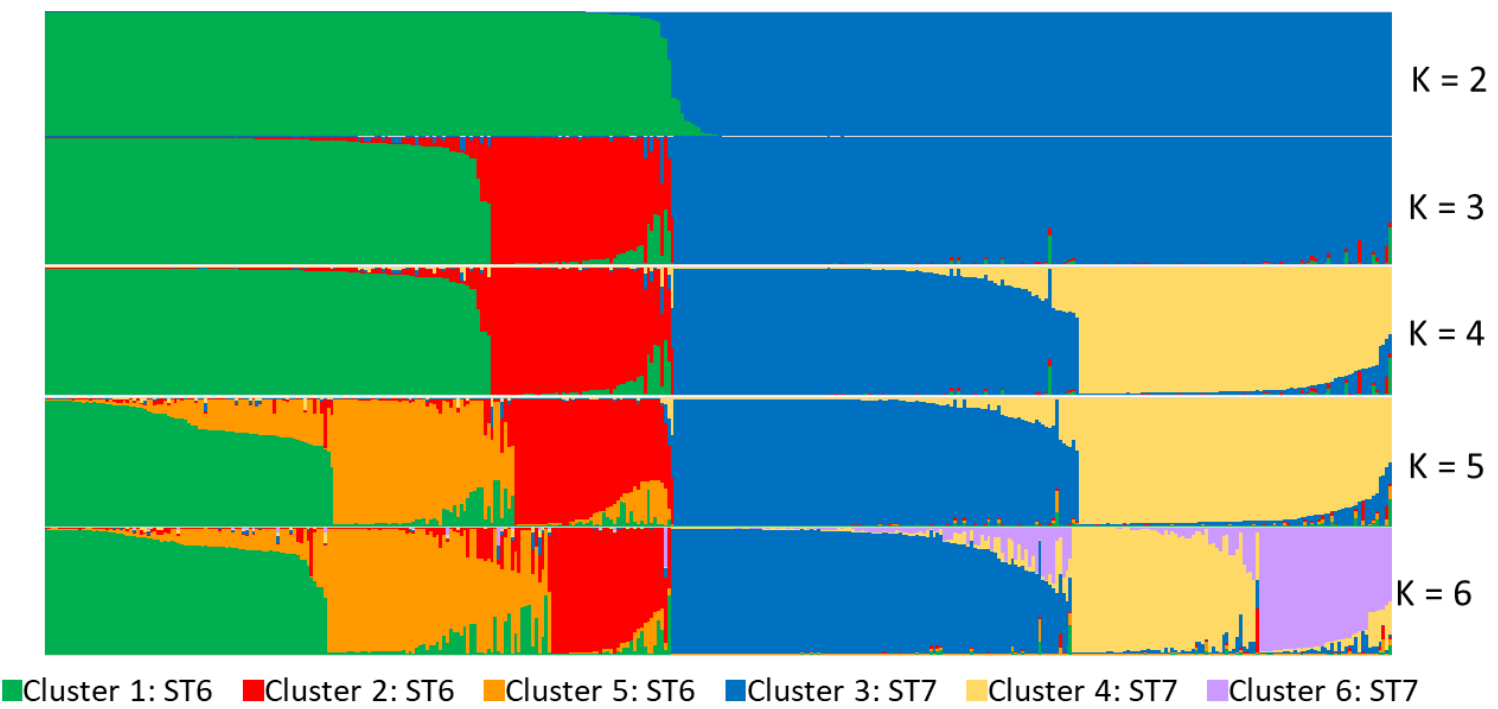


Fig. S9. The scenarios compared using ABC used independently for ST6 and ST7 samples. A) The 12 scenarios compared by the bottom-up approach. All scenarios considered that the French populations (Pop1 and Pop2) derived from an initial USA population. Ghost populations, i.e. populations that would have existed but were not sampled, were used in scenario 5-8 and 10-12. The time on the $\mathrm{Y}$ axis refers to the divergence date between populations. B) The five topologies analyzed by the top-down approach. All scenarios considered that the French populations (Pop1, Pop2 and Pop3) derived from an initial USA population. The time on the $\mathrm{Y}$ axis refers to the divergence date between populations.

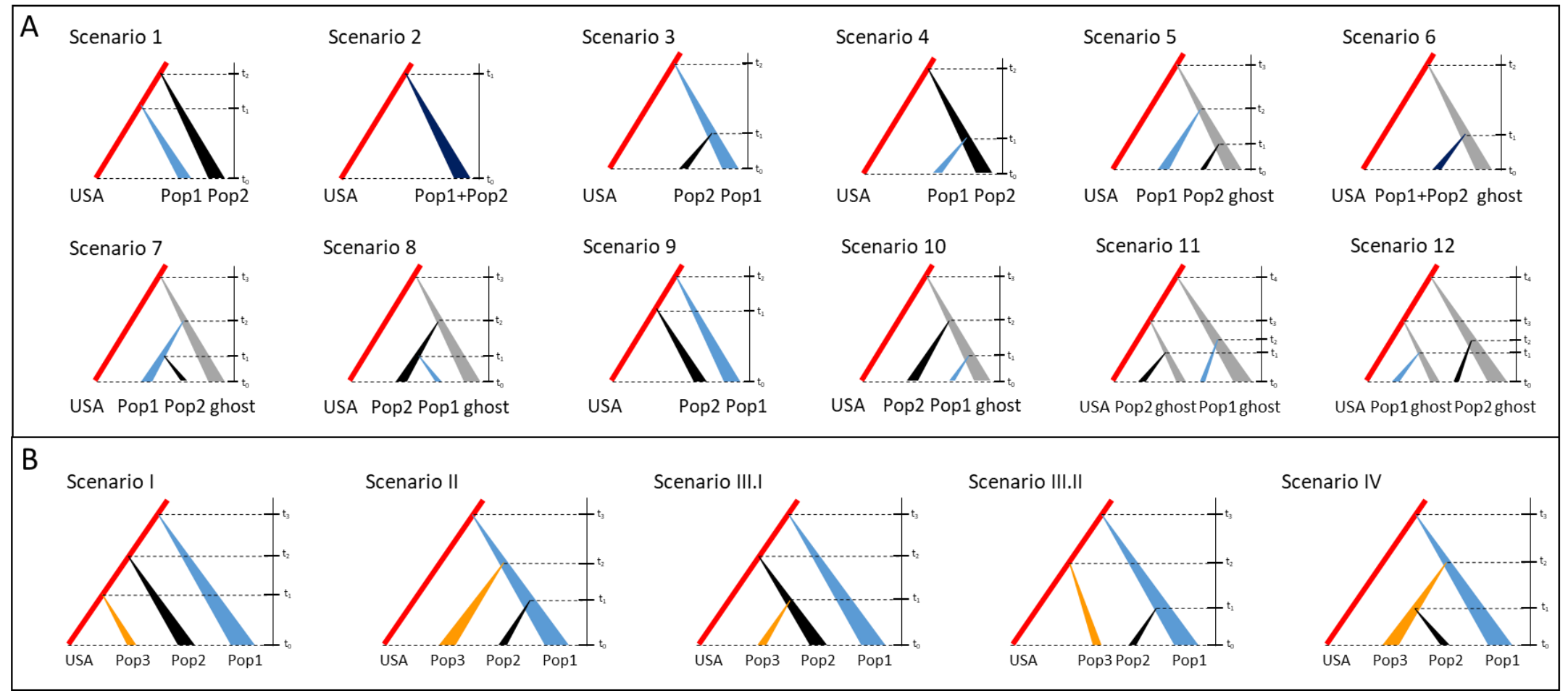


Fig. S10. List and visual representation of the 30 scenarios analyzed by ABC for ST6 samples. All scenarios considered that the French populations (C1P1, C2, and P2) derived from an initial USA population. The time on the Y axis refers to the divergence date between populations. Scenario II.7 (boxed in red) is the one defined by Abcrf analysis as the most probable.
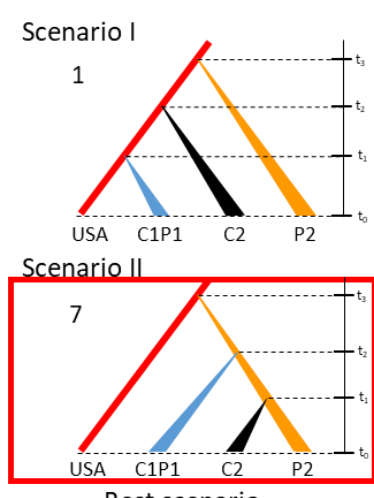

Best scenario

Scenario III.

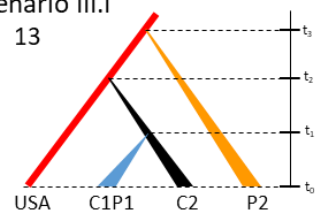

cenario III.II

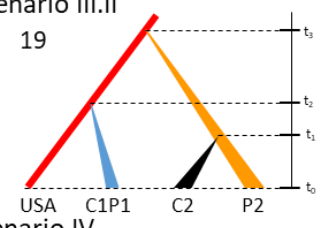
cenario IV

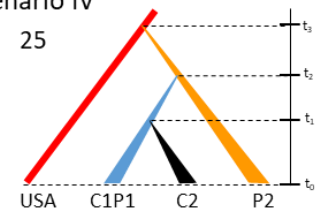

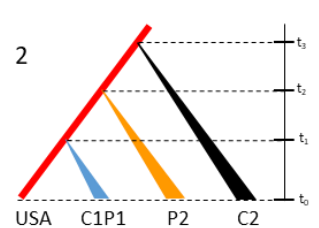
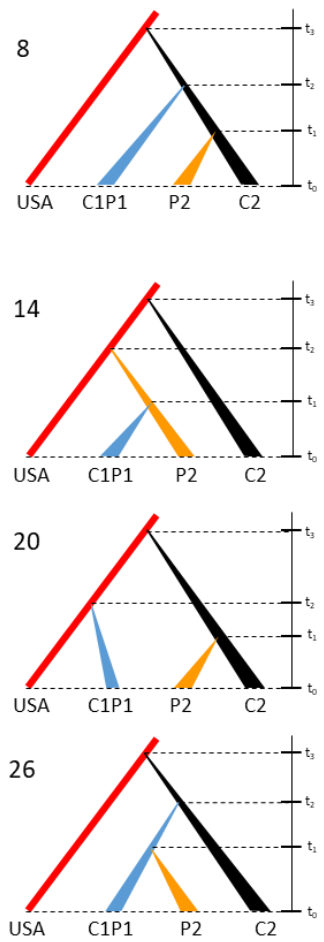
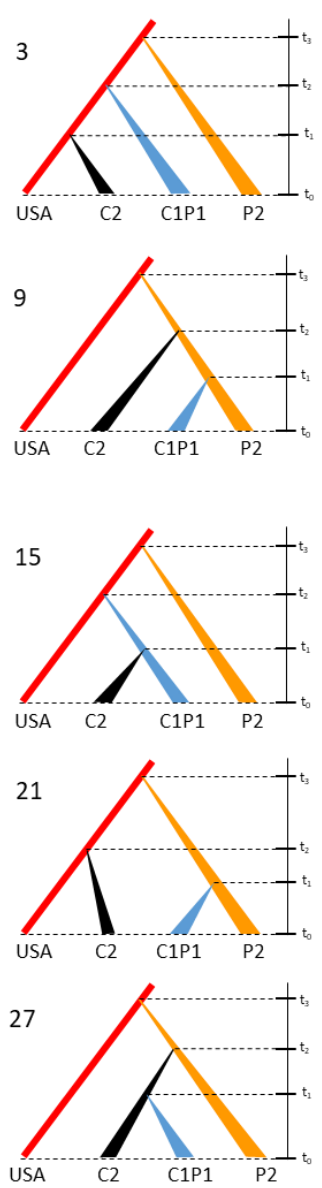
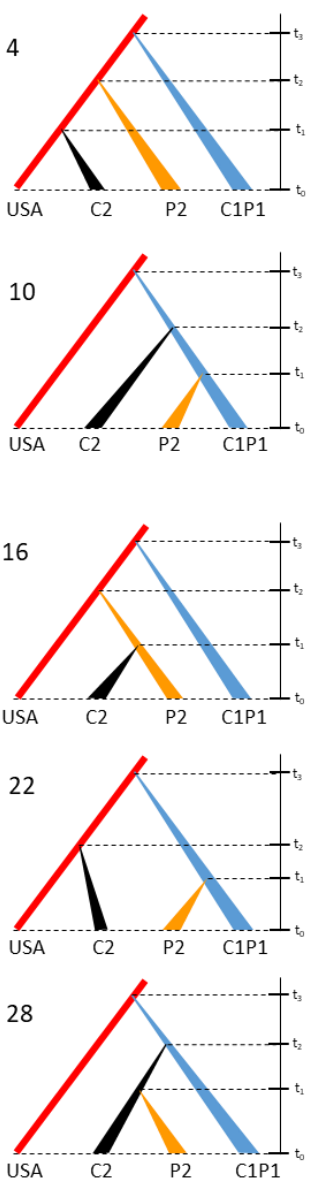
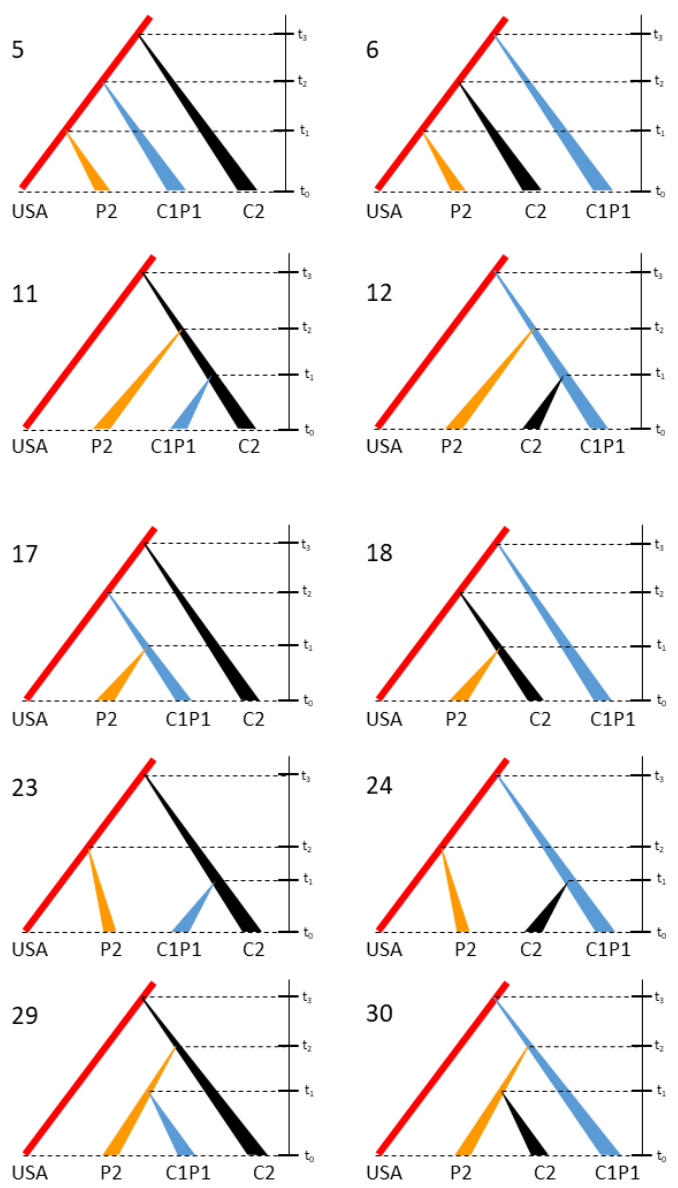
Fig. S11. List and visual representation of the 12 scenarios analyzed by ABC for ST7 samples. All scenarios considered that the French populations (C1P1, C2, and P2) derived from an initial USA population. The time on the Y axis refers to the divergence date between populations. Scenario II.7 (boxed in red) is the one defined by Abcrf analysis as the most probable.
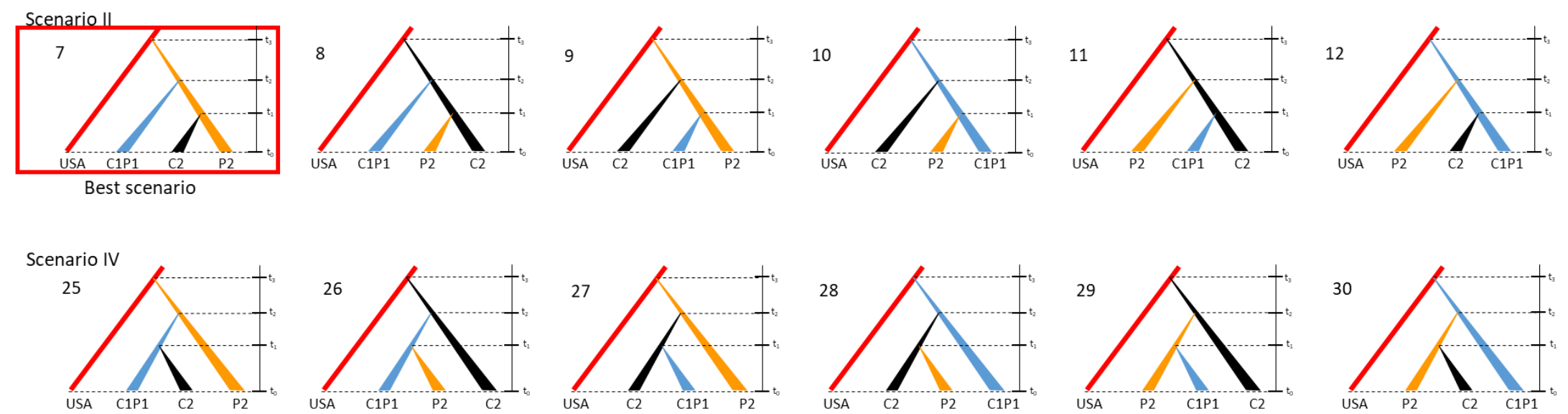
Table S1. $\quad$ List of the $82 \mathrm{X}$. fastidiosa genome sequences used in this study.

List of the $95 \mathrm{X}$. tastidiosa strains used in this study and their VNTR allelic protile. * CFBP reters to strains trom the CIRM-CFBP

(https://www6.inra.fr/cirm_eng/CFBP -Plant-Associated-Bacteria); LSV to strains isolated by the Plant Health Laboratory at ANSES, † NA: not available, $\neq$

Table S2. the 16 strains used as "panel test" to set up the MLVA scheme.

Table S3. List of the 18 Spanish X. fastidiosa subsp. multiplex strain DNAs used in this study and their VNTR allelic profile.

List of the 396 X. fastidiosa subsp. multiplex-infected French plant samples used in this study and their VNTR allelic profile. * 13 pairs of isolated strains and the DNA extracted from the same original plant sample, + the 16 samples for which DAPC clustering differed over the 20 runs, $\neq$ the samples

Table S4. collected by the DGAL in the framework of the national official surveillance strategy.

Table S5. Summary of private allele frequencies of ST6 and ST7 samples.

Genetic differentiation of the clusters of X. fastidiosa subsp. multiplex estimated by RST (bellow the diagonal) and FST (above the diagonal) pairwise comparisons for A) the DAPC k=4 groups; B) the three ST6 clusters used in ABC analyses; C) the three ST7 clusters used in ABC analyses. All pairwise

Table S6 population comparisons were significantly different $(P<0.05)$ after 1,000 permutations.

Table S7. Hierarchical AMOVA for A) ST6 X. fastidiosa subsp. multiplex DiyABC groups and B) ST7 X. fastidiosa subsp. multiplex DiyABC groups. Percentage of votes obtained for each scenario using abcrf. A) results of the ST6 bottom-up analyses; B) results of the ST6 top-down analyses; C) results

Table S8. of the ST7 bottom-up analyses; D) results of the ST7 top-down analyses.

Table S9. Distribution of prior parameters used for the DiyABC analyses. 
Table S1. List of the $82 \mathrm{X}$. fastidiosa genome sequences used in this study.

\begin{tabular}{|c|c|c|c|c|c|c|c|c|c|c|c|}
\hline $\begin{array}{c}\text { CFBP } \\
\text { strain code }\end{array}$ & $\begin{array}{c}\text { Other } \\
\text { strain code }\end{array}$ & ST & Host plant & $\begin{array}{l}\text { Place of } \\
\text { isolation }\end{array}$ & $\begin{array}{l}\text { Year of } \\
\text { isolation }\end{array}$ & $\begin{array}{l}\text { Contig } \\
\text { number }\end{array}$ & sequencing method & N50 & L50 & Accession & Reference \\
\hline CFBP 13551 & Dixon & 6 & Prunus dulcis & USA (California) & 1994 & 32 & & 201792 & 4 & AAAL00000000 & Bhattacharyya et al., 2002 \\
\hline CFBP 13552 & JCS6 & 7 & Polygala myrtifolia & France (Corse) & 2016 & 136 & Illumina Hiseq $\mathrm{X}$ & 97172 & 8 & JAJKBE000000000 & This study \\
\hline CFBP 13584 & LSV 47.06 & 7 & Polygala myrtifolia & France (Corse) & 2015 & 134 & Illumina Hiseq $\mathrm{X}$ & 97172 & 8 & JAJKBD000000000 & This study \\
\hline CFBP 13585 & LSV 47.08 & 7 & Polygala myrtifolia & France (Corse) & 2015 & 142 & Illumina Hiseq $\mathrm{X}$ & 97164 & 8 & JAJKBC000000000 & This study \\
\hline CFBP 13586 & LSV 47.10 & 6 & Lavandula $X$ allardii & France (Corse) & 2015 & 275 & Illumina Hiseq X & 96039 & 9 & JAJKBB000000000 & This study \\
\hline CFBP 13587 & LSV 49.43 & 6 & Prunus cerasus & France (PACA) & 2017 & 278 & Illumina Hiseq $\mathrm{X}$ & 96969 & 9 & JAJKBA000000000 & This study \\
\hline CFBP 13588 & LSV 47.22 & 7 & Polygala myrtifolia & France (Corse) & 2015 & 139 & Illumina Hiseq $\mathrm{X}$ & 97172 & 8 & JAJKAZ000000000 & This study \\
\hline CFBP 13589 & LSV 47.32 & 7 & Spartium junceum & France (PACA) & 2016 & 149 & Illumina Hiseq $\mathrm{X}$ & 98320 & 8 & JAJKAY000000000 & This study \\
\hline CFBP 13590 & LSV 49.27 & 7 & Coronilla glauca & France (PACA) & 2017 & 186 & Illumina Hiseq $\mathrm{X}$ & 97172 & 8 & JAJKAX000000000 & This study \\
\hline CFBP 13591 & LSV 48.34 & 6 & Polygala myrtifolia & France (Corse) & 2016 & 273 & Illumina Hiseq $\mathrm{X}$ & 96039 & 9 & JAJKAW000000000 & This study \\
\hline CFBP 13592 & LSV 48.35 & 7 & Prunus dulcis & France (Corse) & 2016 & 157 & Illumina Hiseq $\mathrm{X}$ & 96972 & 8 & JAJKAV000000000 & This study \\
\hline CFBP 13598 & LSV 49.25 & 7 & Acacia dealbata & France (PACA) & 2017 & 159 & Illumina Hiseq $\mathrm{X}$ & 97172 & 8 & JAJKAU000000000 & This study \\
\hline CFBP 13620 & LSV 47.12 & 6 & Polygala myrtifolia & France (PACA) & 2015 & 295 & Illumina Hiseq $\mathrm{X}$ & 96961 & 9 & JAJKAT000000000 & This study \\
\hline CFBP 13621 & LSV 47.16 & 7 & Polygala myrtifolia & France (Corse) & 2015 & 142 & Illumina Hiseq $\mathrm{X}$ & 96972 & 8 & JAJKAS000000000 & This study \\
\hline CFBP 13622 & LSV 47.17 & 6 & Polygala myrtifolia & France (Corse) & 2015 & 292 & Illumina Hiseq $\mathrm{X}$ & 93226 & 9 & JAJKAR000000000 & This study \\
\hline CFBP 13623 & LSV 47.14 & 6 & Lavandulla angustifolia & France (Corse) & 2015 & 277 & Illumina Hiseq $\mathrm{X}$ & 93663 & 9 & JAJKAQ000000000 & This study \\
\hline CFBP 13624 & LSV 47.18 & 7 & Polygala myrtifolia & France (Corse) & 2015 & 138 & Illumina Hiseq $\mathrm{X}$ & 119392 & 7 & JAJKAP000000000 & This study \\
\hline CFBP 13625 & LSV 47.19 & 7 & Polygala myrtifolia & France (Corse) & 2015 & 125 & Illumina Hiseq $\mathrm{X}$ & 97172 & 8 & JAJKAO0000000000 & This study \\
\hline CFBP 13626 & LSV 47.60 & 6 & Helichrysum italicum & France (Corse) & 2016 & 272 & Illumina Hiseq $\mathrm{X}$ & 93671 & 9 & JAJKAN000000000 & This study \\
\hline CFBP 13627 & LSV 47.61 & 6 & Calicotome villosa & France (Corse) & 2016 & 269 & Illumina Hiseq $\mathrm{X}$ & 118458 & 8 & JAJKAM000000000 & This study \\
\hline CFBP 13628 & LSV 48.29 & 6 & Lavandula sp. & France (Corse) & 2016 & 264 & Illumina Hiseq $\mathrm{X}$ & 96961 & 9 & JAJKAL000000000 & This study \\
\hline CFBP 13629 & LSV 48.30 & 6 & Polygala myrtifolia & France (Corse) & 2016 & 268 & Illumina Hiseq $\mathrm{X}$ & 96033 & 8 & JAJKAK000000000 & This study \\
\hline CFBP 13630 & LSV 48.31 & 6 & Cistus monspeliensis & France (Corse) & 2016 & 259 & Illumina Hiseq $\mathrm{X}$ & 109545 & 8 & JAJKAJ000000000 & This study \\
\hline CFBP 13631 & LSV 48.32 & 7 & Cistus monspeliensis & France (Corse) & 2016 & 145 & Illumina Hiseq X & 97172 & 8 & JAJKAI000000000 & This study \\
\hline CFBP 13632 & LSV 48.33 & 6 & Lavandula stoechas & France (Corse) & 2016 & 245 & Illumina Hiseq $X$ & 109551 & 8 & JAJKAH000000000 & This study \\
\hline CFBP 13633 & LSV 48.36 & 6 & Rosa canina & France (Corse) & 2016 & 264 & Illumina Hiseq X & 96039 & 8 & JAJKAG000000000 & This study \\
\hline CFBP 13634 & LSV 48.37 & 7 & Westrigia fruticosa & France (PACA) & 2017 & 121 & Illumina Hiseq X & 98560 & 8 & JAJKAF000000000 & This study \\
\hline CFBP 13635 & LSV 48.38 & 7 & Cistus creticus & France (Corse) & 2016 & 117 & Illumina Hiseq $\mathrm{X}$ & 97172 & 8 & JAJKAE000000000 & This study \\
\hline CFBP 13636 & LSV 49.26 & 7 & Coronilla glauca & France (PACA) & 2017 & 154 & Illumina Hiseq $\mathrm{X}$ & 97178 & 8 & JAJKAD000000000 & This study \\
\hline CFBP 13637 & LSV 49.36 & 7 & Polygala myrtifolia & France (PACA) & 2017 & 144 & Illumina Hiseq $\mathrm{X}$ & 97178 & 8 & JAJKAC000000000 & This study \\
\hline CFBP 13638 & LSV 49.37 & 6 & Euryops chrysanthemoïdes & France (PACA) & 2017 & 278 & Illumina Hiseq $\mathrm{X}$ & 96039 & 9 & JAJKAB000000000 & This study \\
\hline CFBP 13639 & LSV 49.47 & 6 & Prunus avium & France (PACA) & 2018 & 532 & Illumina Hiseq $\mathrm{X}$ & 78416 & 10 & JAJKAA000000000 & This study \\
\hline CFBP 13677 & AlmaEm3 & 42 & Vaccinium corymbosum & USA (Georgia) & 2011 & 139 & Illumina Hiseq $\mathrm{X}$ & 97040 & 9 & JAJJZZO000000000 & This study \\
\hline CFBP 13679 & Georgia Plum & 10 & Prunus sp. & USA (Georgia) & 2004 & 316 & Illumina Hiseq $\mathrm{X}$ & 91004 & 11 & JAJJZY000000000 & This study \\
\hline CFBP 13683 & BB08-1 & 43 & Vaccinium 'Windsor' & USA (Florida) & 2008 & 143 & Illumina Hiseq $\mathrm{X}$ & 114067 & 7 & JAJJZX000000000 & This study \\
\hline CFBP 13684 & L 95-2 & 37 & Lupinus villosus & USA (Florida) & 1995 & 228 & Illumina Hiseq $\mathrm{X}$ & 80724 & 9 & JAJJZW000000000 & This study \\
\hline CFBP 13685 & T.Oak 95-1 & 9 & Quercus cerris & USA & 1995 & 141 & Illumina Hiseq $\mathrm{X}$ & 99853 & 10 & JAJJZV000000000 & This study \\
\hline CFBP 13687 & LSV 49.35 & 7 & Medicago sativa & France (PACA) & 2017 & 140 & Illumina Hiseq $\mathrm{X}$ & 97172 & 8 & JAJJZU000000000 & This study \\
\hline CFBP 13688 & LSV 50.26 & 7 & Convolvulus cneorum & France (PACA) & 2018 & 132 & Illumina Hiseq $\mathrm{X}$ & 97178 & 8 & JAJJZTO000000000 & This study \\
\hline CFBP 13689 & LSV 50.38 & 7 & Prunus dulcis & France (Corse) & 2018 & 129 & Illumina Hiseq X & 97172 & 8 & JAJJZSO00000000 & This study \\
\hline CFBP 13691 & LSV 50.02 & 7 & Polygala myrtifolia & France (PACA) & 2018 & 167 & Illumina Hiseq $\mathrm{X}$ & 93300 & 9 & JAJJZR000000000 & This study \\
\hline CFBP 13692 & LSV 50.27 & 7 & Convolvulus cneorum & France (PACA) & 2018 & 137 & Illumina Hiseq X & 97150 & 8 & JAJJZQ000000000 & This study \\
\hline CFBP 13693 & LSV 49.64 & 7 & Polygala myrtifolia & France (PACA) & 2018 & 133 & Illumina Hiseq $\mathrm{X}$ & 97166 & 8 & JAJJZP000000000 & This study \\
\hline CFBP 13694 & LSV 50.25 & 7 & Euryops chrysanthemoïdes & France (PACA) & 2018 & 149 & Illumina Hiseq X & 93413 & 9 & JAJJZO0000000000 & This study \\
\hline CFBP 13695 & LSV 50.37 & 7 & Helichrysum italicum & France (PACA) & 2018 & 137 & Illumina Hiseq $\mathrm{X}$ & 96972 & 8 & JAJJZN000000000 & This study \\
\hline CFBP 13741 & & 6 & Polygala myrtifolia & France (Corse) & 2017 & 251 & Illumina Hiseq $\mathrm{X}$ & 109591 & 8 & JAJJZM000000000 & This study \\
\hline CFBP 13742 & & 6 & Polygala myrtifolia & France (Corse) & 2017 & 263 & Illumina Hiseq X & 118458 & 8 & JAJJZLL000000000 & This study \\
\hline CFBP 13743 & & 7 & Helichrysum italicum & France (Corse) & 2017 & 132 & Illumina Hiseq $\mathrm{X}$ & 97582 & 8 & JAJJZK000000000 & This study \\
\hline CFBP 13744 & M12 & 7 & Prunus dulcis & USA (California) & 2003 & 1 & & 2475130 & 1 & NC 010513 & Chen et al., 2010 \\
\hline CFBP 13745 & LSV 47.07 & 6 & Polygala myrtifolia & France (Corse) & 2015 & 272 & Illumina Hiseq $X$ & 96961 & 9 & JAJJZJ000000000 & This study \\
\hline CFBP 8070 & LSV 40.38 & 10 & Prunus spp & USA (Georgia) & 2004 & & PacBio RS II & 2074959 & 1 & JAJKGN000000000 & This study \\
\hline 78 & LSV 43.11 & 51 & Vinca sp. & USA (Florida) & 1983 & 190 & Illumina MiSeg & 87559 & 10 & PHFSO0000000 & Denancé et al., 2019 \\
\hline
\end{tabular}


CFBP 8173 LSV 40.39

CFBP 8416 LSV 46.77

CFBP 8417 LSV 46.78

CFBP 8418 LSV 46.79

CFBP 8430 LSV 47.11

CFBP 8431 LSV 47.13

CFBP 8432 LSV 47.15

CFBP 8433 LSV 47.20

CFBP 8434 LSV 47.21

CFBP 8435 LSV 47.23

BB01

ESVL

Griffin-1

IAS-AXF-212H7

IAS-AXF-235T10

IVIA5901

IVIA6586_2

IVIA6629

IVIA6731

IVIA6902

IVIA6903

RAAR14_plu

RAAR6_Butte

sycamore Sy-VA

TOS14

TOS4

TOS5

XF3348

XYL1752

XYL198

41 Prunus salicina

7 Polygala myrtifolia

6 Spartium junceum

6 Spartium junceum

6 Polygala myrtifolia

6 Prunus cerasifera

Polygala myrtifolia

7 Cistus monspeliensis

7 Pelargonium $s p$.

Coronilla valentina

42 Vaccinium corymbosum

6 Prunus dulcis

7 Quercus ruba

6 Prunus dulcis

6 Prunus dulcis

6 Prunus dulcis

6 Helichrysum italicum

6 Rhamnus alaternus

6 Helichrysum italicum

6 Prunus dulcis

6 Prunus dulcis

26 Prunus domestica

7 Prunus dulcis

87 Platanus occidentalis

87 Spartium junceum

Prunus dulcis

87 Polygala myrtifolia

81 Prunus dulcis

81 Ficus carica
USA (Georgia)

France (Corse)

France (Corse)

France (Corse)

France (PACA)

France (Corse)

France (Corse)

France (Corse)

France (Corse)

USA (California)

Spain (Alicante)

USA (Georgia)

Spain (Alicante)

Spain (Alicante)

Spain (Alicante)

Spain (Alicante)

Spain (Alicante)

Spain (Alicante)

Brazil (Veranopolis)

USA (California)

USA (Virginia)

Italy (Tuscany)

Italy (Tuscany)

Italy (Tuscany)

Spain (Mallorca)

Spain (Mallorca)

Spain (Mallorca)
1983

2015

2015

2015

2015

2015

2015

2015

2015

2016

2018

2006

2018

2018

2018

2018

2018

2018

2018

2018

1995
2002

2002
2018

2018

2018

2018

2018
2018
58 Illumina Hiseq 2000

128 Illumina MiSeq 106692

256 Illumina MiSeq

Illumina MiSeq

PacBio RS II

PacBio RS II

PacBio RS II

PacBio RS II

PacBio RS II

PacBio RS II

113891

96035

2716895

1987931

2560653

CP087991

11 CP087992

19302311 JAJKGQ000000000

10 MPAZO0000000

Illumina HiSeq $4000103116 \quad 7 \quad$ QPQV00000000

454

$74017 \quad 12$ AVGA00000000

年 7 VCPQ00000000

Ilumina Hiseq $4000103901 \quad 7$ VCQO00000000

Nanopore MiniION 2559157

341 Illumina HiSeq 400096774

1099 Illumina HiSeq 400096774

Illumina HiSeq 400098660

Illumina HiSeq 400094781

1 GCA_004023395.2

8 VDCM00000000

8 VCPM00000000

7 VCPNO0000000

VCPO00000000

Illumina HiSeq 10308

192 Illumina HiSeq 400096594

140 Illumina HiSeq 4000128621

454

7 VCPP00000000

7 VDDF00000000

7 VDDE00000000

Illumina NovaSeq 19358

Illumina NovaSeq 17826

4 SMTJ00000000

Illumina NovaSeq $178266 \quad 4 \quad$ SMTI00000000

Illumina HiSeq $4000 \quad 102161 \quad 7 \quad$ VDCL00000000

$\begin{array}{llll}\text { Illumina HiSeq } 4000 & 98273 & 9 & \text { VDCKO0000000 } \\ \text { Illumina HiSeg } 4000 & 96968 & 9 & \text { VDCJ000000000 }\end{array}$
DOE Joint Genome Institute 2013

Denancé et al., 2017

Denancé et al., 2017

Denancé et al., 2017

This study

This study

This study

This study

Van Horn et al., 2017

Giampetruzzi et al., 2019

Chen et al., 2013

Landa et al., 2020

Landa et al., 2020

(a) 2019

Landa et al., 2020

Landa et al., 2020

Landa et al. 2020

Landa et al., 2020

Landa et al., 2020

Guan et al., 2014

Giampetruzzi et al., 2019

Giampetruzzi et al., 2019

Giampetruzzi et al., 2019

Landa et al., 2020

anda et 2020 
Table S2. List of the $95 x$. fastidiosa strains used in this study and their VNTR allelic profile.

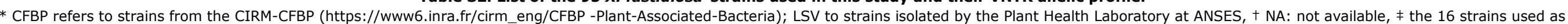
"panel test" to set up the MLVA scheme.

\begin{tabular}{|c|c|c|c|c|c|c|c|c|c|c|c|c|c|c|c|c|c|c|c|}
\hline \multirow[t]{2}{*}{ Taxonomic position } & \multirow{2}{*}{$\begin{array}{l}\text { CFBP } \\
\text { strain code* }\end{array}$} & \multirow{2}{*}{$\begin{array}{l}\text { Other } \\
\text { strain code }\end{array}$} & \multirow{2}{*}{\multicolumn{2}{|c|}{ ST Host plant of isolation }} & \multirow{2}{*}{$\begin{array}{l}\text { Place of } \\
\text { isolation }\end{array}$} & \multirow{2}{*}{$\begin{array}{c}\text { Year of } \\
\text { isolatio } \\
n\end{array}$} & \multicolumn{13}{|c|}{ XFSSR allelic profile } \\
\hline & & & & & & & $\begin{array}{l}\text { ASSR- } \\
11\end{array}$ & $\begin{array}{c}\text { ASSR- } \\
16\end{array}$ & $\begin{array}{c}\text { coss- } \\
1\end{array}$ & $\begin{array}{c}- \text { OSSR- } \\
19\end{array}$ & $\begin{array}{c}\text { GSSR- } \\
7\end{array}$ & $\begin{array}{l}\text { OSSR- } \\
16\end{array}$ & $\begin{array}{c}\text { XFSSR- } \\
37\end{array}$ & $\begin{array}{c}\text { XFSSR- } \\
58\end{array}$ & $\begin{array}{l}\text { ASSR- } \\
9\end{array}$ & $\begin{array}{l}\text { ASSR- } \\
12\end{array}$ & $\begin{array}{c}\text { ASSR- } \\
19\end{array}$ & $\begin{array}{c}\text { GSSR- } \\
4\end{array}$ & $\begin{array}{c}\text { XFSSR- } \\
40\end{array}$ \\
\hline \multirow{21}{*}{$\begin{array}{l}\text { Xylella fastidiosa } \\
\text { subsp. fastidiosa }\end{array}$} & CFBP 13349 & ATCC 35876 & 2 & Ambrosia artemifolia & USA (Florida) & 1983 & 7 & 26 & 8 & 10 & 24 & 11 & 10 & 12 & 2 & 3 & 2 & 24 & 8 \\
\hline & CFBP 13354 & ICMP 15197 & 2 & Vitis vinifera & USA (Florida) & 1987 & 4 & 29 & 5 & 3 & 15 & 9 & 12 & 14 & 2 & 3 & 2 & 26 & 9 \\
\hline & CFBP 13676 & Temecula 1 & 1 & Vitis vinifera & USA (California) & 1998 & 9 & 25 & 11 & 3 & 16 & 8 & 5 & 8 & 2 & 6 & 2 & 17 & 7 \\
\hline & CFBP 13686 & MED PRI 047 & 5 & Nerium oleander & USA (Texas) & NA & 7 & 27 & 1 & 7 & 17 & 13 & 2 & 14 & 16 & 10 & 2 & 24 & 4 \\
\hline & CFBP 7969 & LMG 15553 & 2 & Vitis rotundifolia & USA (North Carolina) & 1985 & 8 & 27 & 1 & 5 & 19 & 7 & 12 & 11 & 2 & 3 & 2 & 24 & 8 \\
\hline & CFBP 7970 & LMG 17159 & 2 & Vitis vinifera & USA (Florida) & 1987 & 8 & 27 & 1 & 5 & 12 & 8 & 12 & 14 & 2 & 3 & 2 & 26 & 9 \\
\hline & CFBP 8069 & PD89.1 & 1 & Vitis sp. & $\mathrm{NA}^{+}$ & NA & 4 & 28 & 4 & 6 & 9 & 7 & 12 & 10 & 2 & 12 & 2 & 22 & 7 \\
\hline & CFBP $8071^{\ddagger}$ & LSV 40.41 & 1 & Prunus dulcis & USA (California) & 1987 & 7 & 23 & 6 & 10 & 23 & 14 & 7 & 7 & 2 & 7 & 2 & 16 & 7 \\
\hline & CFBP $8073^{*}$ & LSV 42.09 & 75 & Coffea canephora & Mexique & 2012 & 7 & 27 & 1 & 5 & 30 & 13 & 8 & 13 & 2 & 13 & 2 & 56 & 8 \\
\hline & CFBP $8077^{*}$ & LSV 42.36 & 5 & Nerium oleander & USA (California) & 1995 & 8 & 23 & 1 & 6 & 18 & 12 & 2 & 8 & 2 & 7 & 2 & 24 & 4 \\
\hline & CFBP 8082 & LMG 9064 & 2 & Ambrosia artemifolia & USA (Florida) & 1983 & 9 & 27 & 1 & 10 & 24 & 11 & 10 & 12 & 2 & 3 & 2 & 24 & 8 \\
\hline & CFBP 8083 & LMG 15554 & 2 & Vitis vinifera & USA (North Carolina) & 1985 & 7 & 28 & 1 & 5 & 17 & 7 & 12 & 12 & 2 & 3 & 2 & 24 & 6 \\
\hline & CFBP $8084^{\ddagger}$ & LMG 15098 & 29 & Mulberry sp. & USA (Georgia) & NA & 8 & 28 & 1 & 5 & 19 & 11 & 5 & 5 & 2 & 8 & 2 & 19 & 10 \\
\hline & CFBP 8174 & ICMP 6576 & 1 & Vitis vinifera & USA (California) & NA & 9 & 23 & 1 & 6 & 27 & 6 & 11 & 7 & 2 & 7 & 2 & 16 & 12 \\
\hline & CFBP 8175 & ICMP 8729 & 1 & Vitis vinifera & USA (Florida) & NA & 9 & 23 & 1 & 6 & 31 & 6 & 11 & 7 & 2 & 7 & 2 & 16 & 12 \\
\hline & CFBP 8176 & ICMP 8730 & 2 & Vitis vinifera & USA (Florida) & NA & 8 & 27 & 1 & 5 & 16 & 9 & 12 & 14 & 2 & 3 & 2 & 26 & 9 \\
\hline & CFBP 8177 & ICMP 8731 & 1 & Vitis vinifera & USA (Florida) & NA & 8 & 23 & 1 & 6 & 23 & 14 & 7 & 7 & 2 & 7 & 2 & 16 & 8 \\
\hline & CFBP 8351 & LSV 46.26 & 1 & Vitis sp. & USA (California) & 1993 & 4 & 28 & 7 & 8 & 23 & 13 & 8 & 8 & 2 & 6 & 2 & 16 & 12 \\
\hline & CFBP 8356 & LSV 46.27 & 72 & Coffea arabica & Costa Rica & 2015 & 9 & 22 & 4 & 10 & 28 & 16 & 3 & 3 & 2 & 10 & 2 & 13 & 6 \\
\hline & CFBP 8419 & LSV 46.39 & 72 & Coffea arabica & France & 2015 & 10 & 29 & 7 & 3 & 18 & 4 & 3 & 3 & 2 & 12 & 2 & 12 & 7 \\
\hline & CFBP 8478 & LSV 46.28 & 72 & Coffea arabica & France & 2015 & 8 & 27 & 1 & 5 & 14 & 4 & 3 & 3 & 2 & 10 & 2 & 12 & 10 \\
\hline \multirow{34}{*}{$\begin{array}{l}\text { Xylella fastidiosa } \\
\text { subsp. multiplex }\end{array}$} & CFBP $13551^{\neq}$ & Dixon & 6 & Prunus dulcis & USA (California) & 1994 & 10 & 29 & 7 & 10 & 20 & 8 & 3 & 5 & 11 & 12 & 9 & 17 & 9 \\
\hline & CFBP $13552^{\ddagger}$ & JCS6 & 7 & Polygala myrtifolia & France (Corsica) & 2016 & 7 & 24 & 9 & 7 & 14 & 22 & 8 & 4 & 15 & 8 & 11 & 9 & 8 \\
\hline & CFBP 13677 & AlmaEm3 & 42 & Vaccinium corymbosum & USA (Georgia) & 2011 & 7 & 24 & 5 & 3 & 9 & 11 & 3 & 9 & 8 & 6 & 2 & 17 & 2 \\
\hline & CFBP 13678 & ALS6 & 27 & Prunus dulcis & USA (California) & NA & 7 & 24 & 6 & 13 & 24 & 14 & 3 & 7 & 13 & 10 & 8 & 14 & 8 \\
\hline & CFBP 13679 & Georgia Plum & 10 & Prunus sp. & USA (Georgia) & 2004 & 25 & 27 & 10 & 14 & 26 & 11 & 8 & 10 & 9 & 10 & 9 & 9 & 5 \\
\hline & CFBP 13680 & GIL GRA 274 EXT & 23 & Helianthus annuus & USA (Texas) & NA & 8 & 19 & 10 & 2 & 23 & 18 & 5 & 9 & 12 & 3 & 11 & 9 & 5 \\
\hline & CFBP 13681 & LLA FAL 718 A & 23 & Iva angustifolia & USA (Texas) & NA & 2 & 27 & 10 & 10 & 10 & 21 & 11 & 10 & 12 & 5 & 9 & 10 & 6 \\
\hline & CFBP 13682 & VAL VAL 072 EXT & 42 & Ambrosia trifida & USA (Texas) & NA & 8 & 27 & 1 & 5 & 24 & 10 & 5 & 5 & 9 & 5 & 2 & 14 & 5 \\
\hline & CFBP 13683 & BB08-1 & 43 & Vaccinium windsor & USA (Florida) & 2008 & 7 & 24 & 8 & 12 & 15 & 11 & 5 & 7 & 10 & 5 & 2 & 11 & 7 \\
\hline & CFBP 13684 & L 95-2 & 37 & Lupinus villosus & USA (Florida) & NA & 23 & 29 & 10 & 2 & 12 & 10 & 2 & 7 & 11 & 3 & 13 & 19 & 5 \\
\hline & CFBP 13685 & T.Oak 95-1 & 9 & $N A$ & USA (Florida) & NA & 7 & 25 & 1 & 5 & 15 & 12 & 4 & 6 & 15 & 8 & 4 & 26 & 3 \\
\hline & CFBP 13690 & UVA $519-1 \mathrm{~B}$ & 45 & Cercis sp. & USA (Texas) & NA & 9 & 23 & 7 & 8 & 15 & 11 & 8 & 8 & 2 & 5 & 9 & 11 & 4 \\
\hline & CFBP 13741 & & 6 & Polygala myrtifolia & France (Corsica) & 2017 & 12 & 27 & 10 & 11 & 12 & 7 & 3 & 8 & 11 & 14 & 9 & 17 & 10 \\
\hline & CFBP 13742 & & 6 & Polygala myrtifolia & France (Corsica) & 2017 & 12 & 29 & 11 & 11 & 22 & 7 & 3 & 8 & 11 & 13 & 9 & 17 & 10 \\
\hline & CFBP 13743 & & 7 & Helichrysum italicum & France (Corsica) & 2017 & 7 & 24 & 7 & 7 & 14 & 22 & 6 & 4 & 15 & 8 & 11 & 9 & 8 \\
\hline & CFBP $8068^{\ddagger}$ & LNPV 00.54 & 41 & Ulmus elm & USA (Washington DC) & NA & 15 & 32 & 11 & 5 & 25 & 8 & 7 & 8 & 3 & 7 & 12 & 8 & 4 \\
\hline & CFBP 8070 & LSV 40.38 & 10 & Prunus sp. & USA (Georgia) & 2004 & 2 & 27 & 7 & 10 & 25 & 11 & 8 & 4 & 9 & 10 & 9 & 9 & 5 \\
\hline & CFBP $8076^{\ddagger}$ & LSV 42.31 & 9 & Quercus rubra & USA (Washington DC) & NA & 7 & 27 & 11 & 6 & 20 & 12 & 5 & 6 & 9 & 6 & 8 & 27 & 5 \\
\hline & CFBP $8078^{\ddagger}$ & LSV 43.11 & 51 & Vinca sp. & USA (Florida) & 1983 & 7 & 21 & 5 & 5 & 11 & 7 & 7 & 4 & 7 & 4 & 8 & 9 & 6 \\
\hline & CFBP $8173^{\ddagger}$ & LSV 40.39 & 41 & Prunus sp. & USA (Georgia) & 1983 & 15 & 32 & 11 & 5 & 24 & 8 & 7 & 8 & 3 & 7 & 12 & 8 & 4 \\
\hline & CFBP 8416 & LSV 46.77 & 7 & Polygala myrtifolia & France (Corsica) & 2015 & 7 & 24 & 7 & 7 & 14 & 22 & 7 & 4 & 15 & 8 & 11 & 9 & 8 \\
\hline & CFBP $8417^{\ddagger}$ & LSV 46.78 & 6 & Spartium junceum & France (Corsica) & 2015 & 12 & 29 & 9 & 11 & 21 & 7 & 3 & 8 & 11 & 13 & 9 & 17 & 11 \\
\hline & CFBP 8418 & LSV 46.79 & 6 & Spartium junceum & France (Corsica) & 2015 & 12 & 29 & 9 & 11 & 22 & 7 & 3 & 8 & 11 & 13 & 9 & 18 & 11 \\
\hline & CFBP 8430 & LSV 47.11 & 6 & Polygala myrtifolia & France (PACA) & 2015 & 11 & 29 & 8 & 13 & 17 & 7 & 3 & 9 & 11 & 12 & 8 & 17 & 9 \\
\hline & CFBP $8431^{\ddagger}$ & LSV 47.13 & 6 & Prunus cerasifera & France (Corsica) & 2015 & 12 & 29 & 9 & 7 & 22 & 7 & 3 & 8 & 11 & 13 & 9 & 17 & 10 \\
\hline & CFBP $8432^{\ddagger}$ & LSV 47.15 & 7 & Polygala myrtifolia & France (PACA) & 2015 & 7 & 24 & 12 & 7 & 16 & 25 & 7 & 4 & 12 & 8 & 12 & 9 & 9 \\
\hline & CFBP $8433^{\ddagger}$ & LSV 47.20 & 7 & Cistus monspeliensis & France (Corsica) & 2015 & 7 & 24 & 6 & 7 & 16 & 16 & 7 & 4 & 13 & 8 & 12 & 9 & 9 \\
\hline & CFBP $8434^{\ddagger}$ & LSV 47.21 & 7 & Pelargonium sp. & France (Corsica) & 2015 & 7 & 24 & 7 & 7 & 13 & 23 & 10 & 4 & 15 & 8 & 12 & 9 & 8 \\
\hline & CFBP $8435^{\ddagger}$ & LSV 47.23 & 6 & Coronilla valentina & France (Corsica) & 2015 & 12 & 29 & 9 & 7 & 22 & 7 & 3 & 8 & 11 & 13 & 9 & 17 & 10 \\
\hline & CFBP 13584 & LSV 47.06 & 7 & Polygala myrtifolia & France (Corsica) & 2015 & 7 & 24 & 8 & 7 & 14 & 20 & 7 & 4 & 15 & 8 & 11 & 9 & 8 \\
\hline & CFBP 13745 & LSV 47.07 & 6 & Polygala myrtifolia & France (Corsica) & 2015 & 12 & 29 & 9 & 11 & 22 & 7 & 3 & 8 & 11 & 13 & 9 & 17 & 10 \\
\hline & CFBP 13585 & LSV 47.08 & 7 & Polygala myrtifolia & France (Corsica) & 2015 & 7 & 24 & 7 & 7 & 14 & 22 & 7 & 4 & 15 & 8 & 11 & 9 & 8 \\
\hline & CFBP 13586 & LSV 47.10 & 6 & Lavandula X allardii & France (Corsica) & 2015 & 12 & 29 & 9 & 11 & 22 & 7 & 3 & 8 & 11 & 13 & 9 & 17 & 10 \\
\hline & CFBP 13620 & LSV 47.12 & 6 & Polygala myrtifolia & France (PACA) & 2015 & 11 & 29 & 8 & 13 & 17 & 7 & 3 & 8 & 11 & 12 & 8 & 17 & 9 \\
\hline
\end{tabular}


CFBP 13623 LSV 47.14 CFBP 13621 LSV 47.16 CFBP 13622 LSV 47.17 CFBP 13624 LSV 47.18 CFBP 13625 LSV 47.19 CFBP 13588 LSV 47.22 CFBP 13589 LSV 47.32 CFBP 13626 LSV 47.60 CFBP 13627 LSV 47.61 CFBP 13628 LSV 48.29 CFBP 13629 LSV 48.30 CFBP 13630 LSV 48.31 CFBP 13632 LSV 48.33 CFBP 13591 LSV 48.34 CFBP 13592 LSV 48.35 CFBP 13634 LSV 48.37 CFBP 13635 LSV 48.38 CFBP 13598 LSV 49.25 CFBP 13636 LSV 49.26 CFBP 13590 LSV 49.27 CFBP 13687 LSV 49.35 CFBP 13637 LSV 49.36 CFBP 13638 LSV 49.37 CFB 13587 LSV 49.43 CFBP 13639 LSV 49.47 CFBP 13693 LSV 49.64 CFBP 13691 LSV 50.02 CFBP 13694 LSV 50.25 CFBP 13688 LSV 50.26 CFBP 13692 LSV 50.27 CFPP 13689 LSV 50.38 CFBP 8072 LSV 50.38 CFBP 8074 LSV 42.10 CFBP 8074 LSV 42.10 CFBP 8402 CFBP 8495
CFBP 8498
6 Lavandula angustifolia Polygala myrtifolia

6 Polygala myrtifolia

7 Polygala myrtifolia

7 Polygala myrtifolia

7 Polygala myrtifolia

- Spartium junceum

Helichrysum italicum

Calicotome villosa

6 Lavandula sp.

6 Polygala myrtifolia

6 Cistus monspeliensis

Cistus monspeliensis

Lavandula stoechas

Polygala myrtifolia

6 Rosa canina

Westrigia fructicosa

Cistus creticus

7 Acacia dealbata

7 Coronilla glauca

Coronilla glauca

Polygala myrtifolia

6 Euryops chrysanthemoïdes

6 Prunus cerasus

Prunus avium

Polygala myrtifolia

Euryops chrysanthemoïdes

Convolvulus cneorum

Helichrysum italicum

7 Prunus dulcis

74 Cofrea art

74 Coffea arabica

53 Olea europaea

73 Coffea arabica

53 Coffea arabica
France (Corsica) France (Corsica)

France (Corsica)

France (Corsica)

France (Corsica)

France (Corsica)

France (PACA)

France (Corsica)

France (Corsica)

France (Corsica)

France (Corsica)

France (Corsica)

France (Corsica)

France (Corsica)

France (Corsica)

France (Corsica)

France (Corsica)

France (PACA)

France (Corsica)

France (PACA)

France (PACA)

France (PACA)

France (PACA)

France (PACA)

France (PACA)

France (PACA)

France (PACA)

France (PACA)

France (PACA)

France (PACA)

France (PACA)

France (PACA)

France (PACA)

Ecuador

Ecuador

Italy (Apulia)

The Netherlands

The Netherlands 
Table S3. List of the 18 Spanish $X$. fastidiosa subsp. multiplex strain DNAs used in this study and their VNTR allelic profile.

\begin{tabular}{|c|c|c|c|c|c|c|c|c|c|c|c|c|c|c|c|c|c|}
\hline Strain code & ST & Host plant & Place of isolation & Year of & & & & & & $\overline{\mathrm{XFSS}}$ & R allelic pr & rofile & & & & & \\
\hline & & Host plant & Place of Isolation & isolation & $\operatorname{coss}-1$ & OSSR-19 & ASSR- & ASSR-16 & XFSSR-58 & XFSSR-37 & GSSR-7 & OSSR-16 & ASSR-9 & GSSR-4 & ASSR-19 & ASSR-12 & XFSSR-40 \\
\hline AXF 120 & 6 & Prunus dulcis & Spain (Alicante, La Vall Alcala) & 2018 & 8 & 7 & 4 & 33 & 6 & 10 & 35 & 4 & 18 & 12 & 9 & 6 & 6 \\
\hline AXF 183 & 6 & Prunus dulcis & Spain (Alicante, Polop) & 2018 & 8 & 7 & 4 & 33 & 6 & 10 & 36 & 6 & 18 & 12 & 9 & 6 & 7 \\
\hline AXF 213 & 6 & Prunus dulcis & Spain (Alicante, Benimantell) & 2018 & 9 & 7 & 4 & 33 & 6 & 9 & 33 & 6 & 16 & 13 & 7 & 6 & 8 \\
\hline AXF 26 & 6 & Prunus dulcis & Spain (Alicante, Xalo) & 2018 & 9 & 7 & 4 & 33 & 6 & 9 & 36 & 6 & 17 & 12 & 7 & 6 & 8 \\
\hline AXF 51 & 6 & Prunus dulcis & Spain (Alicante, Alcalali) & 2018 & 10 & 7 & 4 & 33 & 6 & 9 & 36 & 6 & 17 & 12 & 7 & 6 & 8 \\
\hline AXF 82 & 6 & Prunus dulcis & Spain (Alicante, Castell de Castells) & 2018 & 9 & 7 & 4 & 33 & 6 & 9 & 34 & 6 & 17 & 12 & 7 & 6 & 8 \\
\hline AXF 87 & 6 & Prunus dulcis & Spain (Alicante, Benifato) & 2018 & 10 & 7 & 4 & 33 & 6 & 9 & 36 & 6 & 18 & 12 & 7 & 6 & 8 \\
\hline IAS-AXF212H7 & 6 & Prunus dulcis & Spain (Alicante, Benimantell) & 2018 & 9 & 7 & 4 & 33 & 6 & 9 & 35 & 6 & 18 & 13 & 7 & 6 & 8 \\
\hline IAS-AXF235T1 & 6 & Prunus dulcis & Spain (Alicante, El Castell de Guadalest & 2018 & 8 & 7 & 4 & 33 & 6 & 6 & 42 & 7 & 19 & 12 & 9 & 6 & 8 \\
\hline IAS-AXF235T10 & 6 & Prunus dulcis & Spain (Alicante, El Castell de Guadalest & 2018 & 8 & 7 & 4 & 33 & 6 & 6 & 42 & 7 & 19 & 12 & 9 & 6 & 8 \\
\hline IAS-AXF64H11 & 6 & Prunus dulcis & Spain (Alicante, Benimantell) & 2018 & 9 & 7 & 4 & 33 & 6 & 9 & 33 & 6 & 16 & 13 & 7 & 6 & 8 \\
\hline IAS-AXF64T12 & 6 & Prunus dulcis & Spain (Alicante, Benimantell) & 2018 & 9 & 7 & 4 & 33 & 6 & 9 & 33 & 6 & 16 & 13 & 7 & 6 & 8 \\
\hline IAS-AXF64T13 & 6 & Prunus dulcis & Spain (Alicante, Benimantell) & 2018 & 9 & 7 & 4 & 33 & 6 & 9 & 33 & 6 & 16 & 13 & 7 & 6 & 8 \\
\hline IAS-AXF64T14 & 6 & Prunus dulcis & Spain (Alicante, Benimantell) & 2018 & 9 & 7 & 4 & 33 & 6 & 9 & 33 & 6 & 16 & 13 & 7 & 6 & 8 \\
\hline XF3348 & 81 & Prunus dulcis & Spain (Mallorca) & 2018 & 7 & 5 & 4 & 23 & 6 & 2 & 11 & 12 & 7 & 13 & 11 & 9 & 5 \\
\hline XYL1752 & 81 & Prunus dulcis & Spain (Menorca) & 2018 & 9 & 6 & 6 & 22 & 6 & 2 & 12 & 13 & 6 & 13 & 11 & 9 & 5 \\
\hline XYL1981 & 81 & Ficus carica & Spain (Mallorca) & 2018 & 9 & 6 & 6 & 23 & 6 & 2 & 15 & 7 & 6 & 13 & 11 & 9 & 5 \\
\hline
\end{tabular}


Table S4. List of the $396 X$. fastidiosa subsp. multiplex -infected French plant samples used in this study and their VNTR allelic profile.

"13 pairs of isolated strains and the DNA extracted from the same original plant sample, + the 16 samples for which DAPC clustering differed over the 20 runs, ₹ the samples collected by the DGAL in the framework of the national official surveillance strategy.

\begin{tabular}{|c|c|c|c|c|c|c|c|c|c|c|c|c|c|c|c|c|c|c|c|c|c|}
\hline \multirow{2}{*}{ Sample code } & \multirow{2}{*}{ ST } & \multirow{2}{*}{ Host plant } & \multirow{2}{*}{ Place of sampling } & \multirow{2}{*}{$\begin{array}{l}\text { Year of } \\
\text { isolation }\end{array}$} & \multirow{2}{*}{$\begin{array}{l}\text { Ct with } \\
\text { Harper's } \\
\text { qPCR } \\
\text { test }\end{array}$} & & & & & & & FSSR allelic $p$ & profile & & & & & & Haplotype & $\begin{array}{l}\text { Cluster } \\
\text { Number }\end{array}$ & $A B C$ groups \\
\hline & & & & & & ASSR-11 & ASSR-16 & coss -1 & OSSR-19 & GSSR-7 & OSSR-16 & XFSSR-37 & XFSSR-58 & ASSR-9 & ASSR-12 & ASSR-19 & GSSR-4 & XFSSR-40 & & for $k=4$ & \\
\hline 2015_1053.7¥ & ST6 & Polygala myrtifolia & Corsica, Albitreccia & 2015 & 26.49 & 12 & 29 & 9 & 11 & 23 & 7 & 3 & 8 & 11 & 13 & 9 & 17 & 10 & 316 & 1 & ST6_C1P1 \\
\hline 2015_1067.1‡ & ST6 & Polygala myrtifolia & Corsica, Ajaccio & 2015 & 25.58 & 12 & 29 & 9 & 11 & 22 & 7 & 3 & 8 & 11 & 13 & 9 & 17 & 10 & 309 & 1 & ST6_C1P1 \\
\hline 2015_1188.11‡ & ST6 & Polygala myrtifolia & Corsica, Calvi & 2015 & 26.34 & 10 & 29 & 9 & 11 & 22 & 7 & 3 & 8 & 10 & 13 & 9 & 17 & 10 & 284 & 1 & ST6_C1P1 \\
\hline 2015_1268.12 & $\mathrm{cysG}_{2} 7$ & Polygala myrtifolia & Corsica, Sainte Lucie de Tallano & 2015 & 26.86 & 7 & 24 & 7 & 7 & 14 & 22 & 7 & 4 & 15 & 8 & 11 & 9 & 8 & 138 & 3 & ST7_C1P1 \\
\hline 2015_1268.9¥ & ST7 & Polygala myrtifolia & Corsica, Fozzano & 2015 & 23.35 & 7 & 24 & 7 & 7 & 14 & 22 & 7 & 4 & 15 & 8 & 11 & 9 & 8 & 138 & 3 & ST7_C1P1 \\
\hline 2015_1273.1‡ & ST6 & Spartium junceum & Corsica, Alata & 2015 & 24.81 & 12 & 29 & 9 & 11 & 21 & 7 & 3 & 8 & 11 & 13 & 9 & 17 & 11 & 304 & 1 & ST6_C1P1 \\
\hline 2015_1298.1‡ & cysG_3 & Polygala myrtifolia & Corsica, Appietto & 2015 & 25.25 & 12 & 29 & 9 & 11 & 14 & 7 & 3 & 8 & 11 & 13 & 9 & 17 & 10 & 294 & 1 & ST6_C1P1 \\
\hline 2015_1298.6‡ & ST6 & Polygala myrtifolia & Corsica, Calcatoggio & 2015 & 21.40 & 13 & 29 & 9 & 11 & 21 & 7 & 3 & 5 & 11 & 13 & 10 & 17 & 6 & 222 & 1 & ST6_C1P1 \\
\hline 2015_1298.7¥ & cysG_3 & Polygala myrtifolia & Corsica, Bastelicaccia & 2015 & 24.61 & 12 & 29 & 10 & 11 & 21 & 7 & 3 & 4 & 11 & 13 & 9 & 17 & 10 & 6 & 1 & ST6_C1P1 \\
\hline 2015_1344.1‡ & ST6 & Hebe sp. & Corsica, Pietrosella & 2015 & 30.07 & 10 & 29 & 8 & 11 & 22 & 7 & 3 & 8 & 10 & 13 & 9 & 17 & 10 & 211 & 1 & ST6_C1P1 \\
\hline 2015_1350.1干 & ST7 & Genista X spachiana & Corsica, Coti-Chiavari & 2015 & 25.25 & 7 & 24 & 7 & 7 & 14 & 22 & 7 & 4 & 15 & 8 & 11 & 9 & 8 & 138 & 3 & ST7_C1P1 \\
\hline $2015 \_1381.1 \neq$ & ST6 & Polygala myrtifolia & Corsica, Pietrosella & 2015 & 21.63 & 12 & 29 & 9 & 11 & 22 & 7 & 3 & 7 & 11 & 13 & 9 & 17 & 10 & 292 & 1 & ST6_C1P1 \\
\hline 2015_1396.1干 & ST6 & Polygala myrtifolia & Corsica, Ajaccio & 2015 & 23.22 & 12 & 29 & 10 & 11 & 22 & 7 & 3 & 8 & 11 & 13 & 9 & 17 & 10 & 9 & 1 & ST6_C1P1 \\
\hline $2015 \_1396.10 \ddagger$ & $\mathrm{cysG}_{2} 7$ & Polygala myrtifolia & Corsica, Sartene & 2015 & 26.98 & 7 & 24 & 7 & 7 & 15 & 22 & 7 & 4 & 15 & 8 & 11 & 9 & 8 & 158 & 3 & ST7_C1P1 \\
\hline 2015_1396.2‡ & ST7 & Polygala myrtifolia & Corsica, Propriano & 2015 & 24.37 & 7 & 24 & 7 & 7 & 14 & 22 & 7 & 4 & 15 & 8 & 11 & 9 & 8 & 138 & 3 & ST7_C1P1 \\
\hline $2015 \_1396.5 \neq$ & ST7 & Polygala myrtifolia & Corsica, Propriano & 2015 & 24.18 & 7 & 24 & 7 & 7 & 14 & 20 & 7 & 4 & 15 & 8 & 12 & 9 & 8 & 130 & 3 & ST7_C1P1 \\
\hline 2015_1396.8‡ & ST6 & Polygala myrtifolia & Corsica, Ajaccio & 2015 & 23.11 & 12 & 29 & 5 & 11 & 24 & 7 & 3 & 8 & 7 & 14 & 9 & 17 & 9 & 46 & 1 & ST6_C1P1 \\
\hline 2015_1489.12¥ & cysG_3 & Polygala myrtifolia & Corsica, Lecci & 2015 & 26.99 & 10 & 29 & 7 & 11 & 21 & 7 & 3 & 8 & 11 & 13 & 8 & 17 & 10 & 96 & 2 & ST6_C2 \\
\hline 2015_1527.1‡ & ST7 & Polygala myrtifolia & Corsica, Propriano & 2015 & 25.14 & 7 & 24 & 7 & 7 & 14 & 23 & 3 & 4 & 15 & 8 & 11 & 9 & 8 & 108 & 3 & ST7_C1P1 \\
\hline 2015_1581.2‡ & ST6 & Polygala myrtifolia & Corsica, Appietto & 2015 & 28.27 & 12 & 29 & 9 & 11 & 21 & 7 & 3 & 8 & 11 & 13 & 9 & 17 & 11 & 304 & 1 & ST6_C1P1 \\
\hline $2015 \_1581.5$ † & cysG_3 & Polygala myrtifolia & Corsica, Villanova & 2015 & 27.51 & 12 & 29 & 9 & 11 & 21 & 7 & 3 & 8 & 10 & 13 & 9 & 17 & 10 & 302 & 1 & ST6_C1P1 \\
\hline 2015_1581.7‡ & cysG_3 & Polygala myrtifolia & Corsica, Casaglione & 2015 & 25.85 & 11 & 29 & 10 & 11 & 24 & 7 & 3 & 8 & 12 & 13 & 9 & 17 & 11 & 3 & 1 & ST6_C1P1 \\
\hline 2015_1627.2‡ & cysG_3 & Polygala myrtifolia & Corsica, Zonza & 2015 & 30.94 & 10 & 29 & 7 & 11 & 22 & 7 & 3 & 8 & 11 & 12 & 8 & 17 & 10 & 97 & 2 & ST6_C2 \\
\hline 2015_1627.3‡ & cysG_3 & Polygala myrtifolia & Corsica, Zonza & 2015 & 30.15 & 10 & 29 & 8 & 10 & 22 & 7 & 3 & 8 & 11 & 12 & 8 & 17 & 7 & 201 & 2 & ST6_C2 \\
\hline 2015_1627.6‡ & ST6 & Polygala myrtifolia & Corsica, Zonza & 2015 & 26.62 & 10 & 29 & 10 & 10 & 20 & 7 & 3 & 8 & 11 & 12 & 8 & 17 & 10 & 1 & 2 & ST6_C2 \\
\hline $2015 \_1659.34 \ddagger$ & ST6 & Polygala myrtifolia & Corsica, Calvi & 2015 & 25.73 & 10 & 29 & 9 & 11 & 22 & 7 & 3 & 8 & 10 & 13 & 9 & 17 & 10 & 284 & 1 & ST6_C1P1 \\
\hline 2015_1659.6‡ & ST6 & Polygala myrtifolia & Corsica, Calvi & 2015 & 26.13 & 10 & 29 & 9 & 11 & 22 & 7 & 3 & 8 & 10 & 13 & 9 & 17 & 10 & 284 & 1 & ST6_C1P1 \\
\hline $2015 \_1659.61 \neq$ & ST6 & Polygala myrtifolia & Corsica, Calvi & 2015 & 24.41 & 10 & 29 & 9 & 11 & 22 & 7 & 3 & 8 & 10 & 13 & 9 & 17 & 10 & 284 & 1 & ST6_C1P1 \\
\hline 2015_1659.65‡ & ST6 & Polygala myrtifolia & Corsica, Calvi & 2015 & 22.13 & 10 & 29 & 9 & 11 & 22 & 7 & 3 & 8 & 10 & 13 & 9 & 17 & 10 & 284 & 1 & ST6_C1P1 \\
\hline $2015 \_1725.3 \neq$ & ST7 & Polygala myrtifolia & Corsica, Porto-Vecchio & 2015 & 25.01 & 7 & 24 & 7 & 7 & 16 & 21 & 7 & 4 & 15 & 8 & 11 & 9 & 7 & 167 & 3 & ST7_C1P1 \\
\hline $2015 \_1732.1 \neq$ & ST7 & Polygala myrtifolia & Corsica, Bastelicaccia & 2015 & 26.22 & 7 & 24 & 6 & 7 & 17 & 7 & 7 & 4 & 14 & 8 & 9 & 9 & 8 & 63 & 4 & ST7_C2 \\
\hline 2015_1754.3‡ & ST7 & Polygala myrtifolia & Corsica, Porto-Vecchio & 2015 & 24.00 & 7 & 24 & 7 & 7 & 10 & 21 & 7 & 4 & 15 & 7 & 11 & 9 & 8 & 111 & 3 & ST7_C1P1 \\
\hline $2015 \_1782.5 \neq$ & ST6 & Polygala myrtifolia & Corsica, Zonza & 2015 & 23.38 & 10 & 29 & 7 & 10 & 20 & 7 & 3 & 9 & 11 & 12 & 8 & 17 & 11 & 91 & 2 & ST6_C2 \\
\hline 2015_1809.1‡ & ST7 & Polygala myrtifolia & Corsica, Figari & 2015 & 28.36 & 10 & 24 & 7 & 7 & 15 & 22 & 7 & 4 & 10 & 8 & 13 & 9 & 8 & 103 & 3 & ST7_C1P1 \\
\hline 2015_1809.3¥ & ST7 & Polygala myrtifolia & Corsica, Pianottoli Caldarello & 2015 & 25.39 & 7 & 24 & 7 & 7 & 14 & 22 & 7 & 4 & 15 & 8 & 11 & 9 & 8 & 138 & 3 & ST7_C1P1 \\
\hline 2015_1829.3‡ & ST6 & Polygala myrtifolia & Corsica, Calvi & 2015 & 24.94 & 10 & 29 & 9 & 11 & 21 & 7 & 3 & 8 & 10 & 13 & 9 & 17 & 10 & 283 & 1 & ST6_C1P1 \\
\hline $2015 \_1850.2 \ddagger$ & ST6 & Polygala myrtifolia & Corsica, Porto-Vecchio & 2015 & 28.28 & 10 & 29 & 8 & 11 & 21 & 7 & 3 & 4 & 10 & 12 & 8 & 17 & 10 & 210 & 2 & ST6_C2 \\
\hline 2015_1861.1‡ & ST6 & Polygala myrtifolia & Corsica, Ajaccio & 2015 & 26.05 & 12 & 30 & 9 & 11 & 22 & 7 & 3 & 8 & 11 & 13 & 10 & 17 & 10 & 235 & 1 & ST6_C1P1 \\
\hline 2015_1861.11‡ & ST7 & Polygala myrtifolia & Corsica, Bastelicaccia & 2015 & 24.89 & 7 & 24 & 6 & 7 & 19 & 17 & 7 & 4 & 13 & 8 & 12 & 9 & 8 & 64 & 4 & ST7_C2 \\
\hline $2015 \_1861.2 \neq$ & ST6 & Polygala myrtifolia & Corsica, Ajaccio & 2015 & 26.95 & 12 & 29 & 9 & 11 & 19 & 7 & 3 & 8 & 10 & 13 & 9 & 19 & 10 & 296 & 1 & ST6_C1P1 \\
\hline 2015_1861.4‡ & ST6 & Polygala myrtifolia & Corsica, Ajaccio & 2015 & 26.00 & 12 & 29 & 8 & 11 & 23 & 7 & 3 & 8 & 10 & 13 & 9 & 17 & 11 & 226 & 1 & ST6_C1P1 \\
\hline 2015_1922.1‡ & ST6 & Polygala myrtifolia & Corsica, Zonza & 2015 & 26.81 & 10 & 29 & 7 & 10 & 18 & 7 & 3 & 8 & 10 & 12 & 8 & 17 & 10 & 84 & 2 & ST6_C2 \\
\hline 2015_1925.5‡ & ST6 & Polygala myrtifolia & Corsica, Afa & 2015 & 25.61 & 12 & 29 & 10 & 11 & 22 & 7 & 3 & 8 & 11 & 13 & 9 & 17 & 10 & 9 & 1 & ST6_C1P1 \\
\hline $2015 \_1925.6 \neq$ & ST6 & Polygala myrtifolia & Corsica, Cuttoli-Corticchiato & 2015 & 28.33 & 12 & 29 & 9 & 11 & 21 & 7 & 3 & 8 & 10 & 13 & 9 & 15 & 10 & 301 & 1 & ST6_C1P1 \\
\hline 2015_1939.1‡ & ST6 & Polygala myrtifolia & Corsica, Vero & 2015 & 24.56 & 12 & 29 & 9 & 11 & 23 & 7 & 3 & 8 & 11 & 12 & 9 & 17 & 10 & 315 & 1 & ST6_C1P1 \\
\hline 2015_1939.2‡ & ST6 & Polygala myrtifolia & Corsica, Peri & 2015 & 24.70 & 12 & 29 & 9 & 11 & 22 & 7 & 3 & 8 & 11 & 13 & 9 & 17 & 10 & 309 & 1 & ST6_C1P1 \\
\hline 2015_1980.1‡ & ST7 & Polygala myrtifolia & Corsica, Serra Di Ferro & 2015 & 23.17 & 7 & 24 & 8 & 7 & 14 & 22 & 7 & 4 & 14 & 8 & 11 & 9 & 7 & 254 & 3 & ST7_C1P1 \\
\hline 2015_1980.2‡ & ST7 & Polygala myrtifolia & Corsica, Viggianello & 2015 & 24.57 & 7 & 24 & 6 & 7 & 14 & 22 & 7 & 4 & 16 & 8 & 11 & 9 & 8 & 56 & 3 & ST7_C1P1 \\
\hline 2015_1980.4‡ & ST7 & Polygala myrtifolia & Corsica, Porto-Vecchio & 2015 & 23.40 & 7 & 24 & 7 & 7 & 13 & 23 & 7 & 4 & 17 & 8 & 11 & 9 & 11 & 121 & 3 & ST7_C1P1 \\
\hline 2015_2107.3‡ & cysG_7 & Quercus suber & Corsica, Grosseto-Prugna & 2015 & 27.62 & 7 & 24 & 7 & 7 & 13 & 22 & 7 & 4 & 15 & 8 & 12 & 9 & 8 & 120 & 3 & ST7_C1P1 \\
\hline 2015_2141.3‡ & ST6 & Polygala myrtifolia & Corsica, Grosseto-Prugna & 2015 & 30.09 & 12 & 29 & 9 & 11 & 23 & 8 & 3 & 8 & 12 & 13 & 9 & 17 & 7 & 319 & 1 & ST6_C1P1 \\
\hline 2015_2141.4¥ & ST6 & Polygala myrtifolia & Corsica, Grosseto-Prugna & 2015 & 28.90 & 9 & 29 & 9 & 11 & 20 & 8 & 3 & 8 & 10 & 13 & 9 & 17 & 10 & 101 & 1 & ST6_C1P1 \\
\hline 2015_2141.9‡ & cysG_7 & Polygala myrtifolia & Corsica, Olmeto & 2015 & 26.85 & 7 & 24 & 7 & 7 & 14 & 22 & 8 & 4 & 16 & 8 & 11 & 9 & 8 & 181 & 3 & ST7_C1P1 \\
\hline $2015 \_2151.5 \ddagger$ & ST6 & Polygala grandiffora nana & Corsica, Bastelicaccia & 2015 & 28.60 & 12 & 29 & 9 & 11 & 21 & 8 & 3 & 8 & 11 & 13 & 9 & 17 & 10 & 307 & 1 & ST6_C1P1 \\
\hline $2015 \_2155.1 \neq$ & ST6 & Polygala sp. & PACA, Nice & 2015 & 31.61 & 11 & 29 & 8 & 13 & 17 & 7 & 3 & 8 & 11 & 12 & 8 & 17 & 9 & 238 & 2 & ST6_P2 \\
\hline $2015 \_2155.2 \neq$ & ST6 & Polygala sp. & PACA, Nice & 2015 & 18.93 & 11 & 29 & 8 & 13 & 17 & 7 & 3 & 8 & 11 & 12 & 8 & 17 & 9 & 238 & 2 & ST6_P2 \\
\hline 2015_2155.4/CFBP 13620*末 & ST6 & Polygala sp. & PACA, Nice & 2015 & 19.08 & 11 & 29 & 8 & 13 & 17 & 7 & 3 & 8 & 11 & 12 & 8 & 17 & 9 & 238 & 2 & ST6_P2 \\
\hline $2015 \_2155.5 \neq$ & ST6 & Polygala sp. & PACA, Nice & 2015 & 29.94 & 11 & 29 & 9 & 12 & 25 & 7 & 3 & 8 & 12 & 7 & 8 & 17 & 11 & 95 & 2 & ST6_P2 \\
\hline $2015 \_2166.2 \neq$ & cysG_7 & Polygala myrtifolia & Corsica, Olmeto & 2015 & 25.66 & 7 & 24 & 8 & 7 & 14 & 22 & 8 & 4 & 15 & 8 & 11 & 9 & 8 & 275 & 3 & ST7_C1P1 \\
\hline $2015 \_2171.2 \neq$ & ST6 & Polygala myrtifolia & Corsica, Ajaccio & 2015 & 26.73 & 12 & 29 & 10 & 11 & 22 & 7 & 3 & 8 & 11 & 13 & 9 & 17 & 11 & 10 & 1 & ST6_C1P1 \\
\hline 2015_2192.9¥ & ST7 & Polygala myrtifolia & Corsica, Lecci & 2015 & 27.85 & 7 & 24 & 8 & 7 & 14 & 22 & 7 & 4 & 15 & 8 & 12 & 9 & 8 & 256 & 3 & ST7_C1P1 \\
\hline 2015_2272.3¥ & ST7 & Polygala myrtifolia & Corsica, Santa Ma & 2015 & 27.77 & 7 & 24 & 7 & 7 & 16 & 20 & 7 & 4 & 16 & 8 & 11 & 9 & 8 & 166 & 3 & ST7_C1P1 \\
\hline 2015_2298.3¥ & ST7 & Polygala sp. & PACA, Saint Laurent du Var & 2015 & 26.10 & 7 & 24 & 12 & 7 & 17 & 25 & 7 & 4 & 12 & 8 & 12 & 9 & 9 & 38 & 4 & ST7_P2 \\
\hline
\end{tabular}


PACA, Saint Laurent du

Corsica, Bastelicaccia

Corsicica, Sast Gavino Di Carbini
Conclia Corsica, Sollacaro

Corsica, Sollacaro
Corsica, Sollacaro

Corsica, Viggianello

Corsica, Viggianello

Corsica, San Gavino Di Carbini Corsica, Calvi

PACA, Saint Laurent du Var

PACA, Saint Laurent du Var

PACA, Saint Laurent du Var

PACA, Saint Laurent du V

PACA, La Seyna-sur-Mer

Corsica, Appietto

Corsica, Calvi

Corsica, Belvedere-Campomoro

Corsica, Zonza

Corsica, Viggianello
Corsica, Coti-Chiavari

Corsica, Coti-Chi
Corsica, Lecci

Corsica, Furiani

Corsica, Cargese

Corsica, Arro

Cont Andrea d'Orcino

Corsica, Coggia
Corsica, Sartene

Corsica, Monacia d'Aullene

Corsica, Sainte Lucie de Tallano

Corsica, Propriano

Corsica, Belvedere-Campomoro

Corsica, Zonza

Corsica, Proprian

Corsica, Alata

Compomoro

-Prugna

Corsica, Alata
Corsica, Peri

Corsica, Sartene

Corsicica, Serra Di Ferro
Cortene

Corsica, Serra Di Ferro

Corsica, Cauro

Corsica, Cauro
Corsica, Cargese

Corsica, Alata

Corsica, Ajaccio

Corsica, Ajaccio

Corsica, Ajaccio
Corsica, Ajaccio

\begin{tabular}{|c|c|}
\hline 2015 & 25.00 \\
\hline 2015 & 23.58 \\
\hline 2015 & 26.26 \\
\hline 2015 & 29.57 \\
\hline 2015 & 28.27 \\
\hline 2015 & 24.09 \\
\hline 2015 & 22.16 \\
\hline 2015 & 23.85 \\
\hline 2015 & 29.78 \\
\hline 2015 & 26.74 \\
\hline 2015 & 24.44 \\
\hline 2015 & 25.12 \\
\hline 2015 & 20.02 \\
\hline 2015 & 24.50 \\
\hline 2015 & 25.08 \\
\hline 2015 & 23.61 \\
\hline 2015 & 24.49 \\
\hline 2015 & 24.22 \\
\hline 2015 & 25.41 \\
\hline 2015 & 27.37 \\
\hline 2015 & 25.76 \\
\hline 2015 & 24.94 \\
\hline 2015 & 25.38 \\
\hline 2015 & 26.04 \\
\hline 2015 & 23.45 \\
\hline 2015 & 24.09 \\
\hline 2015 & 23.58 \\
\hline 2015 & 27.71 \\
\hline 2015 & 22.43 \\
\hline 2015 & 21.81 \\
\hline 2015 & 23.53 \\
\hline 2015 & 20.65 \\
\hline 2015 & 22.54 \\
\hline 2015 & 30.81 \\
\hline 2015 & 30.30 \\
\hline 2015 & 25.32 \\
\hline 2015 & 26.75 \\
\hline 2015 & 27.68 \\
\hline 2015 & 29.86 \\
\hline 2015 & 26.83 \\
\hline 2015 & 25.30 \\
\hline 2015 & 31.97 \\
\hline 2015 & 28.83 \\
\hline 2015 & 25.76 \\
\hline 2015 & 27.68 \\
\hline 2015 & 27.54 \\
\hline 2015 & 30.94 \\
\hline 2015 & 25.73 \\
\hline 2015 & 23.98 \\
\hline 2015 & 28.01 \\
\hline 2015 & 20.26 \\
\hline 2015 & 26.96 \\
\hline 2015 & 26.05 \\
\hline 2015 & 26.67 \\
\hline 2015 & 24.86 \\
\hline 2015 & 25.88 \\
\hline 2015 & 22.15 \\
\hline 2015 & 22.43 \\
\hline 2015 & 22.48 \\
\hline 2015 & 21.79 \\
\hline 2015 & 20.19 \\
\hline 2015 & 22.59 \\
\hline 2015 & 23.75 \\
\hline 2015 & 22.93 \\
\hline 2015 & 24.64 \\
\hline 2015 & 25.80 \\
\hline 2015 & 25.89 \\
\hline 2015 & 24.55 \\
\hline 2015 & 22.58 \\
\hline 2015 & \\
\hline 2015 & 21.12 \\
\hline
\end{tabular}




\begin{tabular}{|c|c|c|c|c|c|c|c|c|c|c|c|c|c|c|c|c|c|c|c|c|c|}
\hline 2015_791.5‡ & ST6 & Polygala myrtifolia & Corsica, Ajaccio & 2015 & 26.39 & 12 & 29 & 8 & 11 & 22 & 7 & 3 & 8 & 10 & 13 & 9 & 17 & 10 & 220 & 1 & ST6_C1P1 \\
\hline 2015_791.8‡ & ST6 & Polygala myrtifolia & Corsica, Ajaccio & 2015 & 22.87 & 7 & 29 & 9 & 11 & 20 & 7 & 3 & 8 & 10 & 12 & 9 & 17 & 10 & 199 & 1 & ST6_C1P1 \\
\hline $2015 \_826.11 \neq$ & ST6 & Polygala myrtifolia & Corsica, Zonza & 2015 & 25.86 & 10 & 29 & 7 & 10 & 19 & 7 & 3 & 8 & 11 & 12 & 8 & 17 & 10 & 85 & 2 & ST6_C2 \\
\hline 2015_826.18 = & ST6 & Polygala myrtifolia & Corsica, Zonza & 2015 & 23.04 & 10 & 29 & 7 & 10 & 19 & 7 & 3 & 9 & 11 & 14 & 8 & 17 & 10 & 89 & 2 & ST6_C2 \\
\hline $2015 \_826.2 \mp$ & ST7 & Polygala myrtifolia & Corsica, Propriano & 2015 & 26.23 & 7 & 24 & 7 & 7 & 14 & 22 & 7 & 4 & 15 & 8 & 11 & 9 & 8 & 138 & 3 & ST7_C1P1 \\
\hline 2015_826.4¥ & ST7 & Polygala myrtifolia & Corsica, Propriano & 2015 & 25.30 & 7 & 24 & 7 & 7 & 14 & 22 & 7 & 4 & 13 & 8 & 11 & 9 & 8 & 136 & 3 & ST7_C1P1 \\
\hline 2015_834.13‡ & ST6 & Polygala myrtifolia & Corsica, Zonza & 2015 & 25.41 & 10 & 29 & 7 & 10 & 19 & 7 & 3 & 8 & 12 & 12 & 8 & 21 & 8 & 86 & 2 & ST6_C2 \\
\hline $2015 \_834.14 \neq$ & ST6 & Polygala myrtifolia & Corsica, Zonza & 2015 & 24.15 & 10 & 29 & 7 & 10 & 20 & 7 & 3 & 4 & 12 & 12 & 8 & 17 & 5 & 83 & 2 & ST6_C2 \\
\hline $2015 \_834.7 \neq$ & ST6 & Polygala myrtifolia & Corsica, Zonza & 2015 & 24.45 & 10 & 29 & 7 & 10 & 20 & 7 & 3 & 8 & 12 & 12 & 8 & 17 & 10 & 87 & 2 & ST6_C2 \\
\hline 2015_912.3‡ & ST6 & Polygala myrtifolia & Corsica, Alata & 2015 & 26.86 & 12 & 27 & 9 & 11 & 22 & 7 & 3 & 8 & 10 & 13 & 9 & 17 & 10 & 289 & 1 & ST6_C1P1 \\
\hline 2015_917.1‡ & ST6 & Spartium junceum & Corsica, Alata & 2015 & 18.08 & 12 & 29 & 9 & 11 & 22 & 7 & 3 & 8 & 11 & 13 & 9 & 18 & 11 & 312 & 1 & ST6_C1P1 \\
\hline $2015 \_942.2 \mp$ & ST7 & Polygala myrtifolia & Corsica, Propriano & 2015 & 19.92 & 7 & 24 & 7 & 7 & 16 & 16 & 7 & 4 & 15 & 8 & 12 & 9 & 8 & 164 & 3 & ST7_C1P1 \\
\hline $2015 \_961.2 \neq$ & ST7 & Polygala myrtifolia & Corsica, Serra Di Ferro & 2015 & 26.83 & 9 & 24 & 7 & 7 & 14 & 22 & 7 & 4 & 15 & 8 & 11 & 9 & 8 & 193 & 3 & ST7_C1P1 \\
\hline 2015_961.4‡ & ST7 & Polygala myrtifolia & Corsica, Serra Di Ferro & 2015 & 22.95 & 7 & 24 & 7 & 7 & 15 & 22 & 7 & 4 & 14 & 8 & 11 & 9 & 8 & 157 & 3 & ST7_C1P1 \\
\hline 2015_969.1F & ST6 & Polygala myrtifolia & $\begin{array}{l}\text { Corsica, Ajaccio } \\
\text { litis }\end{array}$ & 2015 & 25.03 & 12 & 29 & 9 & 11 & 20 & 7 & 3 & 8 & 11 & 13 & 9 & 17 & 10 & 299 & 1 & ST6_C1P1 \\
\hline 2015_969.3¥ & ST6 & Polygala myrtifolia & Corsica, Cargese & 2015 & 27.47 & 12 & 29 & 9 & 11 & 24 & 7 & 3 & 8 & 11 & 13 & 9 & 17 & 11 & 248 & 1 & ST6_C1P1 \\
\hline 2015_969.4‡ & ST6 & Polygala myrtifolia & Corsica, Ota & 2015 & 25.16 & 12 & 29 & 8 & 11 & 20 & 7 & 3 & 8 & 10 & 13 & 8 & 17 & 10 & 214 & 1 & ST6_C1P1 \\
\hline $2015 \_969.6 \neq$ & ST6 & Polygala myrtifolia & Corsica, Sarrola Carcopino & 2015 & 27.66 & 12 & 29 & 9 & 11 & 24 & 7 & 3 & 8 & 11 & 13 & 9 & 17 & 10 & 320 & 1 & ST6_C1P1 \\
\hline 2015_973.3‡ & ST6 & Polygala myrtifolia & Corsica, Grosseto-Prugna & 2015 & 25.74 & 12 & 29 & 10 & 11 & 10 & 7 & 3 & 8 & 11 & 11 & 9 & 17 & 10 & 7 & 1 & ST6_C1P1 \\
\hline $2015 \_973.7 \neq$ & ST7 & Polygala myrtifolia & Corsica, Propriano & 2015 & 25.50 & 7 & 24 & 7 & 7 & 13 & 22 & 7 & 4 & 15 & 8 & 11 & 9 & 8 & 119 & 3 & ST7 C1P1 \\
\hline $2015 \_981.10 \ddagger$ & ST7 & Polygala myrtifolia & Corsica, Porto-Vecchio & 2015 & 25.04 & 7 & 24 & 7 & 7 & 14 & 22 & 7 & 4 & 15 & 8 & 11 & 9 & 8 & 138 & 3 & ST7_C1P1 \\
\hline 2015_981.15 & ST7 & Polygala myrtifolia & Corsica, Eccica-Suarella & 2015 & 22.34 & 7 & 24 & 7 & 7 & 14 & 21 & 7 & 4 & 15 & 8 & 10 & 9 & 8 & 133 & 3 & ST7_C1P1 \\
\hline 2015_981.16‡ & ST6 & Polygala myrtifolia & $\begin{array}{l}\text { Corsica, Ajaccio } \\
\text { Pall }\end{array}$ & 2015 & 24.47 & 12 & 29 & 8 & 11 & 22 & 7 & 3 & 8 & 10 & 13 & 9 & 17 & 10 & 220 & 1 & ST6_C1P1 \\
\hline $2015 \_981.17 \neq$ & ST7 & Polygala myrtifolia & Corsica, Pietrosella & 2015 & 23.43 & 7 & 24 & 7 & 7 & 14 & 21 & 7 & 4 & 15 & 8 & 10 & 9 & 8 & 133 & 3 & ST7_C1P1 \\
\hline 2015_981.20 & ST7 & Polygala myrtifolia & Corsica, Albitreccia & 2015 & 24.08 & 8 & 24 & 7 & 7 & 14 & 22 & 7 & 4 & 15 & 8 & 11 & 9 & 8 & 191 & 3 & ST7_C1P1 \\
\hline 2015_981.21‡ & ST7 & Polygala myrtifolia & Corsica, Coti-Chiavari & 2015 & 23.40 & 7 & 24 & 7 & 7 & 13 & 22 & 7 & 4 & 15 & 8 & 11 & 9 & 8 & 119 & 3 & ST7_C1P1 \\
\hline $2015 \_981.22 \neq$ & ST7 & Polygala myrtifolia & Corsica, Cauro & 2015 & 23.35 & 7 & 24 & 7 & 7 & 13 & 22 & 7 & 4 & 15 & 8 & 11 & 9 & 8 & 119 & 3 & ST7_C1P1 \\
\hline $2015981.24 \ddagger$ & ST6 & Polygala myrtifolia & Corsica, Pietrosella & 2015 & 25.55 & 12 & 29 & 9 & 11 & 22 & 7 & 3 & 4 & 11 & 13 & 9 & 17 & 10 & 291 & 1 & ST6 C1P1 \\
\hline 2015_981.25" & ST6 & Polygala myrtifolia & Corsica, Pietrosella & 2015 & 23.99 & 12 & 29 & 9 & 11 & 16 & 7 & 3 & 9 & 12 & 13 & 9 & 17 & 10 & 246 & 1 & ST6_C1P1 \\
\hline 2015_981.4¥ & ST7 & Polygala myrtifolia & Corsica, Grossa & 2015 & 26.14 & 7 & 24 & 7 & 7 & 13 & 22 & 7 & 4 & 15 & 8 & 11 & 9 & 8 & 119 & 3 & ST7_C1P1 \\
\hline $2015 \_981.6 \neq$ & ST7 & Polygala myrtifolia & Corsica, Grossa & 2015 & 24.05 & 7 & 24 & 7 & 7 & 15 & 23 & 7 & 4 & 16 & 8 & 11 & 9 & 8 & 162 & 3 & ST7_C1P1 \\
\hline 2015_981.9 & ST7 & Polygala myrtifolia & Corsica, Porto-Vecchio & 2015 & 26.20 & 7 & 24 & 7 & 7 & 14 & 19 & 7 & 4 & 15 & 8 & 11 & 9 & 8 & 127 & 3 & ST7_C1P1 \\
\hline $2016 \_110.1 \neq$ & ST7 & Polygala myrtifolia & Corsica, Monacia d'Aullene & 2016 & 31.05 & 7 & 24 & 6 & 7 & 14 & 23 & 7 & 4 & 9 & 8 & 10 & 9 & 8 & 58 & 4 & ST7_C2 \\
\hline 2016 110.2‡ & ST7 & Polygala myrtifolia & Corsica, Monacia d'Aullene & 2016 & 30.14 & 7 & 24 & 6 & 7 & 14 & 23 & 7 & 4 & 9 & 8 & 10 & 9 & 8 & 58 & 4 & ST7_C2 \\
\hline $2016 \_110.3 \neq$ & ST7 & Polygala myrtifolia & Corsica, Monacia d'Aullene & 2016 & 27.71 & 7 & 24 & 6 & 7 & 14 & 23 & 7 & 4 & 9 & 8 & 10 & 9 & 6 & 57 & 4 & ST7_C2 \\
\hline 2016_110.4‡ & ST7 & Polygala myrtifolia & Corsica, Monacia d'Aullene & 2016 & 28.62 & 7 & 24 & 6 & 7 & 14 & 23 & 7 & 4 & 9 & 8 & 10 & 9 & 8 & 58 & 4 & ST7_C2 \\
\hline 2016_135.1 & ST6 & Polygala myrtifolia & Corsica, Ajaccio & 2016 & 25.20 & 12 & 29 & 8 & 11 & 22 & 7 & 3 & 8 & 10 & 13 & 9 & 17 & 8 & 221 & 1 & ST6_C1P1 \\
\hline $2016 \_138.1 \neq$ & ST6 & Calicotome villosa & Corsica, Ajaccio & 2016 & 24.38 & 12 & 29 & 6 & 8 & 22 & 7 & 3 & 8 & 11 & 13 & 9 & 17 & 10 & 81 & 1 & ST6_C1P1 \\
\hline $2016 \_145.2 \neq$ & ST6 & Polygala myrtiffolia & Corsica, Cauro & 2016 & 24.73 & 12 & 29 & 9 & 11 & 22 & 7 & 3 & 9 & 11 & 13 & 9 & 17 & 10 & 245 & 1 & ST6_C1P1 \\
\hline $2016 \_145.3 \neq$ & ST6 & Polygala myrtifolia & Corsica, Cauro & 2016 & 24.50 & 12 & 29 & 9 & 11 & 21 & 7 & 3 & 8 & 12 & 13 & 9 & 17 & 10 & 306 & 1 & ST6_C1P1 \\
\hline $2016 \_169.1 \neq$ & ST6 & Calicotome villosa & Corsica, Ajaccio & 2016 & 24.55 & 12 & 29 & 9 & 11 & 19 & 7 & 3 & 8 & 11 & 13 & 9 & 17 & 10 & 298 & 1 & ST6_C1P1 \\
\hline 2016_173.1F & ST7 & Calicotome villosa & Corsica, Pietrosella & 2016 & 24.60 & 7 & 24 & 7 & 7 & 11 & 21 & 7 & 4 & 15 & 8 & 11 & 9 & 8 & 113 & 3 & ST7_C1P1 \\
\hline $2016 \_185.1 \mp$ & ST7 & Helichrysum italicum & Corsica, Fozzano & 2016 & 23.33 & 7 & 24 & 7 & 7 & 14 & 20 & 7 & 4 & 15 & 8 & 11 & 9 & 8 & 128 & 3 & ST7_C1P1 \\
\hline 2016_202.3= & ST7 & Calicotome villosa & Corsica, Coti-Chiavari & 2016 & 28.50 & 7 & 24 & 7 & 7 & 16 & 23 & 7 & 4 & 15 & 8 & 11 & 9 & 8 & 170 & 3 & ST7_C1P1 \\
\hline 2016_223.1‡ & ST7 & Genista corsica & Corsica, Serra Di Ferro & 2016 & 23.02 & 6 & 24 & 8 & 7 & 14 & 22 & 7 & 4 & 15 & 8 & 11 & 9 & 7 & 250 & 3 & ST7_C1P1 \\
\hline 2016_224.1‡ & ST6 & Polygala myrtifolia & Corsica, Biguglia & 2016 & 26.01 & 12 & 29 & 10 & 12 & 28 & 7 & 3 & 8 & 11 & 13 & 9 & 17 & 10 & 16 & 1 & ST6_C1P1 \\
\hline 2016_24.1‡ & cysG_3 & Pelargonium sp. & Corsica, Coti-Chiavari & 2016 & 31.32 & 12 & 29 & 9 & 11 & 22 & 7 & 3 & 8 & 11 & 13 & 9 & 17 & 9 & 311 & 1 & ST6_C1P1 \\
\hline $2016 \_252.2 \mp$ & ST7 & Helichrysum italicum & Corsica, Cauro & 2016 & 18.90 & 7 & 24 & 7 & 7 & 14 & 21 & 7 & 4 & 15 & 8 & 10 & 9 & 8 & 133 & 3 & ST7_C1P1 \\
\hline 2016_253.4‡ & ST7 & Calicotome villosa & Corsica, Cauro & 2016 & 26.95 & 7 & 24 & 7 & 7 & 14 & 24 & 7 & 4 & 15 & 8 & 11 & 9 & 8 & 150 & 3 & ST7_C1P1 \\
\hline 2016_254.1干 & ST7 & Cytisus villosus Pourr. & Corsica, Cauro & 2016 & 23.36 & 7 & 24 & 7 & 7 & 22 & 21 & 7 & 4 & 15 & 8 & 10 & 9 & 8 & 176 & 3 & ST7_C1P1 \\
\hline $2016 \_269.2 \neq$ & ST7 & Calicotome villosa & Corsica, Cauro & 2016 & 29.06 & 7 & 24 & 7 & 7 & 14 & 23 & 7 & 4 & 15 & 8 & 10 & 9 & 8 & 145 & 3 & ST7_C1P1 \\
\hline $2016 \_281.1 \neq$ & ST7 & Helichrysum italicum & Corsica, Porto-Vecchio & 2016 & 24.13 & 7 & 24 & 7 & 7 & 14 & 19 & 7 & 4 & 15 & 8 & 10 & 9 & 7 & 126 & 3 & ST7_C1P1 \\
\hline 2016_282.1‡ & ST7 & Genista corsica & Corsica, Porto-Vecchio & 2016 & 29.67 & 7 & 24 & 7 & 6 & 14 & 23 & 7 & 4 & 15 & 8 & 10 & 9 & 6 & 102 & 3 & ST7_C1P1 \\
\hline $2016 \_303.1+\ddagger$ & ST7 & Phagnalon saxatile & Corsica, Ocana & 2016 & 29.11 & 7 & 24 & 7 & 7 & 16 & 19 & 7 & 4 & 13 & 8 & 13 & 9 & 8 & 165 & 4 & ST7_C2 \\
\hline 2016_308.4‡ & ST7 & Helichrysum italicum & Corsica, Pianottoli Caldarello & 2016 & 21.63 & 7 & 24 & 7 & 7 & 14 & 22 & 7 & 4 & 15 & 8 & 11 & 9 & 8 & 138 & 3 & ST7_C1P1 \\
\hline 2016 311.1‡ & ST6 & Helichrysum italicum & Corsica, Cargese & 2016 & 19.97 & 12 & 29 & 8 & 11 & 22 & 8 & 3 & 8 & 10 & 13 & 9 & 17 & 10 & 224 & 1 & ST6_C1P1 \\
\hline 2016 & ST6 & Spartium junceum & Corsica, Afa & 2016 & 26.62 & 12 & 29 & 10 & 8 & 21 & 7 & 3 & 8 & 11 & 13 & 9 & 17 & 9 & 28 & 1 & ST6_C1P1 \\
\hline $2016 \_332.10 \neq$ & ST7 & Calicotome villosa & Corsica, Cauro & 2016 & 24.88 & 7 & 24 & 7 & 7 & 13 & 21 & 7 & 4 & 12 & 13 & 9 & 17 & 10 & 116 & 4 & ST7_C2 \\
\hline $2016 \_332.5 \neq$ & ST7 & Calicotome villosa & Corsica, Cauro & 2016 & 31.44 & 7 & 24 & 8 & 7 & 15 & 23 & 7 & 4 & 15 & 8 & 10 & 9 & 8 & 263 & 3 & ST7_C1P1 \\
\hline 2016_346.18 & ST7 & Calicotome villosa & Corsica, Coti-Chiavari & 2016 & 25.91 & 7 & 24 & 7 & 7 & 13 & 22 & 7 & 4 & 14 & 8 & 11 & 9 & 8 & 117 & 3 & ST7_C1P1 \\
\hline $2016 \_348.1 \neq$ & ST7 & Genista corsica & Corsica, Sartene & 2016 & 24.99 & 7 & 24 & 8 & 7 & 14 & 23 & 7 & 4 & 15 & 8 & 11 & 9 & 8 & 258 & 3 & ST7_C1P1 \\
\hline 2016 351.1 & ST6 & Spartium junceum & Corsica, Ajaccio & 2016 & 22.84 & 12 & 29 & 10 & 11 & 22 & 7 & 3 & 8 & 11 & 13 & 9 & 17 & 10 & 9 & 1 & ST6_C1P1 \\
\hline 2016_353.3‡ & ST6 & Calicotome villosa & Corsica, Calcatoggio & 2016 & 24.96 & 12 & 29 & 9 & 11 & 22 & 7 & 3 & 8 & 11 & 13 & 9 & 17 & 10 & 309 & 1 & ST6_C1P1 \\
\hline $2016 \_354.1 \neq$ & ST6 & Helichrysum italicum & Corsica, Calcatoggio & 2016 & 19.56 & 12 & 29 & 9 & 11 & 20 & 6 & 1 & 8 & 11 & 13 & 9 & 17 & 10 & 293 & 1 & ST6_C1P1 \\
\hline 2016_379.1‡ & ST6 & Calicotome villosa & Corsica, Ambiegna & 2016 & 23.98 & 12 & 29 & 8 & 11 & 23 & 7 & 3 & 6 & 10 & 13 & 9 & 17 & 11 & 212 & 1 & ST6_C1P1 \\
\hline 2016_390.1‡ & ST7 & Calicotome villosa & Corsica, Grossa & 2016 & 24.30 & 7 & 24 & 7 & 7 & 14 & 20 & 7 & 4 & 15 & 8 & 11 & 9 & 8 & 128 & 3 & ST7_C1P1 \\
\hline 2016_40.1‡ & cysG_7 & Spartium junceum & Corsica, Grosseto-Prugna & 2016 & 30.42 & 7 & 24 & 6 & 7 & 16 & 24 & 7 & 4 & 13 & 8 & 12 & 9 & 8 & 61 & 4 & ST7_C2 \\
\hline $2016 \_40.2 \neq$ & cysG__3 $_{3}$ & Spartium junceum & Corsica, Grosseto-Prugna & 2016 & 22.62 & 12 & 29 & 9 & 9 & 22 & 7 & 3 & 8 & 11 & 14 & 9 & 17 & 10 & 20 & 1 & ST6_C1P1 \\
\hline $2016 \_40.3 \ddagger$ & cysG_3 & Spartium junceum & Corsica, Grosseto-Prugna & 2016 & 21.93 & 12 & 29 & 9 & 11 & 21 & 7 & 3 & 8 & 12 & 13 & 9 & 17 & 10 & 306 & 1 & ST6_C1P1 \\
\hline $2016 \_40.5 \neq$ & $\begin{array}{l}\text { ST7 } \\
\text { ST }\end{array}$ & Spartium junceum & Corsica, Grosseto-Prugna & 2016 & 23.89 & 7 & 24 & 6 & 7 & 17 & 23 & 8 & 4 & 10 & 9 & 12 & 9 & 8 & 65 & 4 & ST7_C2 \\
\hline 2016_400.1/CFB & ST6 & Polygala myrtifolia & Corsica, Appietto & 2016 & 23.17 & 12 & 29 & 9 & 11 & 21 & 7 & 3 & 8 & 11 & 13 & 9 & 17 & 10 & 303 & 1 & ST6_C1P1 \\
\hline
\end{tabular}




\begin{tabular}{|c|c|c|c|c|c|c|c|c|c|c|c|c|c|c|c|c|c|c|c|c|c|}
\hline 2016_403.1干 & ST6 & Spartium junceum & Corsica, Alata & 2016 & 24.07 & 12 & 29 & 10 & 11 & 22 & 7 & 3 & 8 & 12 & 13 & 9 & 17 & 10 & 11 & 1 & ST6_C1P1 \\
\hline $2016 \_461.2 \mp$ & ST7 & Lavandula angustifolia & Corsica, Loreto-Di-Tallano & 2016 & 26.59 & 7 & 24 & 8 & 7 & 14 & 22 & 7 & 4 & 15 & 8 & 11 & 9 & 8 & 255 & 3 & ST7_C1P1 \\
\hline $2016 \_462.1 \neq$ & ST6 & Calicotome villosa & Corsica, San Gavino Di Carbini & 2016 & 30.14 & 11 & 29 & 7 & 10 & 20 & 7 & 3 & 8 & 11 & 12 & 8 & 17 & 11 & 93 & 2 & ST6_C2 \\
\hline 2016_500.1‡ & ST6 & Polygala myrtifolia & Corsica, Biguglia & 2016 & 29.49 & 12 & 29 & 10 & 12 & 29 & 7 & 3 & 8 & 11 & 13 & 9 & 17 & 11 & 17 & 1 & ST6_C1P1 \\
\hline 2016_514.1‡ & ST7 & Helichrysum italicum & Corsica, Olmiccia & 2016 & 25.29 & 7 & 24 & 7 & 8 & 14 & 22 & 7 & 4 & 15 & 9 & 11 & 9 & 8 & 194 & 3 & ST7_C1P1 \\
\hline 2016_534.1‡ & ST6 & Polygala myrtifolia & Corsica, Ajaccio & 2016 & 23.85 & 12 & 29 & 8 & 11 & 22 & 7 & 3 & 9 & 10 & 13 & 9 & 17 & 10 & 227 & 1 & ST6_C1P1 \\
\hline 2016_540.1‡ & ST7 & Artemisia arborescens & Corsica, Bonifacio & 2016 & 30.35 & 7 & 24 & 7 & 7 & 14 & 23 & 7 & 4 & 5 & 8 & 11 & 9 & 5 & 149 & 3 & ST7_C1P1 \\
\hline $2016 \_603.1 \neq$ & ST6 & Polygala myrtifolia & Corsica, Pietrosella & 2016 & 22.65 & 12 & 29 & 9 & 12 & 21 & 7 & 3 & 4 & 11 & 13 & 9 & 17 & 8 & 55 & 1 & ST6_C1P1 \\
\hline 2016_61.11‡ & cysG_3 & Polygala myrtifolia & Corsica, Ajaccio & 2016 & 26.94 & 11 & 29 & 9 & 11 & 20 & 7 & 3 & 8 & 11 & 13 & 9 & 17 & 10 & 285 & 1 & ST6_C1P1 \\
\hline 2016_61.13‡ & cysG_3 & Polygala myrtifolia & Corsica, Ajaccio & 2016 & 21.76 & 12 & 29 & 9 & 11 & 22 & 7 & 3 & 8 & 11 & 13 & 9 & 17 & 10 & 309 & 1 & ST6_C1P1 \\
\hline $2016 \_61.2 \ddagger$ & cysG_3 & Polygala myrtifolia & Corsica, Ajaccio & 2016 & 26.66 & 12 & 29 & 8 & 11 & 21 & 7 & 3 & 8 & 10 & 13 & 9 & 17 & 10 & 215 & 1 & ST6_C1P1 \\
\hline 2016_61.3¥ & ST6 & Polygala myrtifolia & Corsica, Ajaccio & 2016 & 23.11 & 12 & 29 & 9 & 9 & 21 & 7 & 3 & 9 & 11 & 13 & 9 & 17 & 10 & 2 & 1 & ST6_C1P1 \\
\hline $2016 \_61.9 \neq$ & ST6 & Polygala myrtifolia & Corsica, Ajaccio & 2016 & 21.39 & 12 & 29 & 8 & 11 & 21 & 7 & 3 & 8 & 10 & 13 & 9 & 17 & 10 & 215 & 1 & ST6_C1P1 \\
\hline $2016 \_645.1 \neq$ & ST6 & Lavandula sp. & Corsica, Ambiegna & 2016 & 24.62 & 12 & 29 & 9 & 11 & 23 & 7 & 3 & 8 & 9 & 13 & 7 & 17 & 10 & 318 & 1 & ST6_C1P1 \\
\hline $2016 \_706.1 \mp$ & ST7 & Polygala myrtifolia & PACA, La Seyna-sur-Mer & 2016 & 27.31 & 8 & 24 & 6 & 7 & 14 & 23 & 7 & 4 & 12 & 8 & 11 & 9 & 8 & 78 & 4 & ST7_P2 \\
\hline 2016_72.1‡ & ST7 & Spartium junceum & Corsica, Ajaccio & 2016 & 25.99 & 7 & 24 & 6 & 7 & 16 & 23 & 7 & 4 & 13 & 8 & 12 & 9 & 8 & 60 & 4 & ST7_C2 \\
\hline 2016_740.1‡ & ST6 & Polygala myrtifolia & Corsica, Villanova & 2016 & 27.14 & 11 & 29 & 10 & 13 & 22 & 7 & 3 & 8 & 11 & 11 & 9 & 17 & 9 & 19 & 2 & ST6_C2 \\
\hline $2016 \_742.1 \mp$ & ST7 & Spartium junceum & PACA, Theoule sur Mer & 2016 & 21.50 & 7 & 24 & 8 & 7 & 15 & 15 & 9 & 4 & 12 & 8 & 12 & 9 & 8 & 276 & 4 & ST7_P2 \\
\hline $2016 \_762.1 \mp$ & ST7 & Polygala myrtifolia & Corsica, Porto-Vecchio & 2016 & 28.01 & 7 & 24 & 8 & 7 & 14 & 23 & 7 & 4 & 16 & 8 & 11 & 9 & 8 & 259 & 3 & ST7_C1P1 \\
\hline 2016_764.1¥ & ST7 & Polygala myrtifolia & $\begin{array}{l}\text { PACA, Mougins } \\
\text { Pact }\end{array}$ & 2016 & 22.69 & 8 & 24 & 7 & 7 & 13 & 24 & 7 & 4 & 14 & 8 & 12 & 9 & 8 & 188 & 4 & ST7_P2 \\
\hline 2016_799.1‡ & ST7 & Calicotome villosa & Corsica & 2016 & 22.17 & 7 & 24 & 7 & 7 & 14 & 22 & 7 & 4 & 16 & 8 & 8 & 9 & 7 & 142 & 3 & ST7_C1P1 \\
\hline $2016 \_821.4 \neq$ & ST6 & Helichrysum italicum & Corsica, Osani & 2016 & 18.59 & 12 & 27 & 9 & 11 & 21 & 6 & 1 & 8 & 11 & 13 & 9 & 17 & 10 & 288 & 1 & ST6_C1P1 \\
\hline $2016 \_828.2 \neq$ & ST7 & Helichrysum italicum & Corsica, Santa Maria Figanielle & 2016 & 23.96 & 7 & 24 & 7 & 7 & 14 & 22 & 7 & 4 & 17 & 8 & 11 & 9 & 8 & 143 & 3 & ST7_C1P1 \\
\hline $2016 \_83.1 \neq$ & ST7 & Spartium junceum & Corsica, Propriano & 2016 & 29.24 & 7 & 24 & 7 & 7 & 14 & 23 & 7 & 4 & 15 & 8 & 11 & 9 & 8 & 146 & 3 & ST7_C1P1 \\
\hline 2016_830.1‡ & ST7 & Cytisus villosus & Corsica, Mela & 2016 & 29.32 & 7 & 24 & 7 & 7 & 14 & 23 & 7 & 4 & 15 & 9 & 11 & 9 & 9 & 148 & 3 & ST7_C1P1 \\
\hline 2016_836.1‡ & ST6 & Lavandula sp. & Corsica, Arbori & 2016 & 26.02 & 12 & 30 & 1 & 11 & 22 & 7 & 3 & 8 & 10 & 13 & 9 & 17 & 11 & 31 & 1 & ST6_C1P1 \\
\hline 2016 841.1干 & ST6 & Cistus creticus & Corsica, Arbori & 2016 & 24.82 & 12 & 29 & 10 & 11 & 20 & 7 & 3 & 8 & 12 & 13 & 9 & 17 & 9 & 8 & 1 & ST6_C1P1 \\
\hline 2016_848.3* & ST7 & Helichrysum italicum & Corsica, Santa Maria Figanielle & 2016 & 25.00 & 7 & 24 & 7 & 7 & 14 & 22 & 7 & 4 & 15 & 8 & 11 & 9 & 9 & 139 & 3 & ST7_C1P1 \\
\hline $2016 \_85.1 \mp$ & ST7 & Polygala myrtifolia & Corsica, Santa Reparata Di Balagna & 2016 & 30.35 & 7 & 24 & 7 & 7 & 14 & 22 & 7 & 4 & 16 & 8 & 11 & 9 & 7 & 140 & 3 & ST7_C1P1 \\
\hline 2017_101.1‡ & ST7 & Polygala myrtifolia & Corsica, Porto-Vecchio & 2017 & 24.18 & 7 & 24 & 9 & 7 & 15 & 22 & 7 & 4 & 15 & 8 & 11 & 9 & 8 & 24 & 3 & ST7_C1P1 \\
\hline 2017_101.2‡ & ST7 & Polygala myrtifolia & Corsica, Porto-Vecchio & 2017 & 26.48 & 7 & 24 & 8 & 7 & 14 & 23 & 7 & 4 & 15 & 8 & 11 & 9 & 8 & 258 & 3 & ST7_C1P1 \\
\hline 2017_101.3¥ & ST7 & Polygala myrtifolia & Corsica, Porto-Vecchio & 2017 & 26.04 & 7 & 24 & 7 & 7 & 16 & 21 & 7 & 4 & 15 & 8 & 9 & 9 & 8 & 169 & 3 & ST7_C1P1 \\
\hline 2017_15 & ST7 & Spartium junceum & Corsica, Corbara & 2017 & 24.96 & 7 & 24 & 7 & 7 & 14 & 16 & 7 & 4 & 16 & 8 & 8 & 9 & 7 & 123 & 3 & ST7_C1P1 \\
\hline 2017_183.1キ† & ST6 & Polygala myrtifolia & PACA, Antibes & 2017 & 25.94 & 16 & 29 & 8 & 11 & 18 & 7 & 3 & 8 & 10 & 13 & 7 & 17 & 7 & 231 & 2 & ST6_P2 \\
\hline 2017_213.1‡ & ST6 & Polygala myrtifolia & Corsica, Bastelicaccia & 2017 & 23.96 & 12 & 29 & 9 & 11 & 22 & 7 & 3 & 8 & 11 & 13 & 9 & 17 & 10 & 309 & 1 & ST6_C1P1 \\
\hline $2017 \_322.1+\ddagger$ & ST7 & Polygala myrtifolia & PACA, Biot & 2017 & 19.20 & 7 & 24 & 7 & 7 & 15 & 20 & 7 & 4 & 13 & 8 & 13 & 9 & 8 & 155 & 4 & ST7_P2 \\
\hline 2017_324.1/CFBP 13598*十‡ & ST7 & Acacia dealbata & PACA, Villeneuve Loubet & 2017 & 25.63 & 7 & 24 & 7 & 7 & 16 & 12 & 7 & 4 & 13 & 8 & 13 & 9 & 8 & 163 & 4 & ST7_P2 \\
\hline $2017 \_326.1 \neq$ & ST7 & Spartium junceum & PACA, Villeneuve Loubet & 2017 & 24.36 & 7 & 24 & 8 & 7 & 27 & 21 & 7 & 4 & 14 & 8 & 11 & 9 & 9 & 274 & 4 & ST7_P2 \\
\hline 2017_326.2‡ & ST7 & Spartium junceum & PACA, Villeneuve Loubet & 2017 & 25.84 & 7 & 24 & 7 & 7 & 15 & 15 & 7 & 4 & 14 & 8 & 11 & 9 & 10 & 153 & 3 & ST7_C1P1 \\
\hline 2017_328.1干 & ST7 & Polygala sp. & PACA, Villeneuve Loubet & 2017 & 27.22 & 7 & 24 & 7 & 8 & 21 & 21 & 7 & 4 & 12 & 8 & 11 & 9 & 9 & 198 & 4 & ST7_P2 \\
\hline $2017 \_328.2 \mp$ & ST7 & Polygala sp. & PACA, Villeneuve Loubet & 2017 & 24.17 & 7 & 24 & 7 & 8 & 21 & 21 & 7 & 4 & 12 & 8 & 11 & 9 & 9 & 198 & 4 & ST7_P2 \\
\hline 2017_328.3†‡ & ST6 & Polygala sp. & PACA, Antibes & 2017 & 27.38 & 7 & 29 & 7 & 7 & 20 & 7 & 3 & 8 & 10 & 13 & 7 & 17 & 7 & 184 & 2 & ST6_P2 \\
\hline 2017_328.4† & ST6 & Polygala myrtifolia & PACA, Antibes & 2017 & 30.79 & 16 & 29 & 8 & 10 & 16 & 8 & 3 & 4 & 9 & 13 & 9 & 17 & 7 & 205 & 2 & ST6_P2 \\
\hline 2017_337.1‡ & ST6 & Polygala myrtifolia & Corsica, Sarrola Carcopino & 2017 & 27.58 & 12 & 29 & 8 & 11 & 21 & 7 & 3 & 8 & 10 & 13 & 9 & 17 & 11 & 216 & 1 & ST6_C1P1 \\
\hline $2017 \_337.2 \ddagger$ & ST6 & Polygala myrtifolia & Corsica, Grosseto-Prugna & 2017 & 24.20 & 12 & 29 & 9 & 11 & 22 & 7 & 3 & 8 & 11 & 13 & 9 & 17 & 10 & 309 & 1 & ST6_C1P1 \\
\hline 2017_357.1‡ & ST6 & Polygala myrtifolia & Corsica, Ajaccio & 2017 & 28.34 & 12 & 29 & 9 & 11 & 23 & 7 & 3 & 8 & 11 & 13 & 9 & 17 & 11 & 317 & 1 & ST6_C1P1 \\
\hline 2017_357.3‡ & ST7 & Polygala myrtifolia & Corsica, Grosseto-Prugna & 2017 & 26.08 & 7 & 24 & 6 & 7 & 17 & 7 & 8 & 4 & 13 & 8 & 11 & 9 & 8 & 66 & 4 & ST7_C2 \\
\hline 2017_357.4¥ & ST6 & Polygala myrtifolia & Corsica, Bastelicaccia & 2017 & 25.10 & 12 & 29 & 9 & 11 & 22 & 7 & 3 & 8 & 10 & 13 & 9 & 17 & 10 & 308 & 1 & ST6_C1P1 \\
\hline 2017_357.5‡ & ST6 & Polygala myrtifolia & Corsica, Grosseto-Prugna & 2017 & 26.96 & 11 & 29 & 9 & 11 & 23 & 7 & 3 & 8 & 11 & 13 & 9 & 17 & 10 & 286 & 1 & ST6_C1P1 \\
\hline 2017_374.1‡ & ST7 & Polygala myrtifolia & Corsica, Pietrosella & 2017 & 31.11 & 7 & 24 & 7 & 7 & 14 & 24 & 7 & 4 & 16 & 8 & 11 & 9 & 8 & 151 & 3 & ST7_C1P1 \\
\hline 2017_374.2‡ & ST7 & Polygala myrtifolia & Corsica, Pietrosella & 2017 & 30.16 & 7 & 24 & 7 & 7 & 14 & 21 & 7 & 4 & 15 & 7 & 10 & 9 & 9 & 132 & 3 & ST7_C1P1 \\
\hline 2017_374.3¥ & ST6 & Polygala myrtifolia & Corsica, Pietrosella & 2017 & 29.04 & 12 & 29 & 10 & 9 & 29 & 7 & 3 & 8 & 12 & 13 & 10 & 17 & 10 & 29 & 1 & ST6_C1P1 \\
\hline 2017_374.4‡ & ST6 & Polygala myrtifolia & Corsica, Pietrosella & 2017 & 30.73 & 12 & 29 & 8 & 11 & 21 & 8 & 3 & 8 & 10 & 13 & 9 & 17 & 11 & 218 & 1 & ST6_C1P1 \\
\hline 2017_38 & ST6 & Polygala myrtifolia & Corsica, Vignola & 2017 & 25.16 & 12 & 27 & 10 & 11 & 12 & 7 & 3 & 8 & 11 & 14 & 9 & 17 & 10 & 4 & 1 & ST6_C1P1 \\
\hline 2017_392.1‡ & ST6 & Polygala myrtifolia & Corsica, Cargese & 2017 & 27.45 & 12 & 29 & 8 & 11 & 22 & 7 & 3 & 8 & 10 & 13 & 10 & 17 & 10 & 219 & 1 & ST6_C1P1 \\
\hline 2017_42 & ST6 & Polygala myrtifolia & Corsica, Vignola & 2017 & 22.91 & 12 & 29 & 10 & 11 & 22 & 7 & 3 & 8 & 11 & 13 & 9 & 17 & 10 & 9 & 1 & ST6_C1P1 \\
\hline 2017_500.1‡ & ST6 & Polygala myrtifolia & Corsica, Afa & 2017 & 28.16 & 12 & 29 & 9 & 12 & 22 & 7 & 3 & 8 & 11 & 13 & 9 & 17 & 11 & 40 & 1 & ST6_C1P1 \\
\hline 2017_500.2‡ & ST6 & Polygala myrtifolia & Corsica, Afa & 2017 & 26.45 & 12 & 29 & 6 & 11 & 21 & 6 & 3 & 8 & 12 & 13 & 9 & 17 & 12 & 54 & 1 & ST6_C1P1 \\
\hline 2017_500.3‡ & ST6 & Polygala myrtifolia & Corsica, Afa & 2017 & 28.20 & 12 & 29 & 9 & 12 & 16 & 7 & 3 & 8 & 11 & 13 & 9 & 17 & 10 & 49 & 1 & ST6_C1P1 \\
\hline 2017_501.1‡ & ST6 & Polygala myrtifolia & PACA, Antibes & 2017 & 24.69 & 11 & 29 & 8 & 8 & 22 & 7 & 3 & 8 & 10 & 14 & 8 & 15 & 10 & 279 & 2 & ST6_P2 \\
\hline 2017_501.3†キ & ST6 & Polygala myrtifolia & PACA, Antibes & 2017 & 22.38 & 16 & 29 & 8 & 10 & 23 & 7 & 3 & 8 & 10 & 13 & 9 & 17 & 10 & 209 & 2 & ST6_P2 \\
\hline 2017_515.1/CFBP 13687*\# & ST7 & Medicago sativa & PACA, La Seyna-sur-Mer & 2017 & 21.99 & 8 & 24 & 6 & 7 & 13 & 22 & 7 & 4 & 12 & 8 & 11 & 9 & 9 & 74 & 4 & ST7_P2 \\
\hline $2017 \_527.1+\ddagger$ & ST6 & Polygala myrtifolia & PACA, Antibes & 2017 & 28.33 & 15 & 29 & 8 & 10 & 20 & 7 & 3 & 8 & 10 & 13 & 9 & 17 & 9 & 204 & 2 & ST6_P2 \\
\hline $2017 \_527.2 \ddagger$ & ST7 & Polygala myrtifolia & PACA, Antibes & 2017 & 29.69 & 7 & 24 & 8 & 8 & 16 & 22 & 7 & 4 & 12 & 8 & 12 & 9 & 8 & 282 & 4 & ST7_P2 \\
\hline 2017_527.3/CFBP $13637 * \neq$ & ST7 & Polygala myrtifolia & PACA, Antibes & 2017 & 27.80 & 7 & 24 & 8 & 7 & 14 & 23 & 7 & 4 & 12 & 8 & 12 & 9 & 9 & 257 & 4 & ST7_P2 \\
\hline 2017_528.1/CFBP $13638^{* \neq}$ & ST6 & Euryops chrysanthemoides & PACA, Antibes & 2017 & 23.52 & 12 & 29 & 8 & 13 & 25 & 7 & 3 & 8 & 9 & 13 & 8 & 17 & 10 & 242 & 2 & ST6_P2 \\
\hline 2017_550.1₹ & ST7 & Polygala myrtifolia & Corsica, Sartene & 2017 & 30.10 & 7 & 24 & 7 & 7 & 13 & 20 & 7 & 4 & 15 & 8 & 11 & 9 & 9 & 115 & 3 & ST7_C1P1 \\
\hline 2017_552.1‡ & ST6 & Polygala myrtifolia & PACA, Antibes & 2017 & 25.44 & 16 & 29 & 8 & 10 & 19 & 7 & 3 & 8 & 10 & 12 & 10 & 17 & 9 & 207 & 2 & ST6_P2 \\
\hline 2017_563.1干 & ST6 & Polygala myrtifolia & Corsica, Furiani & 2017 & 29.15 & 12 & 29 & 9 & 12 & 27 & 7 & 3 & 9 & 11 & 13 & 9 & 17 & 10 & 39 & 1 & ST6_C1P1 \\
\hline 2017_564.1‡ & ST6 & Polygala myrtifolia & PACA, Antibes & 2017 & 29.62 & 11 & 29 & 8 & 13 & 21 & 7 & 3 & 8 & 10 & 12 & 8 & 17 & 10 & 239 & 2 & ST6_P2 \\
\hline $2017 \_564.2 \ddagger$ & ST6 & Polygala myrtifolia & PACA, Antibes & 2017 & 27.78 & 12 & 29 & 8 & 14 & 23 & 7 & 3 & 8 & 10 & 14 & 8 & 17 & 9 & 243 & 2 & ST6_P2 \\
\hline
\end{tabular}




\begin{tabular}{|c|c|c|c|c|c|c|c|c|c|c|c|c|c|c|c|c|c|c|c|c|c|}
\hline 2017_564.3‡ & ST6 & Polygala myrtifolia & PACA, Antibes & 2017 & 29.49 & 10 & 29 & 8 & 13 & 23 & 7 & 3 & 8 & 10 & 12 & 8 & 17 & 10 & 237 & 2 & ST6_P2 \\
\hline 2017_564.4¥ & ST7 & Polygala myrtifolia & PACA, Antibes & 2017 & 30.81 & 7 & 24 & 8 & 7 & 12 & 19 & 7 & 4 & 14 & 8 & 12 & 9 & 8 & 252 & 4 & ST7_P2 \\
\hline $2017575.1 \neq$ & ST7 & Polygala myrtifolia & PACA, Nice & 2017 & 28.42 & 7 & 24 & 7 & 7 & 13 & 13 & 7 & 4 & 15 & 8 & 11 & 9 & 8 & 114 & 3 & $\mathrm{ST7} C 1 \mathrm{P} 1$ \\
\hline 2017_575.4‡ & ST6 & Polygala myrtifolia & PACA, Antibes & 2017 & 31.84 & 12 & 29 & 7 & 11 & 15 & 7 & 3 & 8 & 10 & 13 & 8 & 17 & 8 & 98 & 1 & ST6_C1P1 \\
\hline 2017_601.1‡ & ST6 & Polygala myrtifolia & PACA, Vallauris & 2017 & 30.51 & 11 & 29 & 9 & 13 & 16 & 7 & 3 & 8 & 10 & 12 & 8 & 17 & 9 & 34 & 2 & ST6_P2 \\
\hline 2017_601.2‡ & ST7 & Polygala myrtifolia & PACA, Vallauris & 2017 & 30.47 & 7 & 24 & 7 & 7 & 14 & 23 & 7 & 4 & 14 & 8 & 12 & 9 & 9 & 144 & 4 & ST7_P2 \\
\hline 2017_601.3¥ & ST7 & Polygala myrtifolia & PACA, Vallauris & 2017 & 28.21 & 8 & 24 & 7 & 7 & 13 & 23 & 6 & 4 & 15 & 8 & 11 & 9 & 8 & 185 & 3 & ST7_C1P1 \\
\hline 2017_601.4‡ & ST7 & Polygala myrtifolia & PACA, Vallauris & 2017 & 28.56 & 8 & 24 & 6 & 7 & 13 & 22 & 7 & 4 & 15 & 8 & 13 & 9 & 7 & 76 & 4 & ST7_P2 \\
\hline 2017_601.5‡ & ST7 & Polygala myrtifolia & PACA, Vallauris & 2017 & 29.41 & 7 & 24 & 7 & 7 & 11 & 20 & 7 & 4 & 18 & 8 & 11 & 9 & 7 & 112 & 3 & ST7_C1P1 \\
\hline $2017 \_607.1 \mp$ & ST7 & Polygala myrtifolia & PACA, Menton & 2017 & 20.52 & 7 & 24 & 8 & 7 & 17 & 24 & 7 & 4 & 13 & 8 & 13 & 9 & 9 & 271 & 4 & ST7_P2 \\
\hline 2017_615.1‡ & ST7 & Polygala myrtifolia & PACA, Vallauris & 2017 & 27.26 & 7 & 24 & 8 & 7 & 15 & 27 & 7 & 4 & 15 & 8 & 11 & 9 & 8 & 266 & 3 & ST7_C1P1 \\
\hline $2017 \_615.2 \ddagger$ & ST7 & Polygala myrtifolia & PACA, Vallauris & 2017 & 26.30 & 8 & 24 & 7 & 7 & 15 & 24 & 7 & 4 & 13 & 8 & 12 & 9 & 6 & 192 & 4 & ST7_P2 \\
\hline $2017 \_615.3 \neq$ & ST6 & Polygala myrtifolia & PACA, Vallauris & 2017 & 27.81 & 12 & 29 & 7 & 9 & 13 & 7 & 3 & 10 & 10 & 13 & 10 & 17 & 8 & 200 & 1 & ST6_C1P1 \\
\hline 2017_621.1‡ & ST7 & Euryops chrysanthemoides & PACA, Ollioules & 2017 & 27.95 & 8 & 24 & 3 & 7 & 13 & 23 & 7 & 4 & 12 & 8 & 11 & 9 & 8 & 41 & 4 & ST7_P2 \\
\hline 2017_625.2‡ & ST6 & Polygala myrtifolia & Corsica, Peri & 2017 & 25.42 & 12 & 29 & 9 & 11 & 22 & 7 & 3 & 8 & 11 & 13 & 9 & 17 & 11 & 310 & 1 & ST6_C1P1 \\
\hline $2017 \_625.3 \ddagger$ & ST6 & Polygala myrtifolia & Corsica, Peri & 2017 & 29.07 & 12 & 29 & 8 & 10 & 20 & 7 & 3 & 8 & 11 & 13 & 9 & 17 & 10 & 202 & 1 & ST6_C1P1 \\
\hline $2017 \_631.1 \mp$ & ST7 & Polygala myrtifolia & PACA, Vallauris & 2017 & 28.73 & 7 & 24 & 7 & 7 & 14 & 23 & 7 & 4 & 15 & 8 & 11 & 9 & 8 & 146 & 3 & ST7_C1P1 \\
\hline 2017_633.1/CFBP 13639*十‡ & ST6 & Prunus avium & PACA, Antibes & 2017 & 30.51 & 16 & 29 & 8 & 11 & 19 & 7 & 7 & 8 & 10 & 13 & 8 & 17 & 7 & 233 & 2 & ST6_P2 \\
\hline 2017_77 & ST7 & Genista corsica & Corsica, Rocapina & 2017 & 26.07 & 7 & 24 & 7 & 7 & 14 & 22 & 8 & 4 & 15 & 8 & 11 & 9 & 8 & 180 & 3 & ST7_C1P1 \\
\hline 2017_78 & ST7 & Polygala myrtifolia & Corsica, Pont de I'Oso & 2017 & 23.96 & 7 & 24 & 7 & 8 & 14 & 27 & 7 & 4 & 15 & 8 & 10 & 9 & 8 & 195 & 3 & ST7_C1P1 \\
\hline 2017_XF24 & $\mathrm{cysG}_{7} 7$ & Genista corsica & Corsica, Sartene & 2017 & 28.80 & 7 & 24 & 7 & 7 & 14 & 21 & 8 & 4 & 15 & 8 & 11 & 9 & 8 & 179 & 3 & ST7_C1P1 \\
\hline $2017 \times \mathrm{XF} 32$ & cysG 3 & Polygala myrtifolia & Corsica, Ajaccio & 2017 & 24.89 & 12 & 29 & 8 & 11 & 21 & 7 & 3 & 8 & 10 & 13 & 9 & 17 & 7 & 217 & 1 & ST6 C1P1 \\
\hline 2017_XF41 & $\mathrm{cysG}_{2} 7$ & Polygala myrtifolia & Corsica, Porto-Vecchio & 2017 & 26.22 & 7 & 24 & 7 & 7 & 14 & 22 & 7 & 4 & 16 & 8 & 11 & 9 & 8 & 141 & 3 & ST7_C1P1 \\
\hline $2018 \_176.1 \neq$ & ST6 & Polygala myrtifolia & Corsica, Ajaccio & 2018 & 27.56 & 12 & 29 & 8 & 12 & 22 & 7 & 3 & 8 & 10 & 13 & 9 & 17 & 10 & 234 & 1 & ST6_C1P1 \\
\hline $2018 \_182.1 \neq$ & ST7 & Polygala myrtifolia & PACA, Saint Laurent du Var & 2018 & 28.35 & 7 & 24 & 6 & 7 & 18 & 18 & 6 & 5 & 12 & 9 & 12 & 9 & 7 & 68 & 4 & ST7_P2 \\
\hline $2018 \_192.1 \neq$ & cysG_3 & Helichrysum italicum & PACA, Nice & 2018 & 29.16 & 11 & 29 & 8 & 13 & 29 & 7 & 3 & 8 & 9 & 12 & 8 & 17 & 10 & 240 & 2 & ST6_P2 \\
\hline $2018 \_222.1 \neq$ & ST7 & Polygala myrtifolia & PACA, Villeneuve Loubet & 2018 & 31.55 & 7 & 24 & 8 & 7 & 17 & 25 & 7 & 4 & 13 & 8 & 11 & 9 & 7 & 272 & 4 & ST7_P2 \\
\hline $2018 \_225.1 \mp$ & ST6 & Polygala myrtifolia & PACA, Antibes & 2018 & 25.36 & 11 & 29 & 9 & 13 & 23 & 7 & 3 & 8 & 11 & 13 & 8 & 17 & 10 & 33 & 2 & ST6_P2 \\
\hline $2018 \_226.1 \dagger \ddagger$ & ST7 & Euryops chrysanthemoides & PACA, Villeneuve Loubet & 2018 & 29.75 & 7 & 24 & 5 & 7 & 25 & 20 & 6 & 4 & 15 & 9 & 11 & 9 & 9 & 50 & 4 & ST7_P2 \\
\hline 2018_226.3¥ & ST7 & Euryops chrysanthemoides & PACA, Villeneuve Loubet & 2018 & 27.15 & 7 & 24 & 7 & 7 & 25 & 21 & 7 & 4 & 12 & 8 & 11 & 9 & 9 & 178 & 4 & ST7_P2 \\
\hline $2018 \_283.1 \neq$ & ST7 & Helichrysum italicum & PACA, Villeneuve Loubet & 2018 & 27.69 & 7 & 24 & 5 & 8 & 21 & 7 & 7 & 4 & 12 & 8 & 11 & 9 & 9 & 53 & 4 & ST7_P2 \\
\hline $2018 \_284.1 \neq$ & ST7 & Euryops chrysanthemoides & PACA, Villeneuve Loubet & 2018 & 27.12 & 7 & 24 & 7 & 7 & 14 & 19 & 7 & 4 & 13 & 8 & 12 & 9 & 9 & 125 & 4 & ST7_P2 \\
\hline 2018 287.1‡ & ST7 & Spartium junceum & PACA, Toulon & 2018 & 29.07 & 8 & 24 & 7 & 7 & 13 & 23 & 7 & 4 & 12 & 8 & 11 & 9 & 8 & 187 & 4 & ST7_P2 \\
\hline $2018 \_287.2 \neq$ & ST7 & Spartium junceum & PACA, La Seyna-sur-Mer & 2018 & 31.85 & 8 & 24 & 7 & 7 & 13 & 26 & 7 & 4 & 13 & 8 & 11 & 9 & 8 & 189 & 4 & ST7_P2 \\
\hline 2018_288.1‡ & ST7 & Polygala myrtifolia & PACA, La Seyna-sur-Mer & 2018 & 26.17 & 8 & 24 & 6 & 7 & 13 & 22 & 7 & 4 & 13 & 8 & 12 & 9 & 8 & 75 & 4 & ST7_P2 \\
\hline 2018_316.1†‡ & ST6 & Polygala myrtifolia & PACA, Antibes & 2018 & 28.55 & 16 & 29 & 8 & 10 & 22 & 7 & 3 & 8 & 9 & 13 & 9 & 17 & 9 & 208 & 2 & ST6_P2 \\
\hline $2018 \_316.2 \neq$ & ST6 & Polygala myrtifolia & PACA, Antibes & 2018 & 29.13 & 10 & 29 & 8 & 13 & 22 & 7 & 3 & 8 & 10 & 12 & 8 & 17 & 8 & 236 & 2 & ST6_P2 \\
\hline 2018_316.4¥ & ST7 & Polygala myrtifolia & PACA, Antibes & 2018 & 29.94 & 7 & 24 & 8 & 7 & 16 & 22 & 7 & 4 & 14 & 8 & 9 & 9 & 8 & 267 & 4 & ST7_P2 \\
\hline $2018 \_316.5+\ddagger$ & ST6 & Polygala myrtifolia & PACA, Antibes & 2018 & 26.72 & 16 & 29 & 8 & 10 & 19 & 6 & 1 & 8 & 10 & 13 & 9 & 17 & 9 & 206 & 2 & ST6_P2 \\
\hline $2018 \_323.2+\ddagger$ & ST6 & Polygala myrtifolia & PACA, Antibes & 2018 & 27.60 & 16 & 29 & 8 & 11 & 19 & 7 & 3 & 8 & 9 & 13 & 9 & 17 & 9 & 232 & 2 & ST6_P2 \\
\hline 2018_369.1†‡ & cysG_3 & Polygala myrtifolia & PACA, Antibes & 2018 & 25.80 & 16 & 29 & 7 & 10 & 19 & 7 & 3 & 4 & 10 & 13 & 9 & 17 & 9 & 94 & 2 & ST6_P2 \\
\hline $2018 \_390.1 \neq$ & ST7 & Polygala myrtifolia & PACA, La Seyna-sur-Mer & 2018 & 28.74 & 8 & 24 & 6 & 7 & 14 & 23 & 7 & 4 & 12 & 8 & 11 & 8 & 8 & 77 & 4 & ST7_P2 \\
\hline $2018 \_390.2 \neq$ & ST7 & Polygala myrtifolia & $\begin{array}{l}\text { PACA, Ollioules } \\
\text { Pats }\end{array}$ & 2018 & 27.42 & 8 & 24 & 6 & 7 & 13 & 23 & 6 & 4 & 11 & 8 & 11 & 9 & 9 & 69 & 4 & ST7_P2 \\
\hline 2018_391.1‡ & ST7 & Spartium junceum & PACA, Ollioules & 2018 & 21.49 & 8 & 24 & 6 & 7 & 13 & 19 & 7 & 4 & 12 & 8 & 11 & 9 & 9 & 72 & 4 & ST7_P2 \\
\hline $2018 \_410.1 \neq$ & ST7 & Spartium junceum & PACA, Ollioules & 2018 & 28.27 & 8 & 24 & 6 & 7 & 11 & 23 & 7 & 4 & 11 & 7 & 11 & 9 & 8 & 70 & 4 & ST7_P2 \\
\hline $2018 \_410.2 \neq$ & ST7 & Spartium junceum & PACA, Ollioules & 2018 & 23.35 & 8 & 24 & 6 & 7 & 13 & 14 & 7 & 4 & 11 & 8 & 11 & 9 & 8 & 71 & 4 & ST7_P2 \\
\hline $2018 \_410.3 \neq$ & ST7 & Spartium junceum & PACA, Ollioules & 2018 & 25.19 & 8 & 24 & 7 & 7 & 13 & 28 & 7 & 4 & 12 & 8 & 12 & 9 & 8 & 190 & 4 & ST7_P2 \\
\hline $2018 \_410.4 \mp$ & ST7 & Spartium junceum & PACA, Ollioules & 2018 & 26.11 & 8 & 24 & 6 & 7 & 14 & 24 & 7 & 4 & 11 & 8 & 11 & 9 & 8 & 79 & 4 & ST7_P2 \\
\hline $2018 \_410.5 \ddagger$ & ST7 & Spartium junceum & PACA, Toulon & 2018 & 29.13 & 8 & 24 & 6 & 7 & 13 & 21 & 7 & 4 & 12 & 8 & 11 & 9 & 8 & 73 & 4 & ST7_P2 \\
\hline $2018 \_422.1 \neq$ & ST7 & Coronilla glauca & PACA, Mougins & 2018 & 26.00 & 8 & 24 & 7 & 7 & 13 & 22 & 7 & 4 & 14 & 8 & 12 & 9 & 8 & 186 & 4 & ST7_P2 \\
\hline $2018 \_437.1 \neq$ & ST6 & Lonicera japonica & PACA, Villeneuve Loubet & 2018 & 28.92 & 13 & 29 & 8 & 10 & 19 & 7 & 3 & 9 & 10 & 13 & 8 & 17 & 9 & 203 & 2 & ST6_P2 \\
\hline $2018 \_438.1 \neq$ & ST7 & Grevillea juniperina & PACA, Villeneuve Loubet & 2018 & 28.13 & 7 & 24 & 10 & 5 & 15 & 24 & 7 & 4 & 12 & 8 & 12 & 9 & 8 & 23 & 4 & ST7_P2 \\
\hline 2018_486.1‡ & ST7 & Polygala myrtifolia & PACA, Toulon & 2018 & 19.96 & 8 & 24 & 8 & 7 & 12 & 22 & 7 & 4 & 12 & 8 & 11 & 9 & 8 & 277 & 4 & ST7_P2 \\
\hline $2018 \_511.1 \neq$ & ST7 & Euryops chrysanthemoides & PACA, Theoule sur Mer & 2018 & 24.89 & 7 & 24 & 7 & 7 & 15 & 23 & 7 & 4 & 13 & 8 & 10 & 9 & 9 & 160 & 4 & ST7_P2 \\
\hline $2018 \_545.1 \neq$ & ST6 & Polygala myrtifolia & Corsica, Ajaccio & 2018 & 28.04 & 11 & 29 & 9 & 11 & 20 & 7 & 3 & 8 & 11 & 13 & 9 & 17 & 10 & 285 & 1 & ST6_C1P1 \\
\hline $2018 \_626.2 \neq$ & ST7 & Polygala myrtifolia & PACA, Antibes & 2018 & 29.16 & 7 & 24 & 8 & 7 & 15 & 23 & 7 & 4 & 12 & 8 & 12 & 9 & 7 & 262 & 4 & ST7_P2 \\
\hline $2018 \_626.3 \ddagger$ & ST7 & Polygala myrtifolia & PACA, Nice & 2018 & 29.22 & 7 & 24 & 8 & 7 & 14 & 24 & 7 & 4 & 12 & 8 & 11 & 9 & 9 & 260 & 4 & ST7_P2 \\
\hline $2018 \_626.4 \ddagger$ & ST7 & Polygala myrtifolia & PACA, Nice & 2018 & 30.76 & 7 & 24 & 8 & 7 & 14 & 24 & 7 & 4 & 12 & 8 & 12 & 9 & 9 & 261 & 4 & ST7_P2 \\
\hline $2018 \_627.1 \neq$ & ST7 & Euryops chrysanthemoides & PACA, Antibes & 2018 & 31.96 & 7 & 24 & 8 & 7 & 17 & 23 & 7 & 4 & 12 & 8 & 12 & 9 & 8 & 269 & 4 & ST7_P2 \\
\hline $2018 \_65.1 \neq$ & ST7 & Polygala myrtifolia & PACA, Saint Raphael & 2018 & 23.59 & 5 & 24 & 8 & 7 & 23 & 20 & 7 & 4 & 12 & 8 & 11 & 9 & 6 & 249 & 4 & ST7_P2 \\
\hline $2018 \_65.2 \neq$ & ST7 & Polygala myrtifolia & PACA, Saint Raphael & 2018 & 20.96 & 5 & 24 & 8 & 7 & 23 & 20 & 7 & 4 & 12 & 8 & 11 & 9 & 6 & 249 & 4 & ST7_P2 \\
\hline $2018 \_65.3 \neq$ & ST7 & Polygala myrtifolia & PACA, Saint Raphael & 2018 & 21.75 & 7 & 24 & 7 & 7 & 21 & 21 & 7 & 4 & 12 & 8 & 12 & 9 & 9 & 173 & 4 & ST7_P2 \\
\hline 2018_65.4/CFBP 13693*\# & ST7 & Polygala myrtifolia & PACA, Saint Raphael & 2018 & 20.99 & 7 & 24 & 8 & 7 & 22 & 20 & 7 & 4 & 12 & 8 & 11 & 9 & 6 & 273 & 4 & ST7_P2 \\
\hline $2018 \_666.1 \neq$ & ST7 & Polygala myrtifolia & PACA, Nice & 2018 & 21.51 & 6 & 24 & 7 & 7 & 14 & 24 & 7 & 4 & 12 & 8 & 10 & 9 & 8 & 105 & 4 & ST7_P2 \\
\hline $2018 \_683.1 \mp$ & ST6 & Prunus dulcis & PACA, Antibes & 2018 & 27.25 & 9 & 29 & 7 & 12 & 17 & 7 & 3 & 8 & 10 & 12 & 8 & 17 & 10 & 100 & 2 & ST6_P2 \\
\hline $2018 \_684.1 \neq$ & ST7 & Polygala myrtifolia & PACA, Le Cannet & 2018 & 24.26 & 8 & 24 & 6 & 7 & 12 & 22 & 8 & 4 & 15 & 8 & 12 & 9 & 8 & 80 & 4 & ST7_P2 \\
\hline 2018 700.1干 & ST7 & Polygala myrtifolia & PACA, Saint Raphael & 2018 & 24.48 & 7 & 24 & 7 & 7 & 22 & 21 & 7 & 4 & 12 & 8 & 11 & 9 & 9 & 175 & 4 & ST7_P2 \\
\hline $2018 \_700.2 \neq$ & ST7 & Polygala myrtifolia & PACA, Saint Raphael & 2018 & 25.44 & 7 & 24 & 7 & 7 & 21 & 21 & 7 & 4 & 12 & 8 & 12 & 9 & 9 & 173 & 4 & ST7_P2 \\
\hline $2018 \_716.1 \neq$ & ST7 & Veronica sp. & PACA, Villeneuve Loubet & 2018 & 30.70 & 7 & 24 & 4 & 7 & 14 & 22 & 7 & 4 & 11 & 8 & 14 & 9 & 8 & 42 & 3 & ST7_C1P1 \\
\hline $2018 \_716.2 \neq$ & $\mathrm{cysG}_{2} 7$ & Veronica elliptica & PACA, Villeneuve Loubet & 2018 & 30.21 & 7 & 24 & 8 & 5 & 15 & 23 & 7 & 4 & 12 & 8 & 12 & 9 & 8 & 244 & 4 & ST7_P2 \\
\hline 2018 717.1‡ & ST7 & Convolvulus cneorum & PACA, Villeneuve Loubet & 2018 & 22.93 & 7 & 24 & 8 & 7 & 12 & 19 & 7 & 4 & 11 & 9 & 12 & 9 & 8 & 251 & 4 & ST7_P2 \\
\hline
\end{tabular}


PACA, Villeneuve Loubet

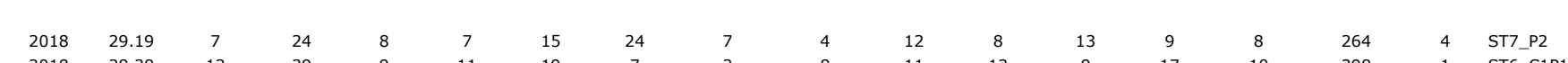

2018_727.1干

cysG_7 Polygala myrtifolia

(2018 $794.1+$

ST7 Polygala myrtifolia
ST7 Polygala myrtifiala

Corsica, Grosseto-Prug

PACA, Nice

PACA, Saint Raphael

PACA, Saint Rapha

Corsica, Alata

Corsica, Sartene
Corsica, Sartene

Corsica, Propriano

Corsica, Porto-Vecchio

Corsica, Ajaccio

PACA, Antibes
Corsica, Proprian

Corsica, Prop
PACA, Afa

PACA, Villeneuve Loubet

Corsica

Corsica
Corsica, Ajaccio

Corsica, Propriano

Corsica

Corsica

Corsica

Corsica

Corsica
PACA, Alpes-Maritimes

COA, A

PACA, Villeneuve Loubet

PACA, Villeneuve Lo

PACA, Saint Laurent du Var

PACA, Villeneuve Loubet

PACA, Villeneuve Loube

Corsica, Vignola

Corsica, Vignola

Corsica, Propriano

Corsica, Fontanaccia Bastelicaccia

Corsica, Propriano

Corsica, Alata

PACA, Nice

PACA, Nice

PACA, Saint Laurent du Var

Corsica, Grosseto-Prugna

ST7_P2

ST7_P2

ST7_C1P1
ST7_C1P1

ST7_C1P1

ST7_C1P1

ST6_P2

ST7_C1P1

ST7_P2

ST6_C1P1

ST7_C1P1

ST7_C2

ST6_C1P1

ST6_C1P1

ST6_C2

3 ST7_CIP

$\begin{array}{ll}2 & \text { ST6_C2 } \\ 1 & \text { ST6_C1P1 }\end{array}$

3 STI_C1P1

3 ST7_C1P1

ST7_P2

ST7_C2

ST7 P2

ST7_P2

ST7_P2

ST6_C1P1
ST6_C1P1

ST7_C1P1

ST6_C1P1

ST7_C1P1

ST6_C1P1

ST6_CIP1

ST6_P2

Corsica, Propriano
Corsica, Peri

Pelargonium sp. 
Table S5. Summary of private allele frequencies of ST6

and ST7 samples.

bioRxiv preprint doi: https://doi.org/10.1101/2022.02.11.480026; this version posted February 11, 2022. The copyright holder for this preprint

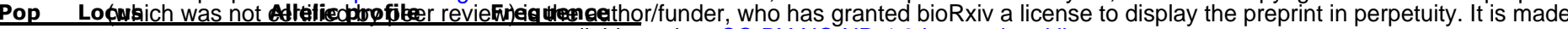

ST6 ASSR-1

ST6 ASSR-11

ST6 ASSR-11

ST6 ASSR-16

ST6 ASSR-16

ST6 ASSR-16

ST6 COSS-1

ST6 COSS-1

ST6 OSSR-19

ST6 OSSR-19

ST6 OSSR-19

ST6 OSSR-19

ST6 OSSR-19

ST6 GSSR-7

ST6 GSSR-7

ST6 GSSR-7

ST6 OSSR-16

ST6 OSSR-16

ST6 XFSSR-37

ST6 XFSSR-58

ST6 XFSSR-58

ST6 XFSSR-58

ST6 XFSSR-58

ST6 XFSSR-58

ST6 ASSR-9

ST6 ASSR-9

ST6 ASSR-12

ST6 ASSR-12

ST6 ASSR-19

ST6 GSSR-4

ST6 GSSR-4

ST6 GSSR-4

ST6 GSSR-4

ST7 ASSR-11

ST7 ASSR-1

ST7 ASSR-11

ST7 ASSR-16

ST7 ASSR-16

ST7 ASSR-16

ST7 COSS-1

ST7 COSS-1

ST7 OSSR-19

ST7 OSSR-19

ST7 OSSR-19

ST7 GSSR-7

ST7 OSSR-16

ST7 OSSR-16

ST7 OSSR-16

ST7 OSSR-16

ST7 OSSR-16

ST7 OSSR-16

ST7 OSSR-16

ST7 OSSR-16

ST7 OSSR-16

ST7 OSSR-16

ST7 OSSR-16

ST7 OSSR-16

ST7 OSSR-16

ST7 OSSR-16

ST7 OSSR-16

ST7 OSSR-16

ST7 OSSR-16

ST7 OSSR-16

ST7 XFSSR-37

ST7 XFSSR-37

ST7 XFSSR-37

ST7 XFSSR-37

ST7 XFSSR-37

ST7 ASSR-9

ST7 ASSR-9

ST7 ASSR-9

ST7 ASSR-9

ST7 ASSR-9

ST7 ASSR-12

ST7 ASSR-12

ST7 ASSR-19

ST7 ASSR-19

ST7 ASSR-19

ST7 GSSR-4 0.agailable under aCC-BY-NC-ND 4.0 International license.

022

0.005

0.005

0.022

0.011

0.005

0.005

0.033

0.125

0.065

0.005

0.043

0.011

0.022

0.043

0.027

0.005

0.011

0.071

0.011

0.005

0.005

0.011

0.038

0.016

0.011

0.016

0.005

0.009

0.014

0.118

0.005

0.986

0.005

0.005

0.009

0.005

0.009

0.005

0.014

0.005

0.009

0.005

0.009

0.014

0.009

0.019

0.042

0.071

0.127

0.316

0.198

0.104

0.033

0.005

0.005

0.005

005

0.033

0.042

0.005

0.005

0.005

0.071

0.09

0.014

0.005

0.906

0.057

0.208

0.005 
bioRxiv preprint doi: https://doi.org/10.1101/2022.02.11.480026; this version posted February 11, 2022. The copyright holder for this preprint

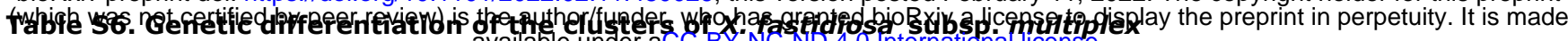
estimated by RST (bellow the diagonal) and FST (above the diagonal) pairwise comparisons for A) the DAPC $k=4$ groups; B) the three ST6 clusters used in ABC analyses; $C$ ) the three ST7 clusters used in ABC analyses.

All pairwise population comparisons were significantly different $(P<0.05)$ after 1,000 permutations.

A) RST \FST

Cluster 1: ST6

Cluster 2: ST6

Cluster 3: ST7

Cluster 4: ST7

B) RST \FST

Cluster C1P1

Cluster C2

Cluster P2

C) RST \FST

Cluster C1P1

Cluster C2

Cluster P2

$\begin{array}{cc}\text { Cluster 1: ST6 } & \text { Cluster 2: ST6 } \\ / & \mathbf{0 . 3 1 8 6} \\ 0.0992 & / \\ 0.9557 & 0.9441 \\ 0.9039 & 0.8608\end{array}$

Cluster 3: ST7

0.7309

0.6574

I

0.1981

Cluster 4: ST7

0.6302

.5109

0.2099

/

$\begin{array}{ccc}\text { Cluster C1P1 } & \text { Cluster C2 } & \text { Cluster P2 } \\ / & \mathbf{0 . 4 2 9} & \mathbf{0 . 3 3 7 7} \\ 0.199 & / & \mathbf{0 . 2 1 2 2} \\ 0.1447 & 0.157 & / \\ & & \\ \text { Cluster C1P1 } & \text { Cluster C2 } & \text { Cluster P2 } \\ / & \mathbf{0 . 2 7 0 7} & \mathbf{0 . 2 3 4 1} \\ 0.2723 & / & \mathbf{0 . 0 9 6 5} \\ 0.2442 & 0.0602 & /\end{array}$


bioRxiv preprint doi: https://doi.org/10.1101/2022.02.11.480026; this version posted February 11, 2022. The copyright holder for this preprint

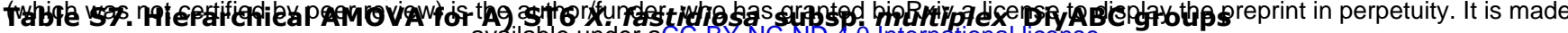

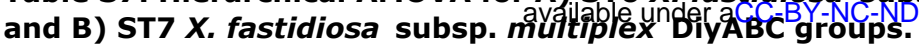

A) ST6: C1P1 - C2 - P2

\begin{tabular}{lcccc}
\hline \multicolumn{1}{c}{ Source of variation } & d.f. & Sum of scares & Variance components & $\begin{array}{c}\text { Percentage of } \\
\text { variation }\end{array}$ \\
\hline Among population & 2 & 92.873 & 1.17077 & 36.01 \\
& 181 & 376.632 & 2.08084 & 63.99 \\
\hline Within populations & 183 & 469.505 & 3.25161 & \\
\hline Total & &
\end{tabular}

B) ST7: C1P1 - C2 - P2

\begin{tabular}{lcccc}
\hline \multicolumn{1}{c}{ Source of variation } & d.f. & Sum of scares & Variance components & $\begin{array}{c}\text { Percentage of } \\
\text { variation }\end{array}$ \\
\hline Among population & 2 & 74.199 & 0.59253 & 21.88 \\
Within populations & 209 & 442.117 & 2.11539 & 78.12 \\
\hline Total & 211 & 516.316 & 2.70792 & \\
\hline
\end{tabular}


A)

Analyses Posterior Best

A probability scenario

C1P1_C2 $0.39-0.47$

C1P1 $0.38-0.47(70 \%)-9(30 \%$

C2_P2 $0.34-0.42(80 \%)-9(20 \%)$

B)

\section{Posterior Best} probability scenario $0.26-0.37$
$\begin{array}{llll}\text { Sc1 } & \text { Sc2 } & \text { Sc3 } & \text { Sc4 }\end{array}$
Sc4
$\mathrm{Sc} 5$

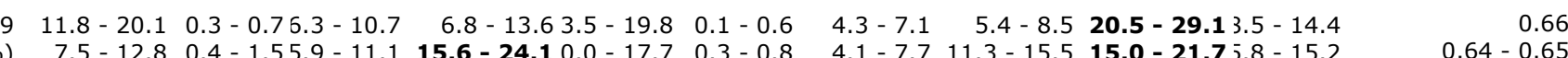

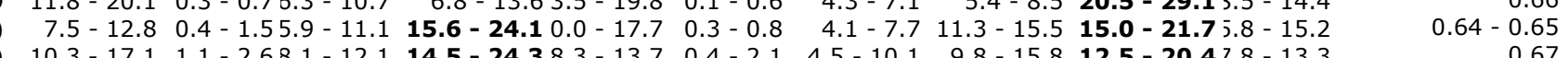

Percentage of vote attributed to each scenario

\begin{tabular}{cccccccccccccccc}
\multicolumn{1}{c}{ Sc1 } & Sc2 & Sc3 & Sc4 & Sc5 & Sc6 & Sc7 & Sc8 & Sc9 & Sc10 & Sc11 & Sc12 & Sc13 & Sc14 & Sc15 \\
7 & $4.5-6.7$ & $2.9-7.0$ & $2.8-5.4$ & $1.8-3.3$ & $3.4-4.6$ & $2.1-3.3$ & $\mathbf{8 . 5}-\mathbf{1 1 . 3}$ & $3.8-5.9$ & $4.2-6.4$ & $1.4-2.6$ & $2.1-4.2$ & $1.5-3.2$ & $0.9-3.0$ & $1.1-2.7$ & $0.7-2.2$
\end{tabular}

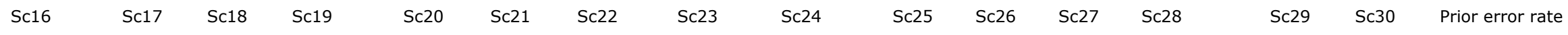

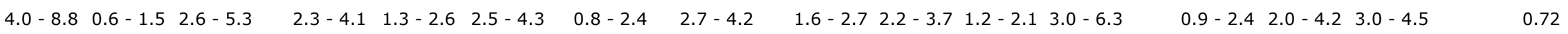

C)

Analyses Posterior Best

1P1 C2 $0.43-0.50$

C1P1_P2 $0.45-0.54$

C2_P2 $0.43-0.52(70 \%)-8(20 \%)$

D)

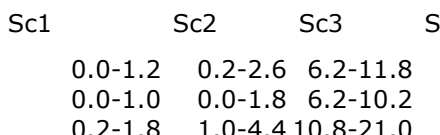

Percentage of votes attributed to each scenario

\begin{tabular}{|c|c|c|c|c|c|c|c|c|}
\hline Sc5 & Sc6 & c7 & Sc8 & Sc9 & c10 & cc11 & Sc12 & Pric \\
\hline & & & & & & & & \\
\hline & $0.0-1.2$ & -21.2 & -41.4 & & & $0.0-0.6$ & & \\
\hline $0<2$ & $1.6-5.0$ & & 16.6 & & $7.4-13.6$ & $0.0-0.6$ & $0.0-0.6$ & 0.67 \\
\hline
\end{tabular}

\section{scenario}

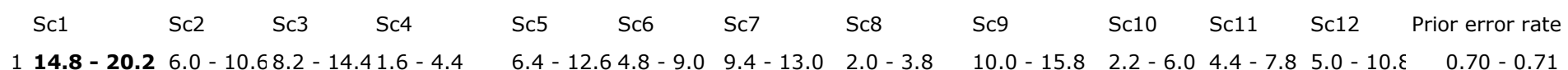


Table S9. Distribution of prior parameters used for the DiyABC analyses.

\begin{tabular}{|c|c|c|}
\hline Parameters & Parameters name & Priors \\
\hline $\begin{array}{l}\text { Population effective size of the ancestral American population } \\
\text { and the unsampled population }\end{array}$ & $\mathrm{N}_{\text {USA, }}, \mathrm{N}_{\text {ghost }}$ & Loguniform $\left[10^{3}-10^{6}\right]$ \\
\hline Population effective size of the French populations & $\mathrm{N}_{\mathrm{C} 1}, \mathrm{~N}_{\mathrm{C} 2}, \mathrm{~N}_{\mathrm{P} 1}, \mathrm{~N}_{\mathrm{P} 2}, \mathrm{~N}_{\mathrm{C} 1 \mathrm{P} 1}$ & Loguniform $\left[10^{2}-10^{4}\right]$ \\
\hline Founder event of the French populations & $t_{1}, t_{2}, t_{3}, t_{4}$ & Loguniform $\left[5-5 \times 10^{2}\right]$ \\
\hline $\begin{array}{l}\text { Founder event of the unsampled population } \\
\text { Duration of the bottleneck }\end{array}$ & $\begin{array}{l}\mathrm{t}_{\text {ghost }} \\
\mathrm{db} 1, \mathrm{db} 2, \mathrm{db} 3, \mathrm{db} 4\end{array}$ & $\begin{array}{l}\text { Loguniform }\left[5 \times 10^{1}-10^{4}\right] \\
\text { Uniform }[0-20]\end{array}$ \\
\hline $\begin{array}{l}\text { Population effective size of the French populations } \\
\text { bottleneck time }\end{array}$ & $\begin{array}{l}\mathrm{Nb}_{\mathrm{C} 1}, \quad \mathrm{Nb}_{\mathrm{C} 2}, \quad \mathrm{Nb}_{\mathrm{P} 1} \\
\mathrm{Nb}_{\mathrm{P} 2}, \mathrm{Nb}_{\mathrm{C} 1 \mathrm{P} 1}\end{array}$ & Uniform $\left[1-10^{2}\right]$ \\
\hline Mean mutation rate & $M \mu_{\text {mic }}$ & Uniform $\left[10^{-6}-10^{-3}\right]$ \\
\hline Individual locus mutation rate & $M \mu L_{o c}$ & Gamma $\left[10^{-7}-10^{-2}\right]$ \\
\hline
\end{tabular}

